$$
\angle A-5 u B--94-146-T_{a} K-1
$$

\title{
FINAL REPORT FOR CONFINEMENT VESSEL ANALYSIS \\ TASK 1 \\ CORRELATION OF NEW VESSEL DATA WITH FINITE \\ ELEMENT RESULTS
}

Subcontract Number 9-XH3-0607K-1

Prepared by

Barbara B. Lewis

APTEK, Inc.

November 30, 1993 


\section{FINAL REPORT FOR CONFINEMENT VESSEL ANALYSIS TASK 1 \\ CORRELATION OF NEW VESSEL DATA WITH FINITE ELEMENT RESULTS \\ Subcontract Number 9-XH3-0607K-1 \\ Barbara B. Lewis \\ APTEK, Inc \\ November 30, 1993}

\section{Objectives}

Los Alamos performed tests of a modified confinement vessel in November 1992 to gain a better understanding of the response of the confinement vessel. The first test was meant to duplicate, with additional instrumentation, tests done previously for correlation with analysis. Task 1 of Subcontract Number 9-XH3-0607K-1 was the correlation of this new vessel test data with the results of finite element analyses. We also examined the data for the other test, which was for optical port development.

\section{Description of Tests}

The tests were numbered H-1573 and H-1562 and were fired on November 9 and 10, 1992, respectively. Test $\mathrm{H}-1573$ was identical to the previous $40 \mathrm{lb}$ tests except that a Burke tube was used to support the explosive charge while the explosive was freely suspended in the earlier tests. The second test, H-1562, was for development of the optical port. In addition to the Burke tube, this test also had additional components on the inside of the ports to protect the windows. Instrumentation for each test consisted of 3 pressure gages, 3 strain gage rosettes of 3 elements each, and 2 accelerometers. The locations of the gages are given in the memo by $\mathrm{W}$. $\mathrm{E}$. Baker, Los Alamos memo number M-4:93-187. The test data was provided to us by Tom Beery of Los Alamos. We also used information from reports by W. E. Baker, Christopher Romero and Tom Duffey. 


\section{Test Data Assessment and Correlation}

We examined the test data for overall quality, differences between the two tests, and differences between gages. We also correlated the test results with analysis using the finite element models that we had previously developed. These observations and comparisons are presented here according to the different types of data, followed by a discussion of the implications and conclusions that can be drawn from the tests.

\subsection{Pressure}

Figure 1 shows the three pressures measured for test $\mathrm{H}-1573$ for the first half millisecond of recording time. Gages 1 and 2, which are on the upper hemisphere of the vessel, show the pressure increasing at 0.20 milliconds while gage 3 , on the bottom hemisphere, shows no response until about 0.23 milliseconds. Note the timing signal dip at 0.10 milliseconds indicating that the delayed start in gage 3 is a true delay, and not a shift in the recording time. This indicates a non-uniformity of the loading, possibly due to shadowing of the bottom hemisphere by the Burke tube. The pressures recorded in test $\mathrm{H}-1562$ show a similar delay for gage 3 . Also, the magnitudes of the three pressures are very different. The peak magnitude for gage 3 appears to have been clipped. That is, the recording band was not large enough to capture the peak. The pressures measured in test $\mathrm{H}-1562$ show the same trends, Figure 2, but have lower magnitudes.

Al Bowman of Los Alamos predicted the pressure and APTEK used the predictions in the finite element analyses. Figures 3 through 5 show comparisons of the analysis and the pressures measured in Test $\mathrm{H}-1573$. The test data has been shifted in time to match the initial rise time of the predicted pressure. The timing and magnitudes of the predicted pressure reflections match the test data well. The predicted pressure is generally higher than measured between the pulses.

\section{DISCLAIMER}

This report was prepared as an account of work sponsored by an agency of the United States Government. Neither the United States Government nor any agency thereof, nor any of their employees, makes any warranty, express or implied, or assumes any legal liability or responsibility for the accuracy, completeness, or usefulness of any information, apparatus, product, or process disclosed, or represents that its use would not infringe privately owned rights. Reference herein to any specific commercial product, process, or service by trade name, trademark, manufacturer, or otherwise does not necessarily constitute or imply its endorsement, recommendation, or favoring by the United States Government or any agency thereof. The views and opinions of authors expressed herein do not necessarily state or reflect those of the United States Government or any agency thereof. 


\section{DISCLAIMER}

Portions of this document may be illegible in electronic image products. Images are produced from the best available original document. 


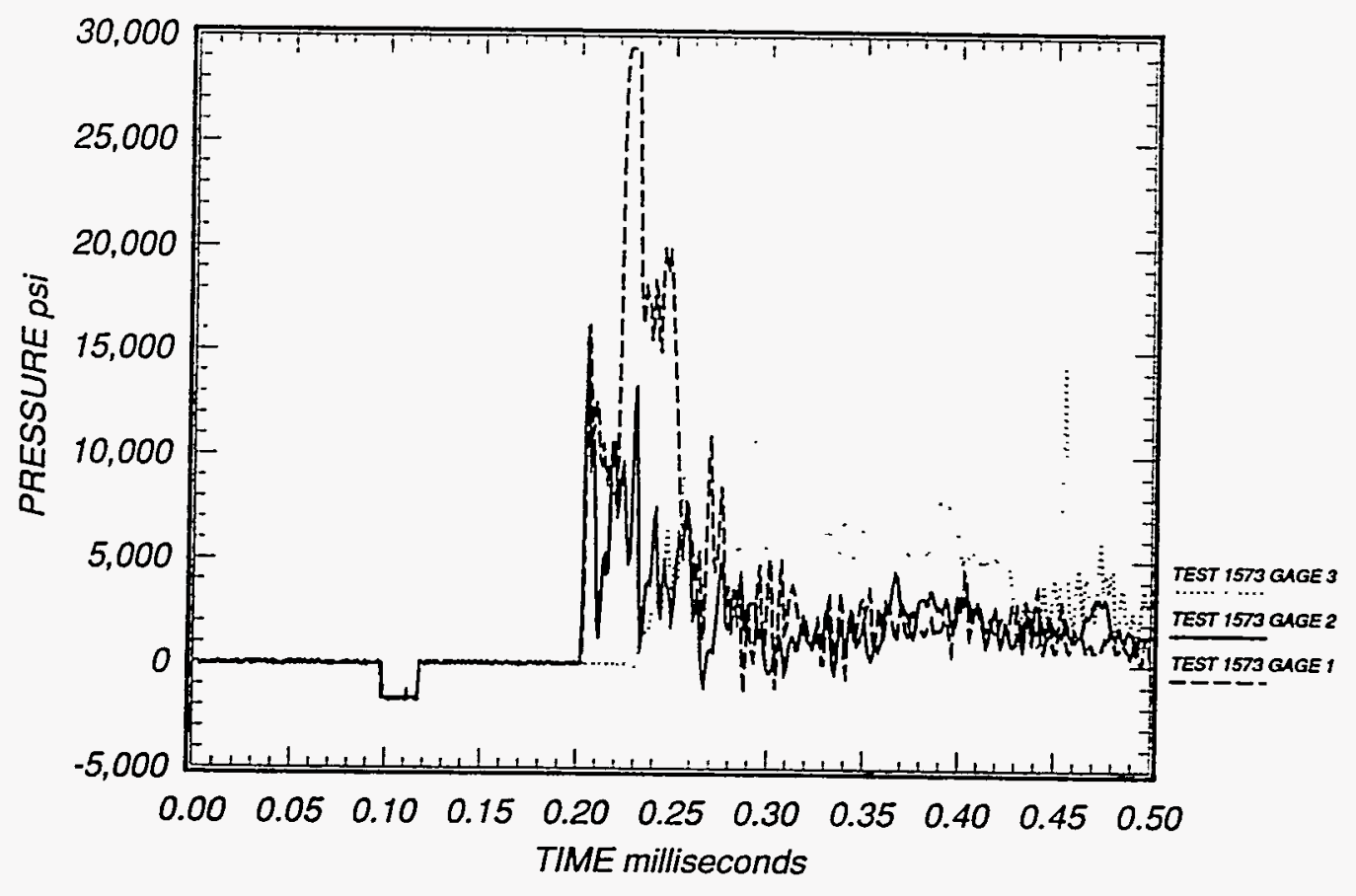

Figure 1: Pressures measured in Test H-1573.

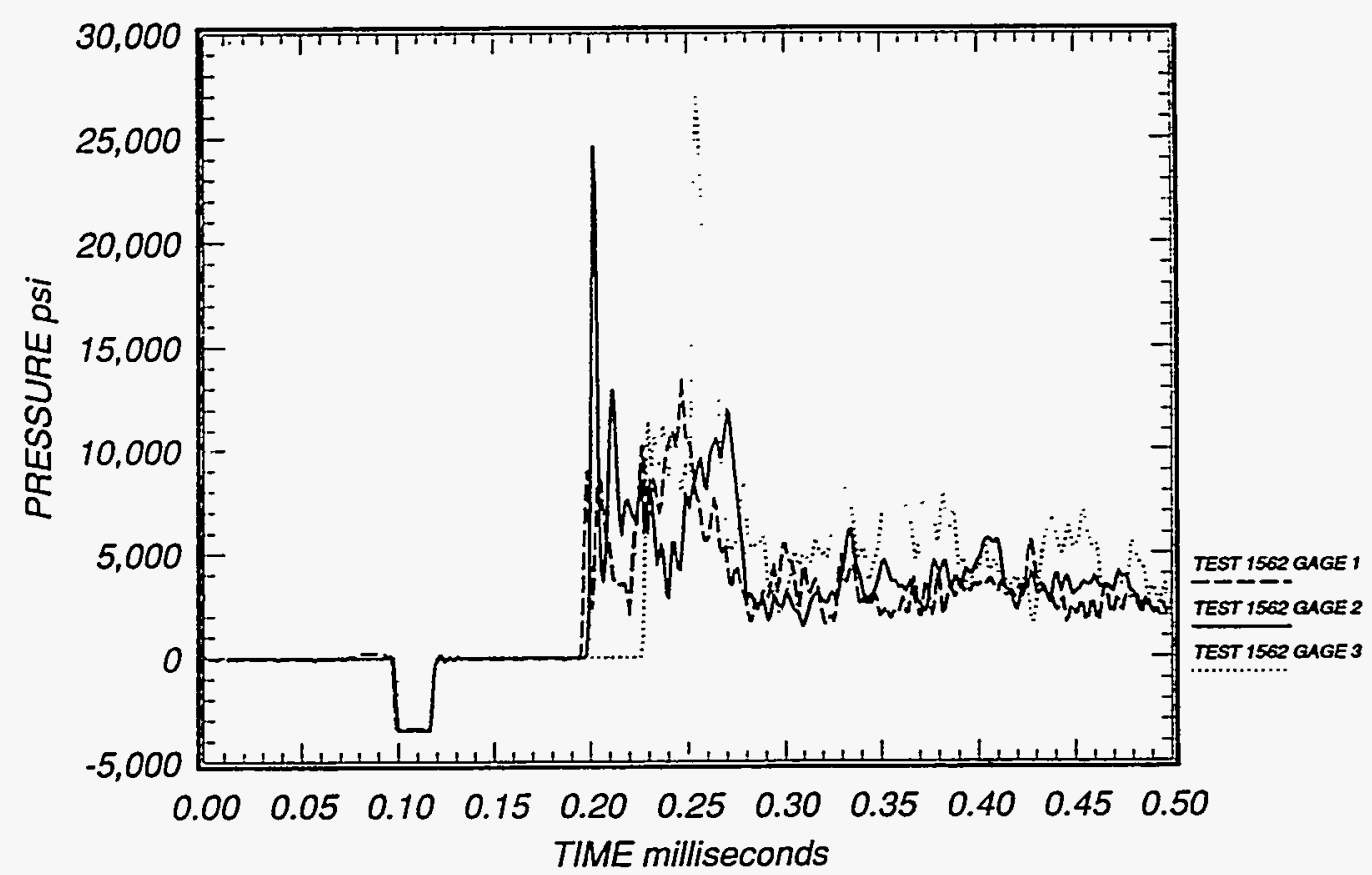

Figure 2: Pressures measured in Test H-1562. 

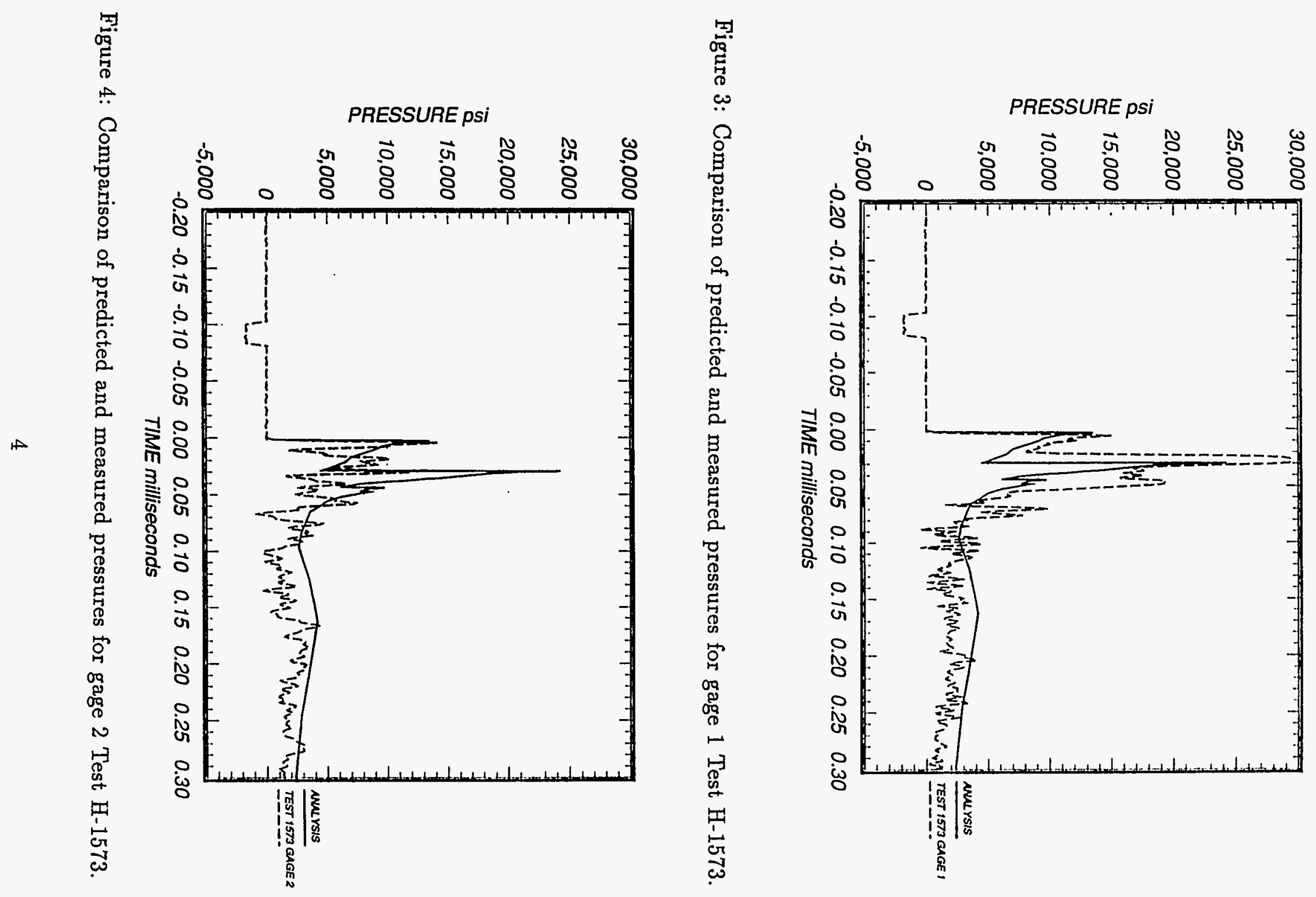


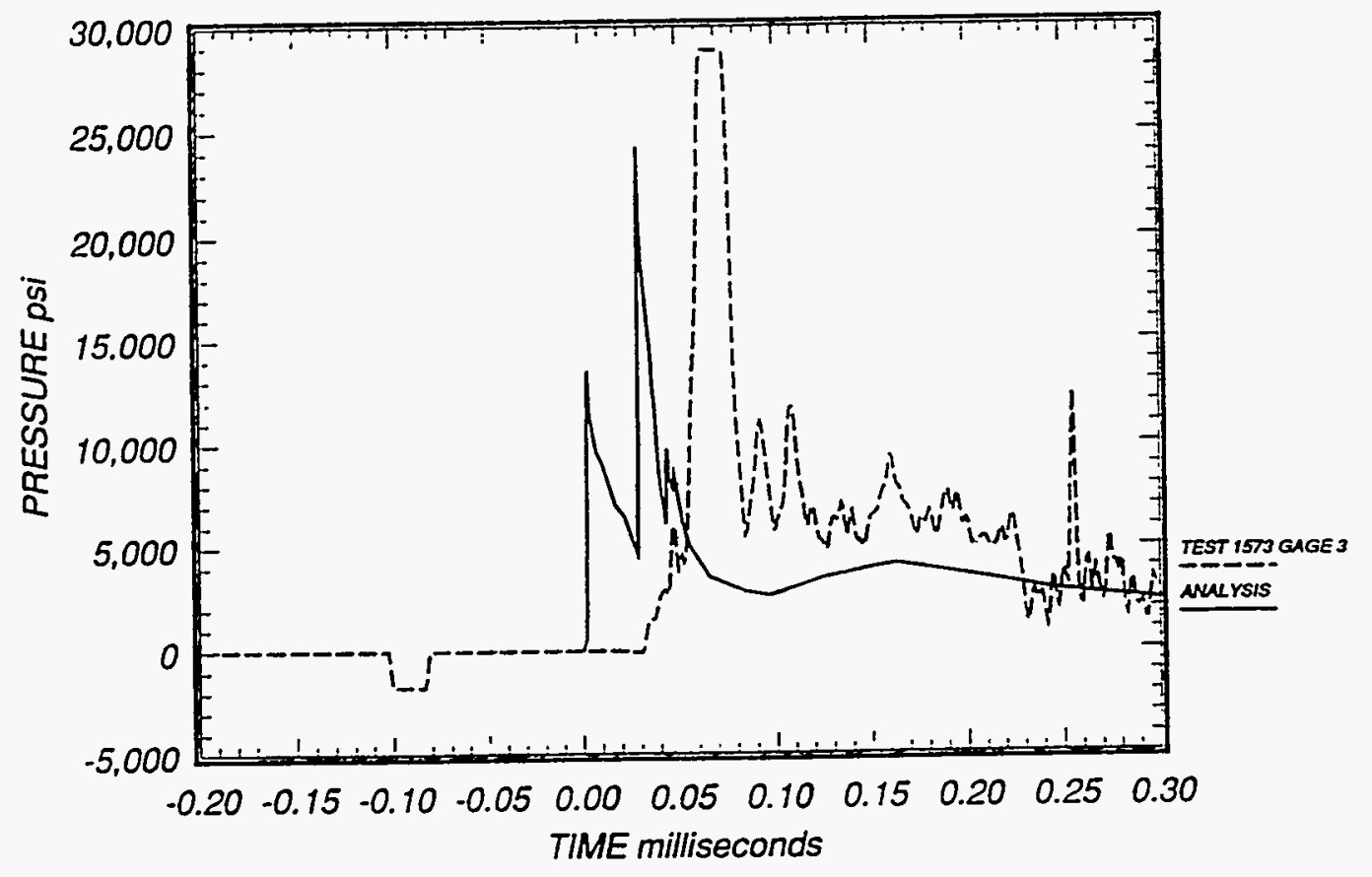

Figure 5: Comparison of predicted and measured pressures for gage 3 Test H-1573. 


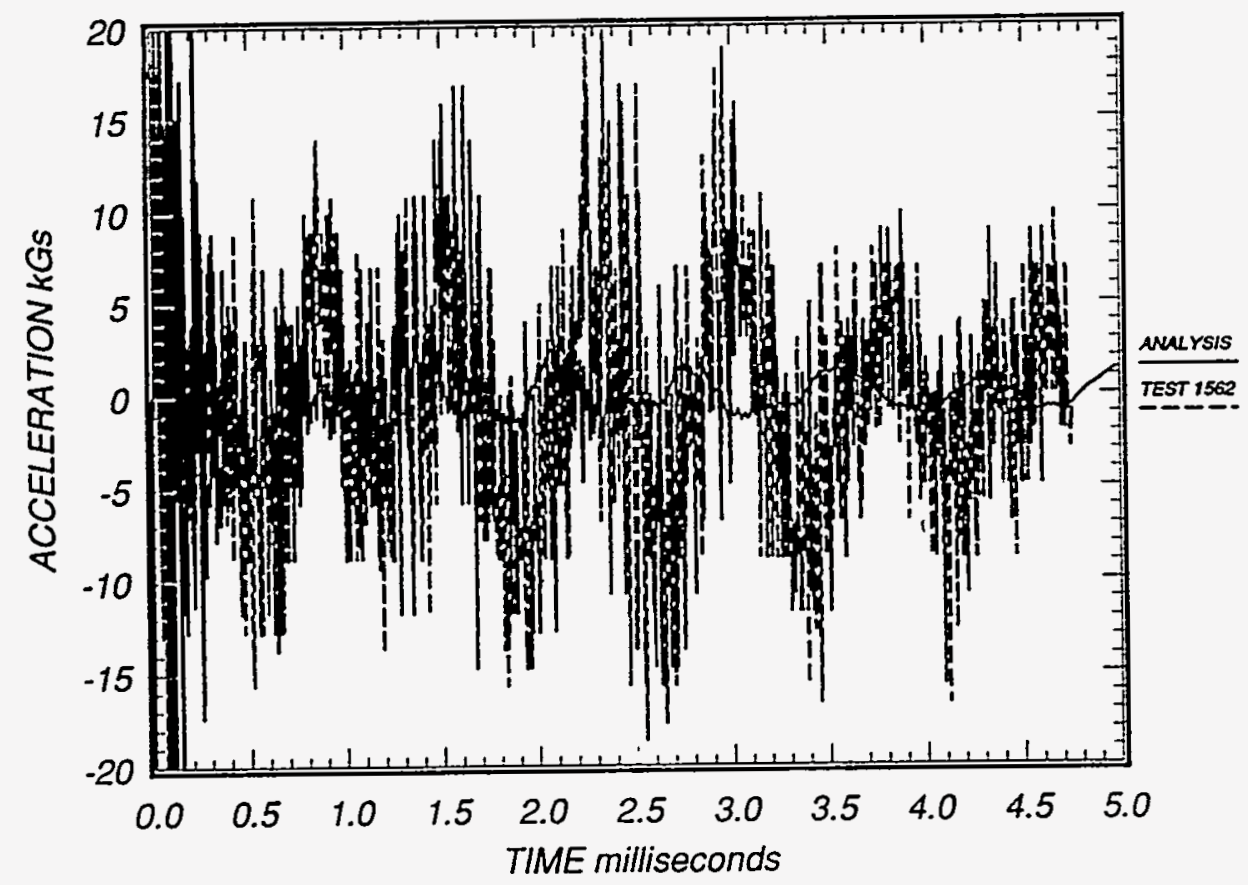

Figure 6: Comparison of predicted and measured accelerations.

\subsection{Accelerations}

Of the four accelerometer recordings, only one recording appears to be valid. Figure 6 shows the accelerometer data from gage 1 of test $\mathrm{H}-1562$ along with the accelerations predicted using the finite element model. This accelerometer was located on the port door just outside of a quartz window. The analytical curve is out of phase with the test, but the same fundamental frequency is apparent in both curves. The test results have a considerably higher magnitude, due largely to the presence of higher frequency response. 


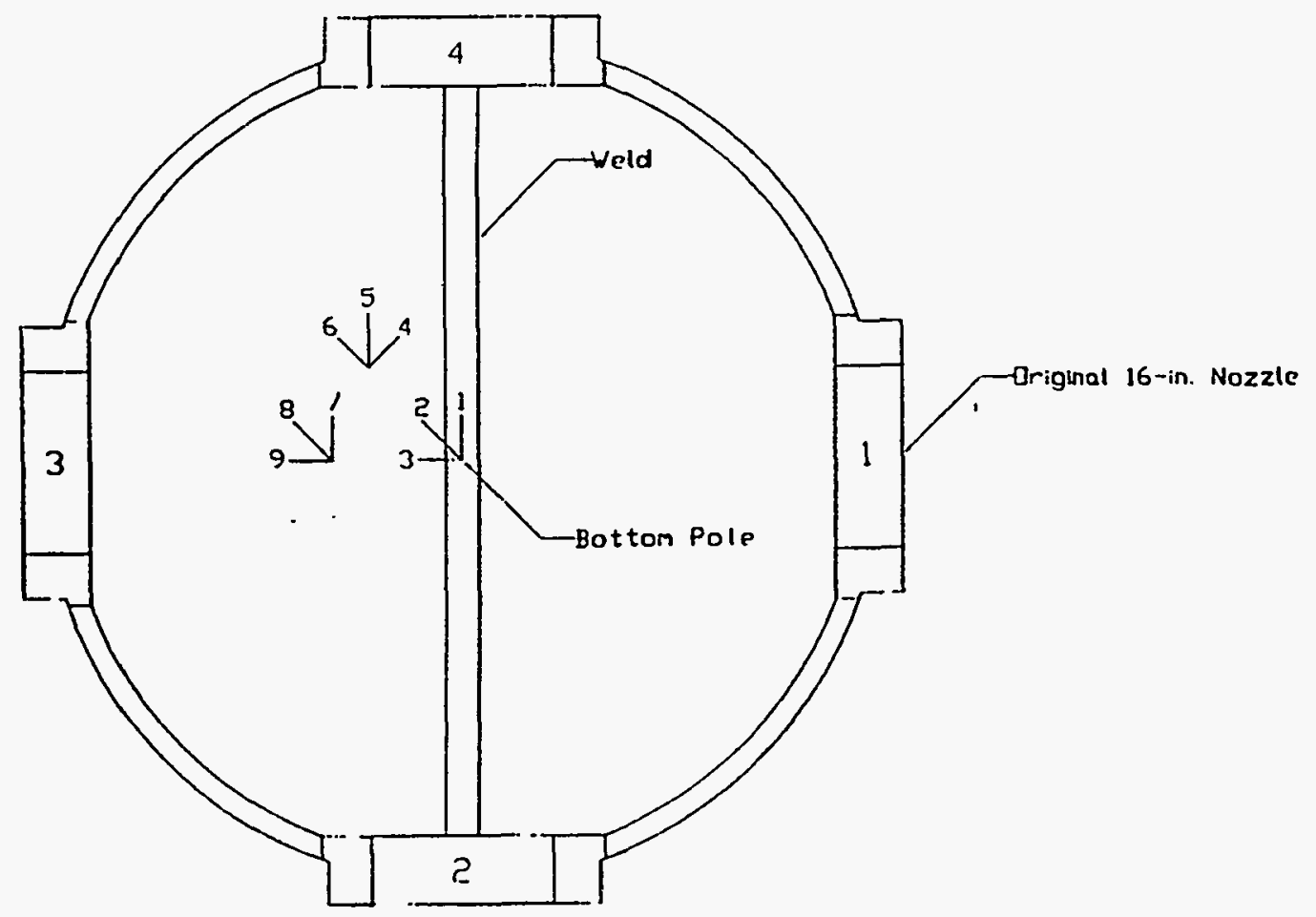

Figure 7: Orientation of strain gages.

\subsection{Strains}

The strain gages were three rosettes of three gages each. Gages 1 through 3 were at the bottom pole of the vessel; gages 4 through 6 were at 45 degrees longitude and -73 degrees latitude; gages 7 through 9 were at 0 degrees longitude and -73 degrees latitude. Figure 7 shows the orientations of the gages.

Figures 8 through 13 show the comparison of predicted and measured strains for gages 4 through 9 . The two tests compare well with each other, and the analysis matches the fundamental frequency reasonably well. The magnitudes of the measured strains are higher than the predicted peaks and the beating phenomenon observed in earlier tests is again apparent in these plots. Measurements of the strain gage circuits made after the tests indicated permanent strains at all gages. These were reported by Baker and are apparent in the data as an offset of the test curves from each other and from the analysis. This is especially apparent for gage 4 which had the largest permanent strains. Higher permanent strains were recorded for the first test than for the second, consistent with the work hardening property of steel. Since the onset of yielding is based on the total strain state at a given location and time, it is difficult to determine when yielding is indicated from this data. However, the first peak of each measured strain history is higher than the peak of the analysis which stayed elastic. Also, the offset between the curves is apparent almost from the beginning of the data. 


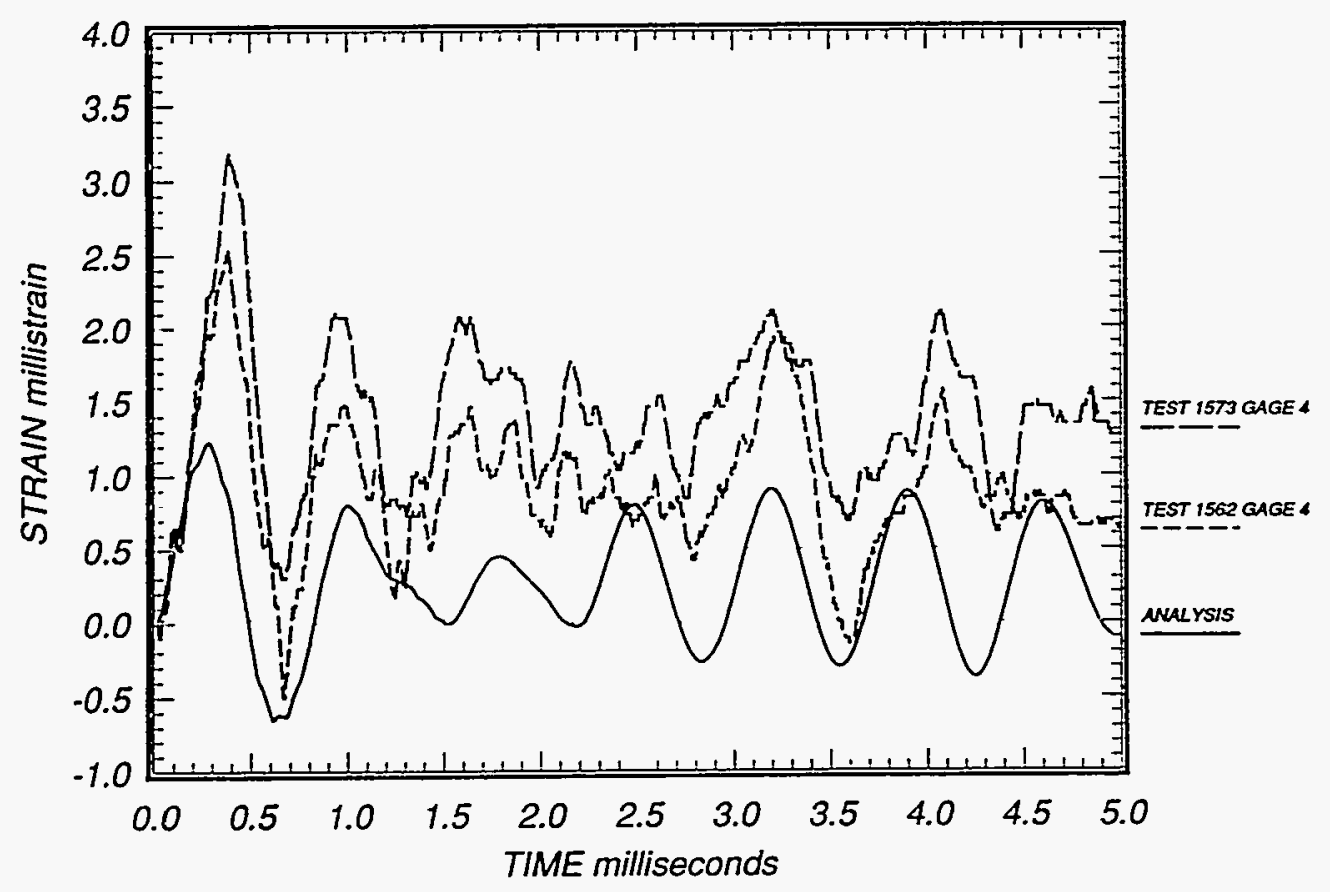

Figure 8: Comparison of predicted and measured strains for gage 4 .

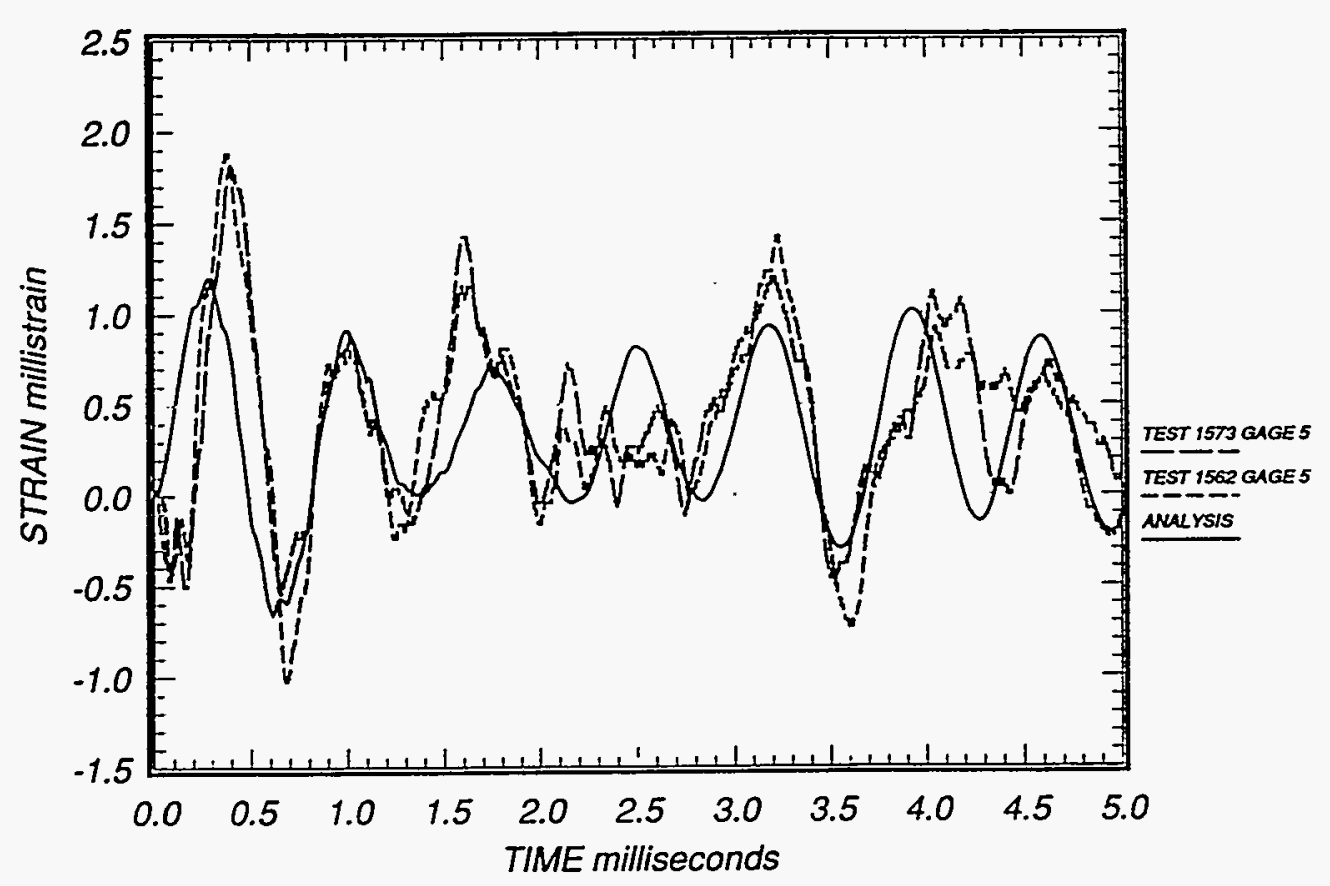

Figure 9: Comparison of predicted and measured strains for gage 5 . 


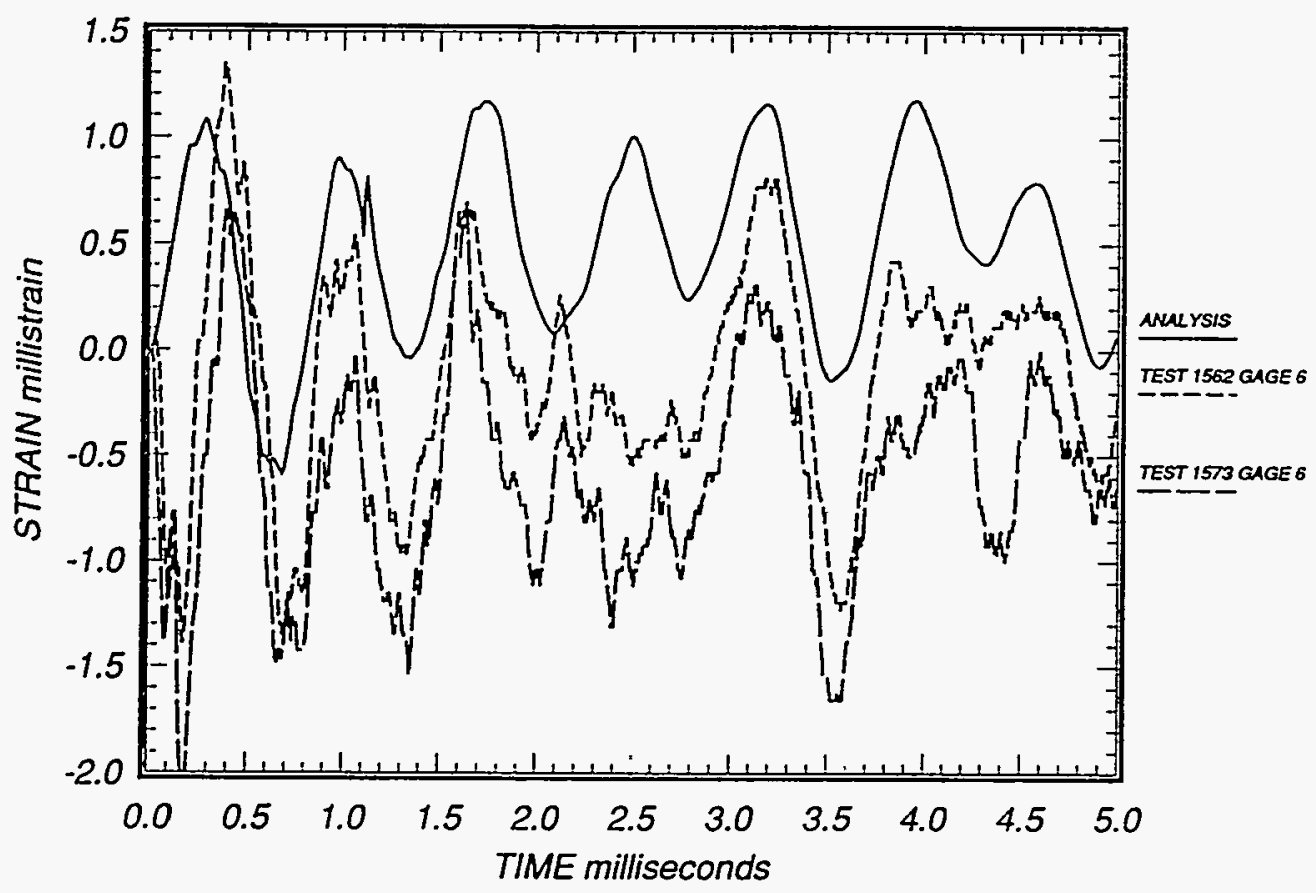

Figure 10: Comparison of predicted and measured strains for gage 6.

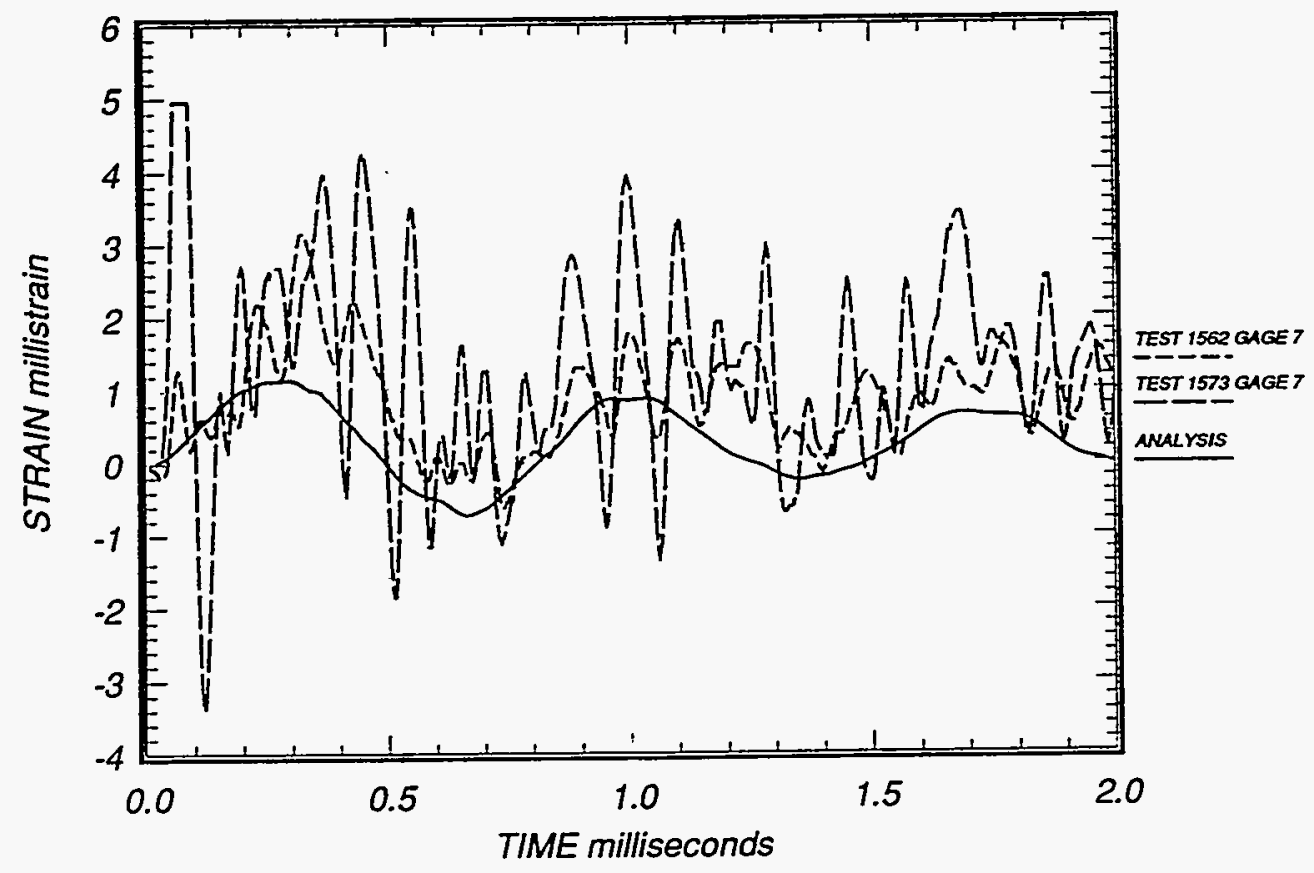

Figure 11: Comparison of predicted and measured strains for gage 7. 


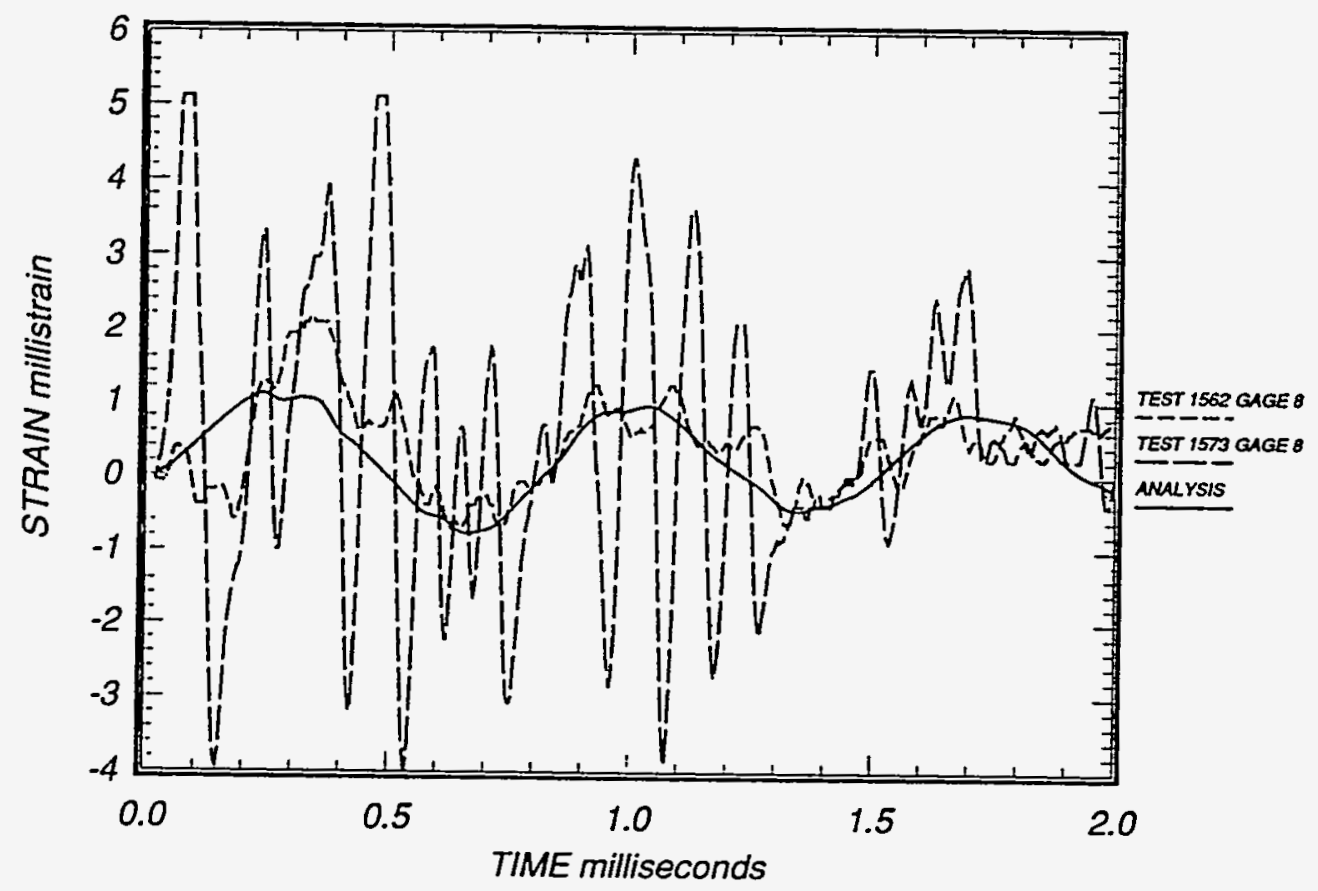

Figure 12: Comparison of predicted and measured strains for gage 8 .

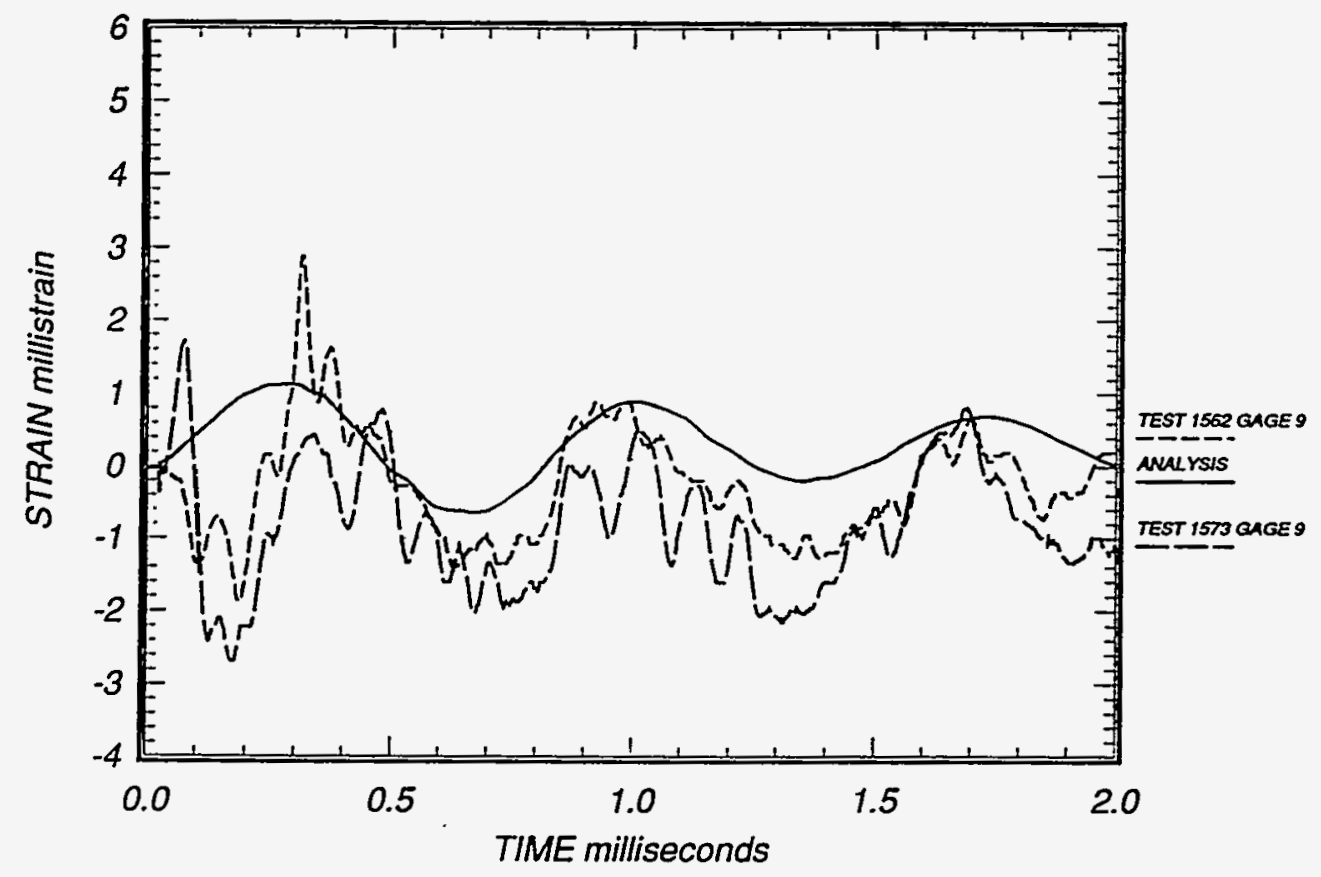

Figure 13: Comparison of predicted and measured strains for gage 9. 


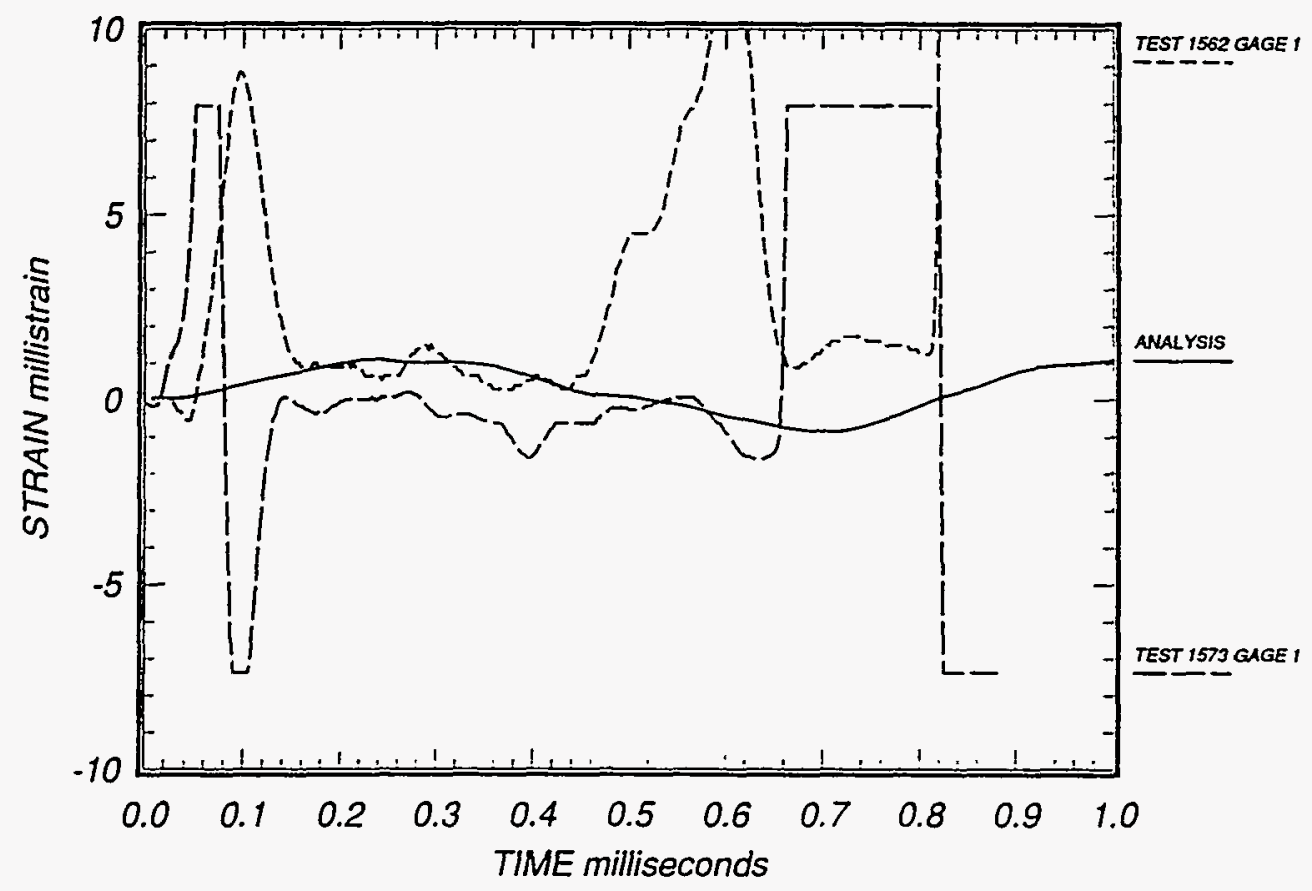

Figure 14: Comparison of predicted and measured strains for gage 1.

All six of these gages show high frequency content, especially gages 7 and 8 . The most obvious high frequency component is about $10 \mathrm{kHz}$. This response was not apparent in the previous tests, but since it is close to the upper frequency filter, it might have been filtered out in the 1991 tests.

Gages 1 through 3 at the bottom of the vessel were destroyed during both tests. The data was lost after about 0.25 milliseconds, but even the data recorded prior to that time is suspect. Figures 14 and 15 show the strains recorded by gages 1 and 3 for both tests and the corresponding analytical prediction. The initial peaks measured for the two tests are very different in character and are much higher in magnitude than the predicted strains.

Another question we wish to comment on are the initial compressive strains measured by some of the strain gages. The initial response of the vessel should be a large tensile peak corresponding to the first membrane expansion. On gages 5 and 6 shown in Figures 11 and 12, a short compressive strain appears before the first expansion peak. Since it does not appear on every gage, it is probably a higher frequency mode. We believe it is excited by the nonuniformity of the pressure load. It appears to overcome and then reinforce the first membrane response, and is probably a large cause of the yielding at these gage locations. 


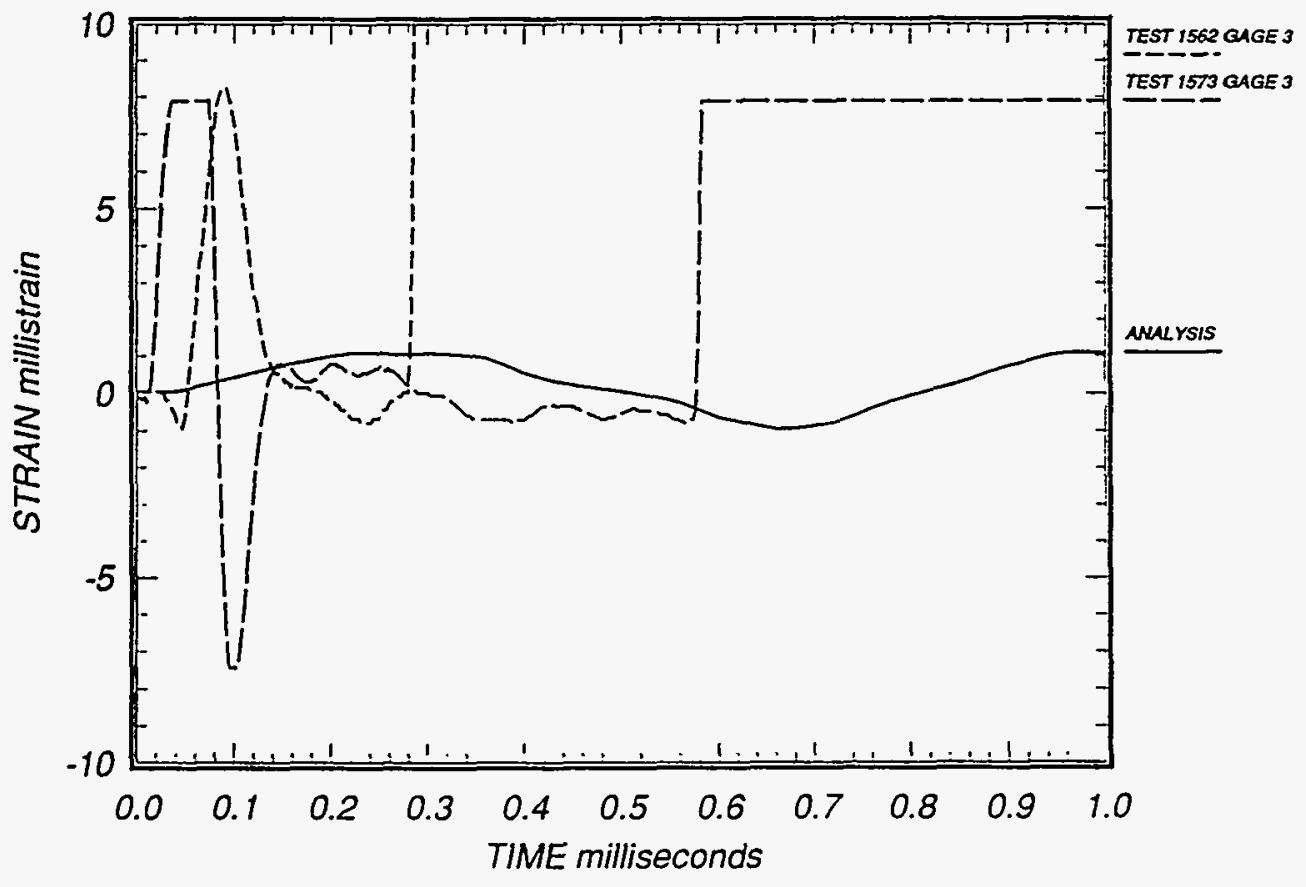

Figure 15: Comparison of predicted and measured strains for gage 3.

Also as part of this task, we have provided information to Los Alamos on the natural mode shapes as predicted by the NIKE3D finite element code. The mode shapes for the first twenty modes of the confinement vessel were used to determine the magnitudes of strains at each gage location with respect to the overall mode shape for each frequency. These were provided to Tom Beery of LANL for comparison with his modal decomposition results.

\subsection{Window Development}

Test H-1562 was done to test two optical window designs, a tapered window and a cylindrical window. The tapered window was cracked during the test and the cylindrical window was blown out. Both windows had cones to protect them from the direct blast. If the cones worked as planned, the damage to the windows was caused by interaction with the structure. We had theorized that the additional mass of the cones attached to the ports would have made a more significant difference in the test results. However, the strains were very similar between the two tests. Differences were apparent in the magnitudes of the measured pressures, but the trends in the data were the same for both tests. That is, both tests showed a delay in the pressure at gage 3 , both showed differences in peak magnitude between the three gages, and both showed the same pattern of reflected pressure. 


\section{Discussion of Results}

The overall purpose for performing test $\mathrm{H}-1573$ was to obtain data to determine if yielding is occurring at the bottom of the vessel and if so, why. The test results indicate permanent strains at the bottom, meaning that yielding occurred due to the $40 \mathrm{lb}$ explosive charge. Unfortunately, the reason for the yielding is not clear. The results are clouded by the presence of material used to support the explosive in these tests but not in the earlier tests. The support was made of a Burke tube and some plywood. It is possible that the tube focused the pressure at the bottom of the vessel, causing larger strains than would otherwise have occurred. Shadowing of the lower portion of the vessel, giving nonuinform pressures, is evidenced by the differences in the pressure measurements. There were not enough gage locations in these tests to obtain direct comparisons with the earlier tests. The bottom strain gages were lost in both sets of tests, and the pressure measurements from the earlier tests are of poor quality. Without a direct comparison, it is difficult to assess how much the change in the test set up affected the results. We did note that the strains measured at -73 degrees latitude and 0 and 45 degrees longitude are in-phase with each other while the 0 and 45 degrees strains at -55 degrees latitude from the previous tests are out of pliase. We do not know if that is a result of the mode shape being excited or a difference caused by the changed loading.

The correlation of strain measurements with analysis show good agreement for the frequencies, but the peak magnitudes are significantly underpredicted. This suggests that the mass and stiffness of the finite element model, which control the frequencies, are adequate representations of the real structure. The magnitudes of the response are controlled by the driving function, i.e. the pressure.

The damage done to the optical windows in spite of the presence of the protective cones has two possible causes. One is that the cones did not protect the windows from the blast as well as expected. The second is that the damage is caused by the interaction of the port structure with the window during dynamic structural response. If not mitigated in some manner, the windows would not survive the blast load for this level, but the cones should have protected them from the direct blast. From our previous work on the windows, we believe the problem is due to the structural response and not the blast load. 


\section{Conclusions and Recommendations}

The following are conclusions and recommendations drawn from assessment and correlation of tests $\mathrm{H}-1573$ and $\mathrm{H}-1562$ :

- Yielding was measured at the bottom of the vessel for these tests. The yielding appeared to have occurred during the first membrane response.

- The presence of a support tube in the vessel may have caused focusing of the pressure at the bottom, obscurring the response mechanism thought to have caused yielding in earlier tests.

- The frequencies predicted using the finite element analysis correlated fairly well with the test results, but the analysis did not predict the yielding measured at the -73 degrees locations. This suggests that the mass and stiffness representation of the structure is adequate, but improvements should be made in the load definition.

- Excellent pressure measurements were obtained. They showed nonuniformities of the pressure in both time and magnitude which could be a result of the support tube used in the test.

- Better methods of obtaining acceleration data for the windows need to be developed. A pressure measurement alongside the window (within the protected area of the cone) would aid in determining the loads on the windows.

- We believe that the window damage is caused by response of the vessel. We recommend that steps be taken to isolate the windows as much as possible from the vessel motion. A thicker gasket should certainly be used. Also, the design could alow a gap between the window and door as much as is possible given the constraint of maintaining a pressure seal. 
Los Alamos National Laboratory

P. O. Box 1663, Mail Stop P942

Los Alamos, NM 87545

Attn: Christopher Romero

Subject: June Progress Report for Confinement Vessel Analysis Subcontract.

Reference: Subcontract Number 9-XH3-0607K-1

Dear Christopher,

Attached are three copies of the June Progress Report for the Confinement Vessel Analysis Contract. If you have any questions, please call.

Sincerely,

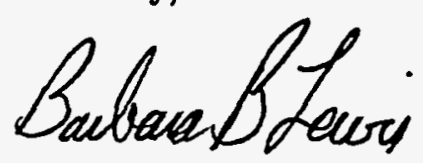

Barbara B. Lewis (719)576-8100

cc: C. Vigil, LANL M/S P274 w/3 copies

E. Fitzgerald, APTEK

B. Lewis, APTEK

C. Niemet, APTEK 


\section{PROGRESS REPORT FOR CONFINEMENT VESSEL ANALYSIS Barbara B. Lewis \\ APTEK, Inc \\ June 18 to July 13,1993}

In the last month, we have done some additional work as part of Task 1, correlation of test and analysis, and started on Task 3, analysis of port closure details.

\section{Observations and Correlation of Test Data}

First, we will give few additional details of the correlation of analysis and test results as reported in the last progress report. We will also elaborate on some of the discussion in that report.

\subsection{Additional Detail}

The following figures are presented to clarify and/or correct figures in the last progress report. Figures 1 through 3 show the early time pressures predicted by APTEK compared to those measured in test H-1573. The measured pressures have been shifted by 0.2 milliseconds in order to match the timing used for the pressure input to the analysis code. Figure 2 is the same as Figure 3 of the last progress report, but with an expanded scale.

Figures 12 and 13 of the previous progress report did not have a clear distinction between the curves representing analysis and test. Figures 4 and 5 are corrected versions of those figures. 


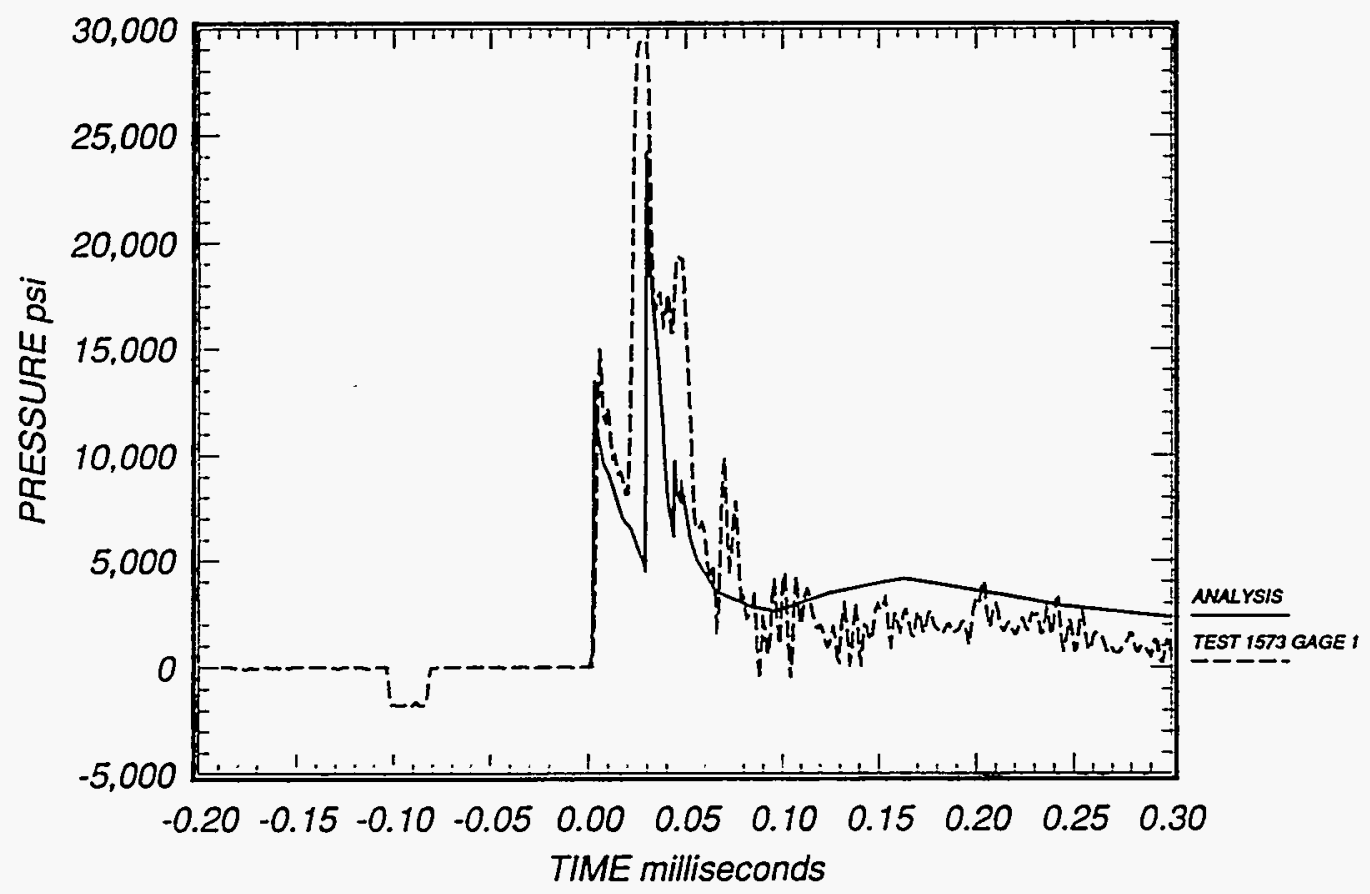

Figure 1: Comparison of predicted and measured pressures for gage 1.

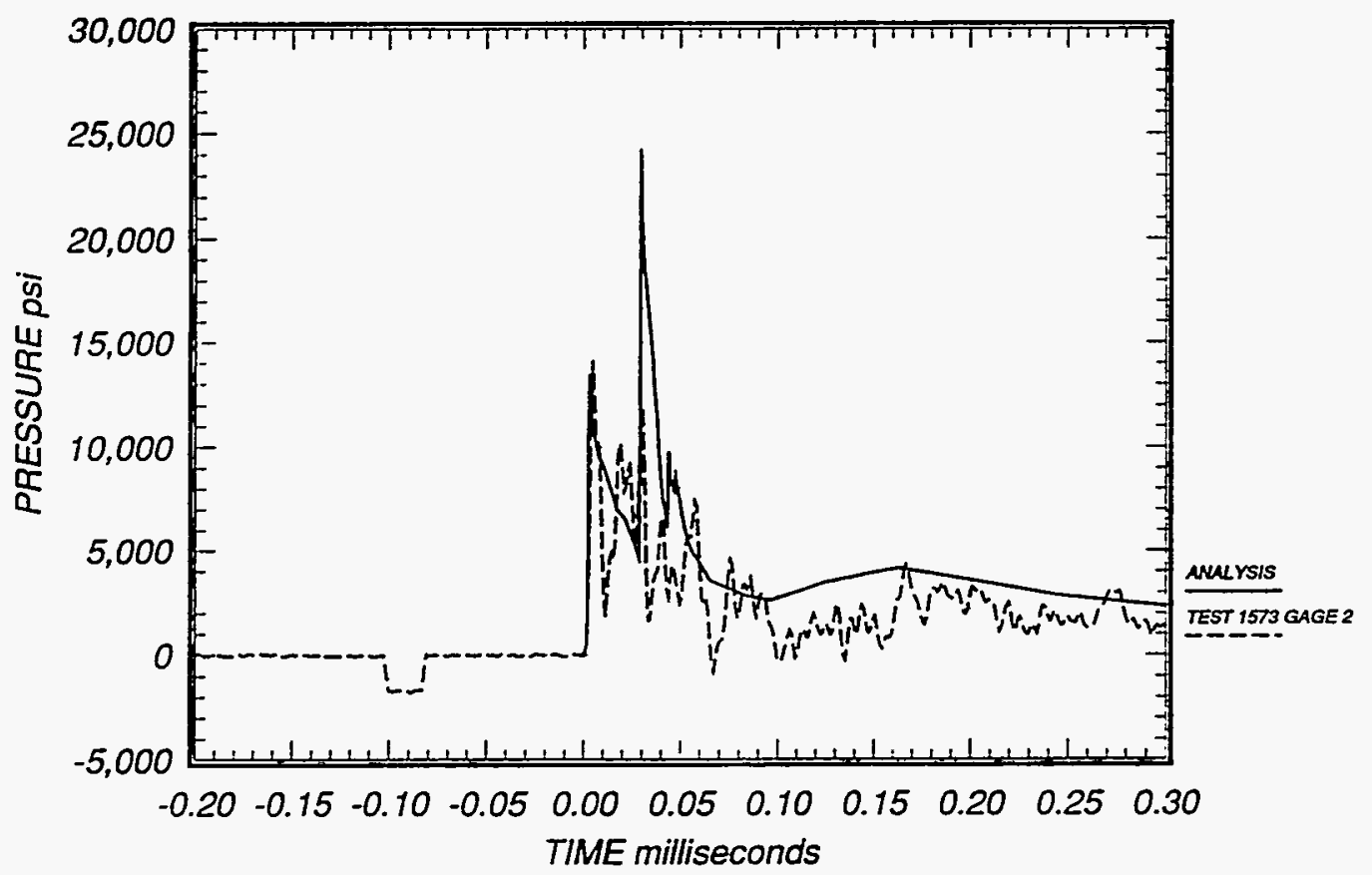

Figure 2: Comparison of predicted and measured pressures for gage 2 . 


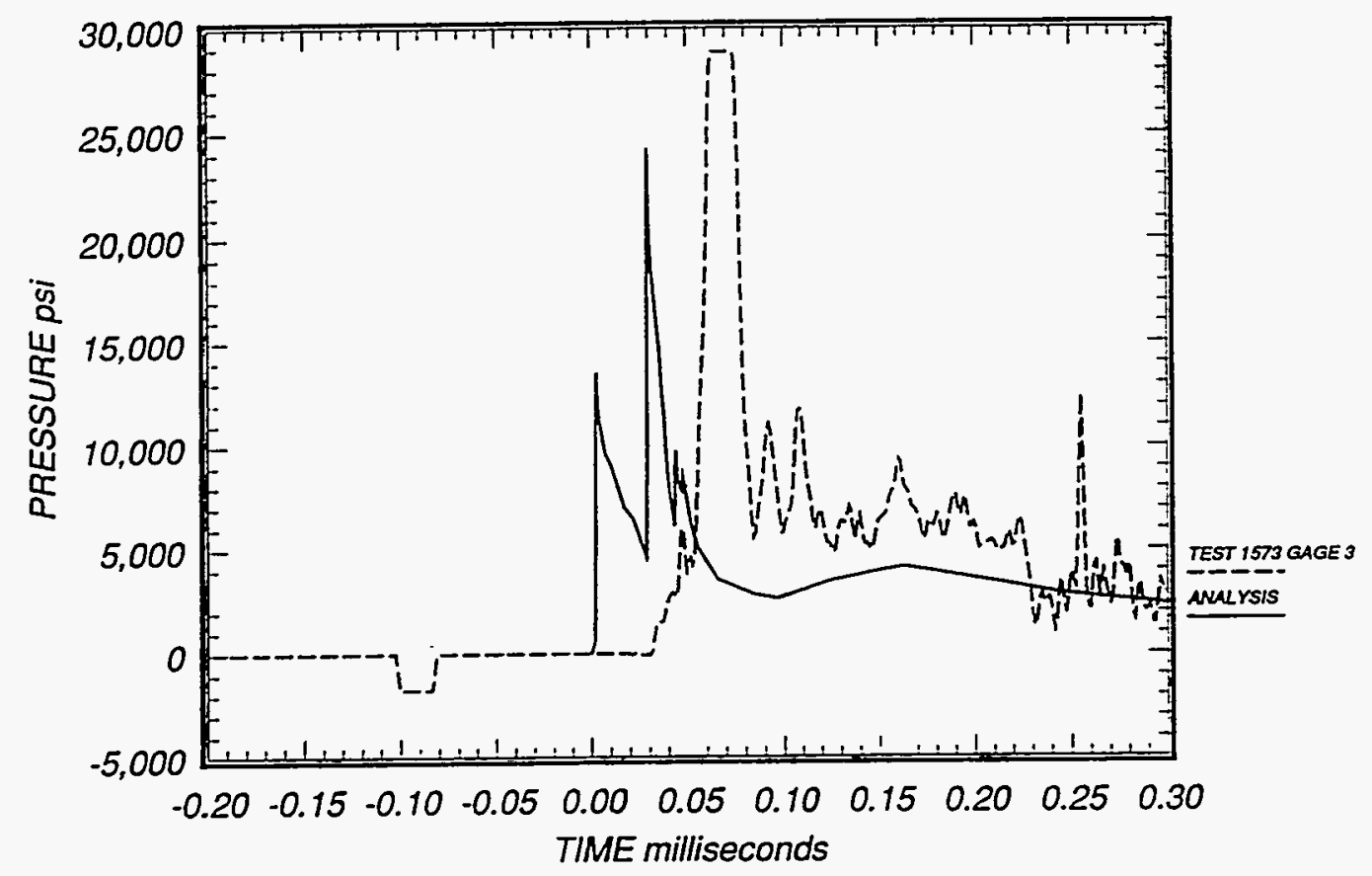

Figure 3: Comparison of predicted and measured pressures for gage 3. 


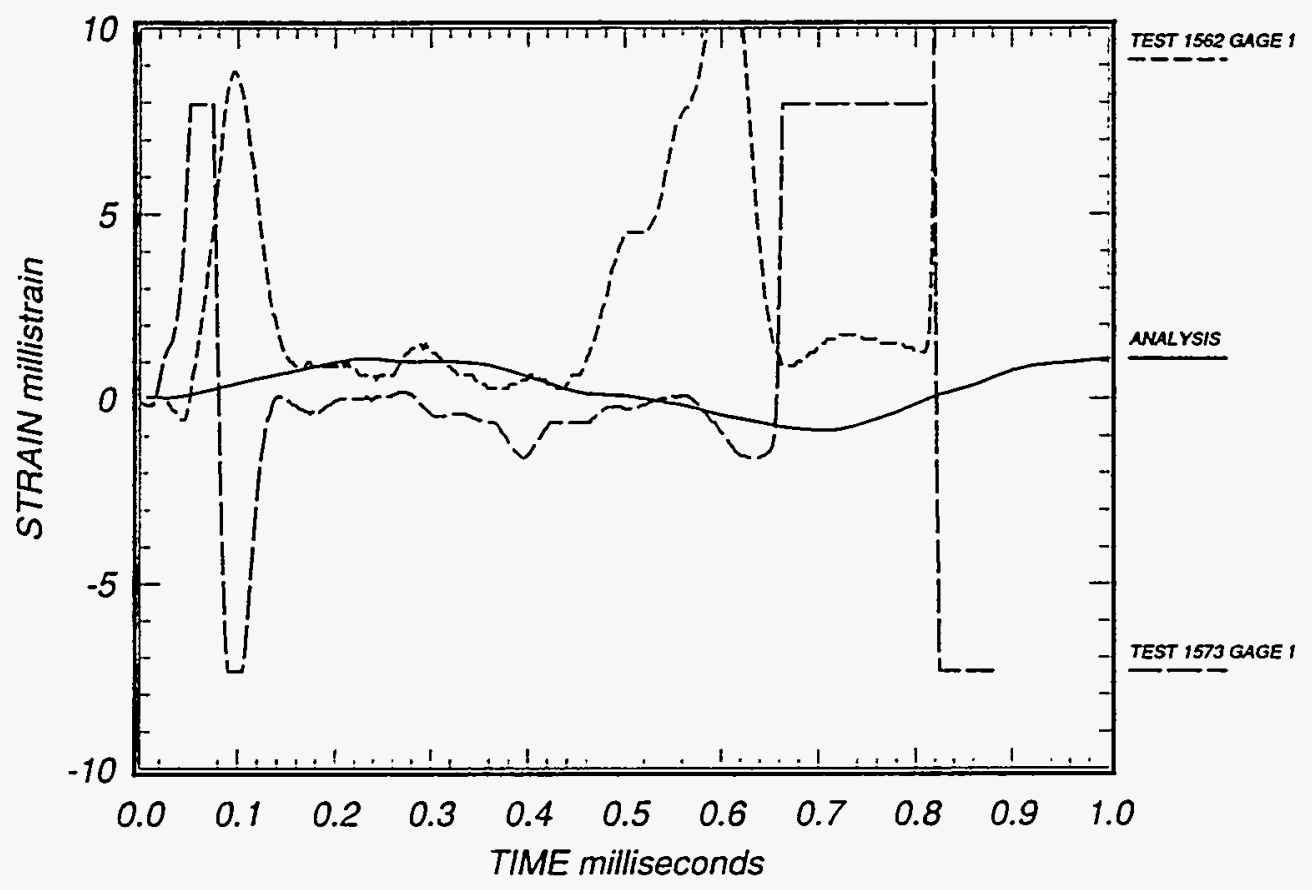

Figure 4: Comparison of predicted and measured strains for gage 1.

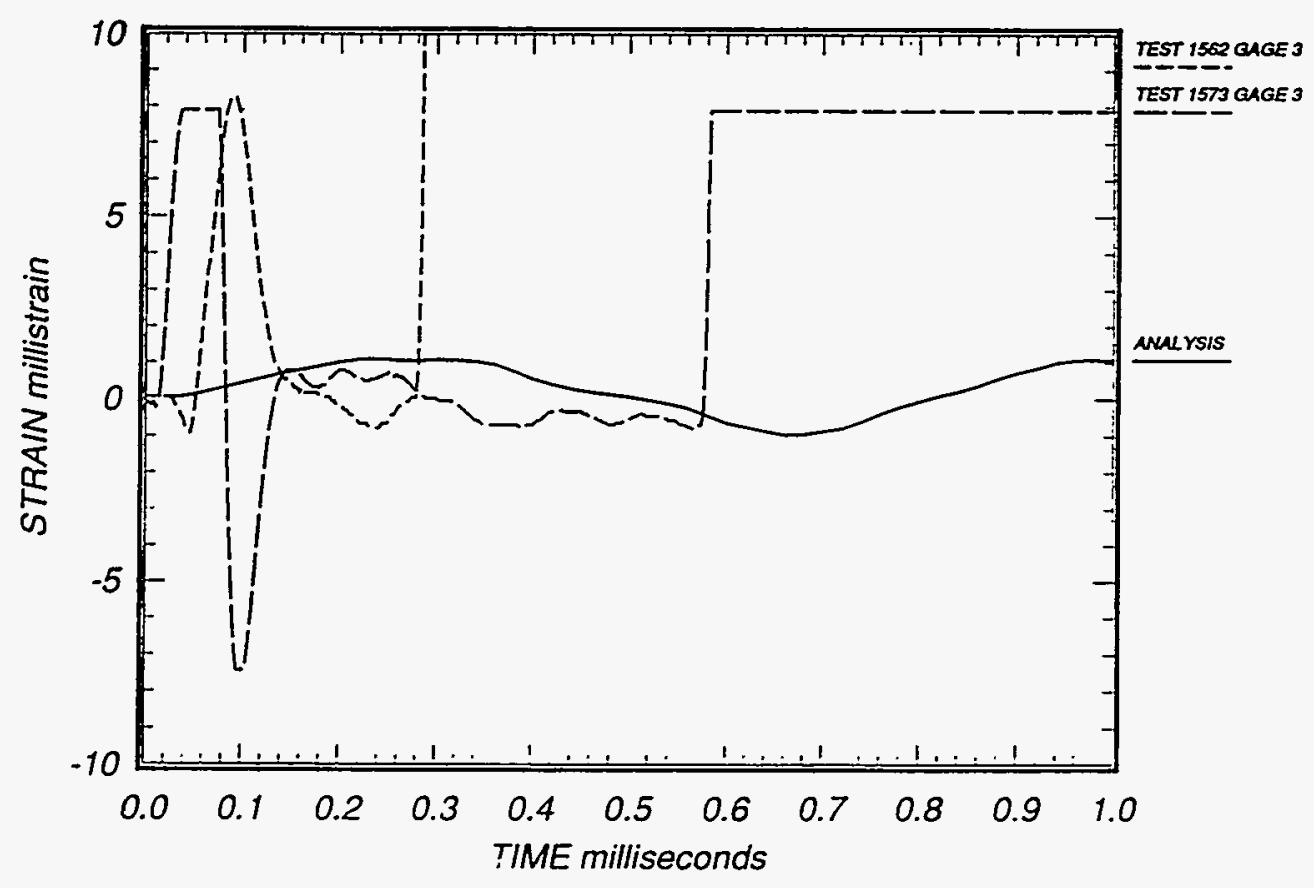

Figure 5: Comparison of predicted and measured strains for gage 3. 


\subsection{Additional discussion}

Several questions have been raised as a result of the discussion of test results given in the last progress report. The first is why the measured pressures are sometimes less than zero. A normal open air airblast has a positive and a negative phase as shown in Figure 6, but we do not know the effect of having the airblast confined. The pressures measured in Test 1562, shown in Figures 7 through 9, show very little pressure excursion below zero. However, the pressures measured in Test 1573, Figures 10 through 12, remain less than zero for most of the recording. Since we know of no physical reason for this, we suspect a baseline shift in the measurements. In all other respects, the test data appears to be valid. The predictions by Al Bowman did not show any negative pressures.

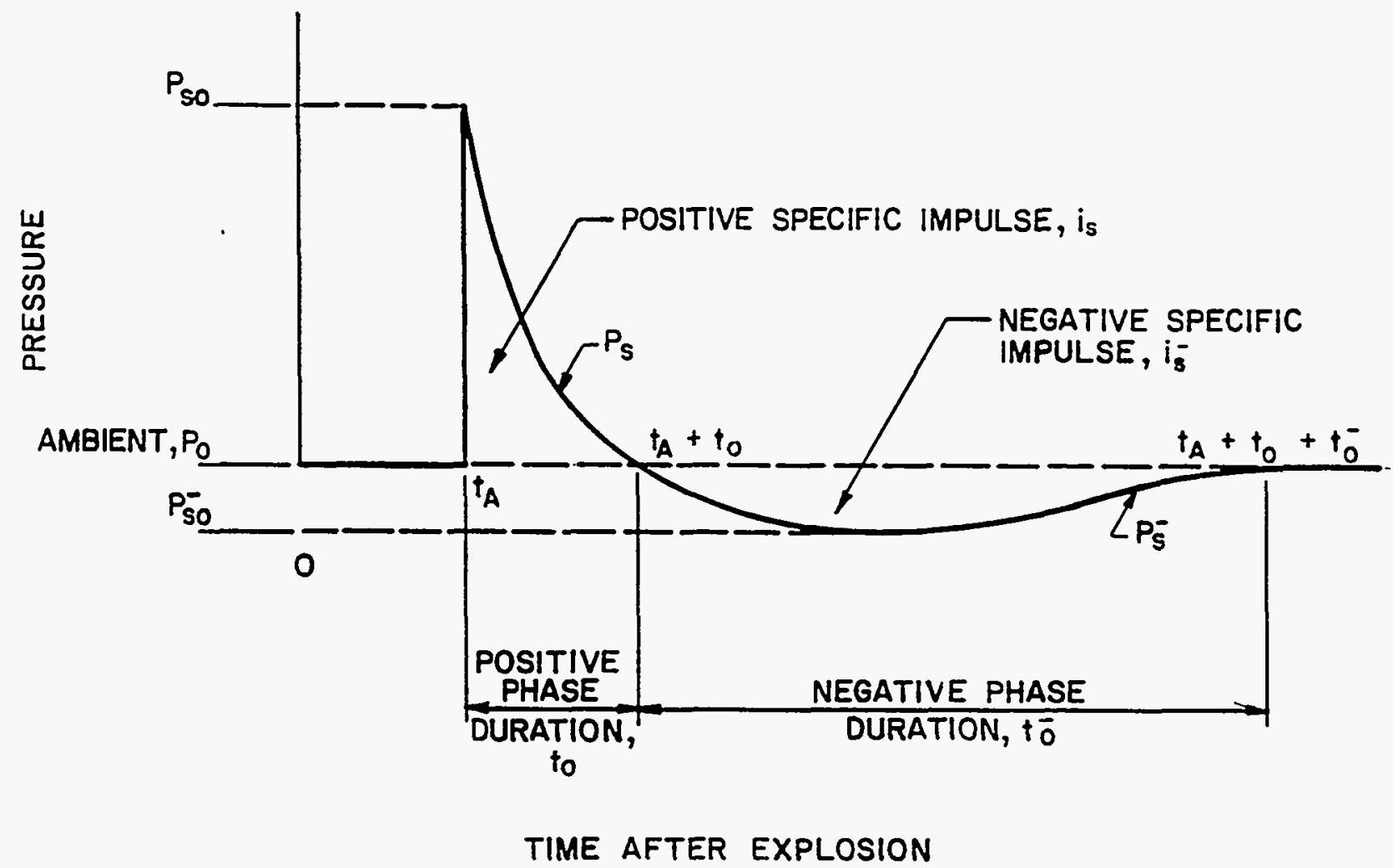

Figure 6: Shape of pressure pulse for open air blast wave. 


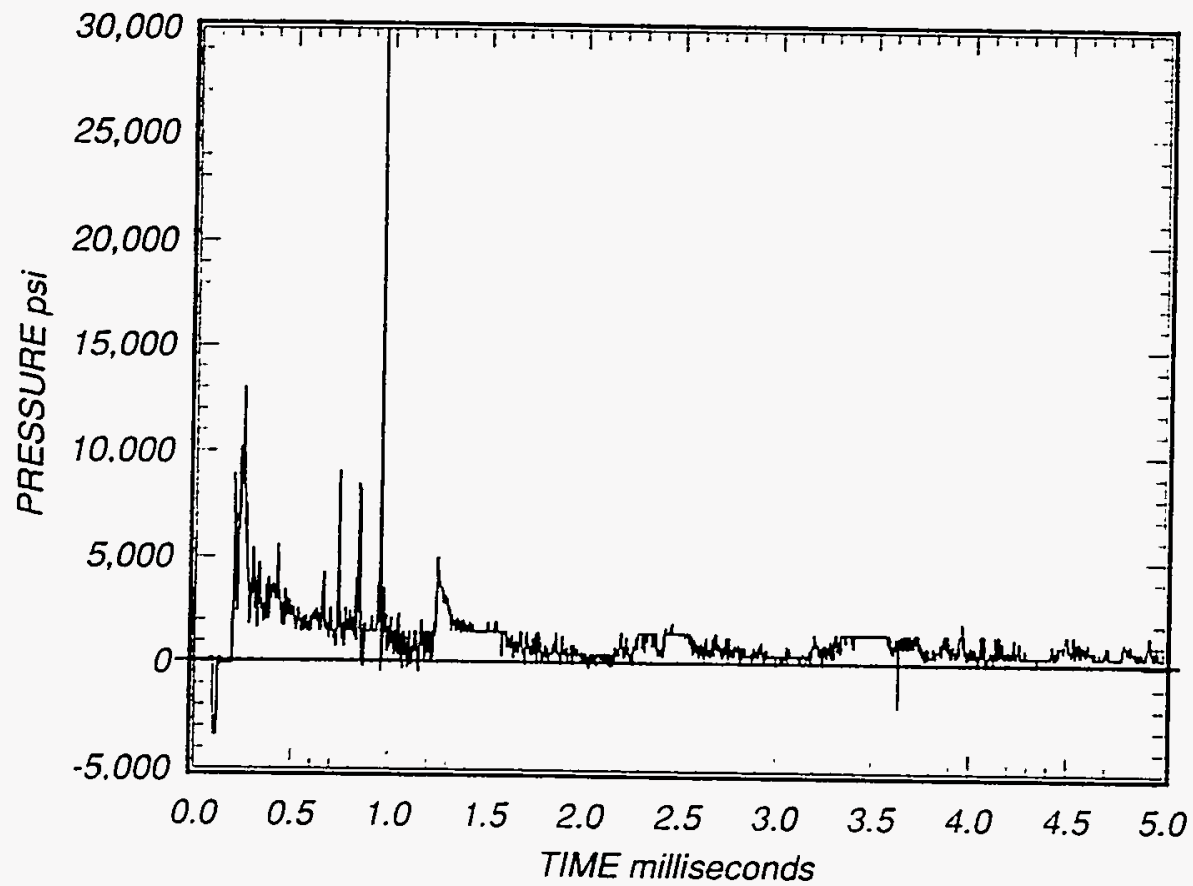

Figure 7: Pressure measured in Test H1562 gage 1.

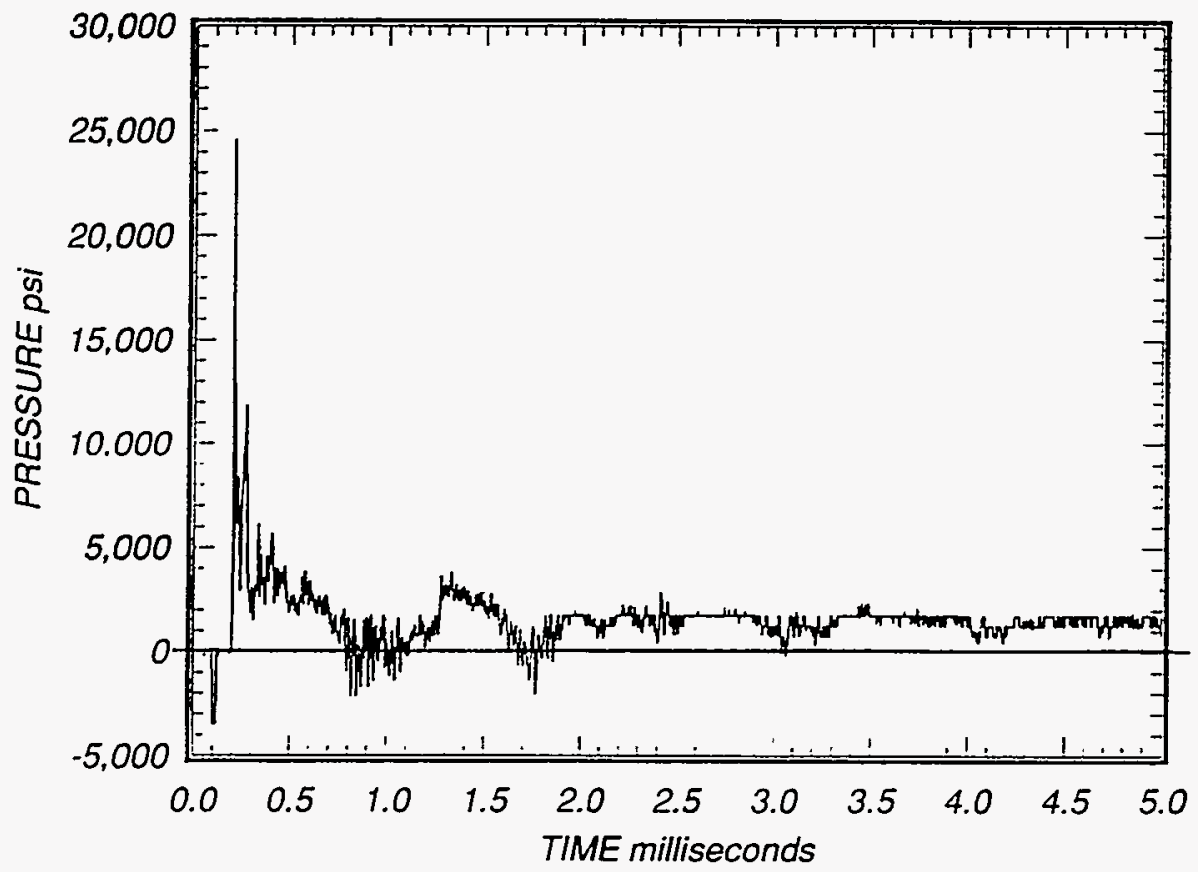

Figure 8: Pressure measured in Test H1562 gage 2. 


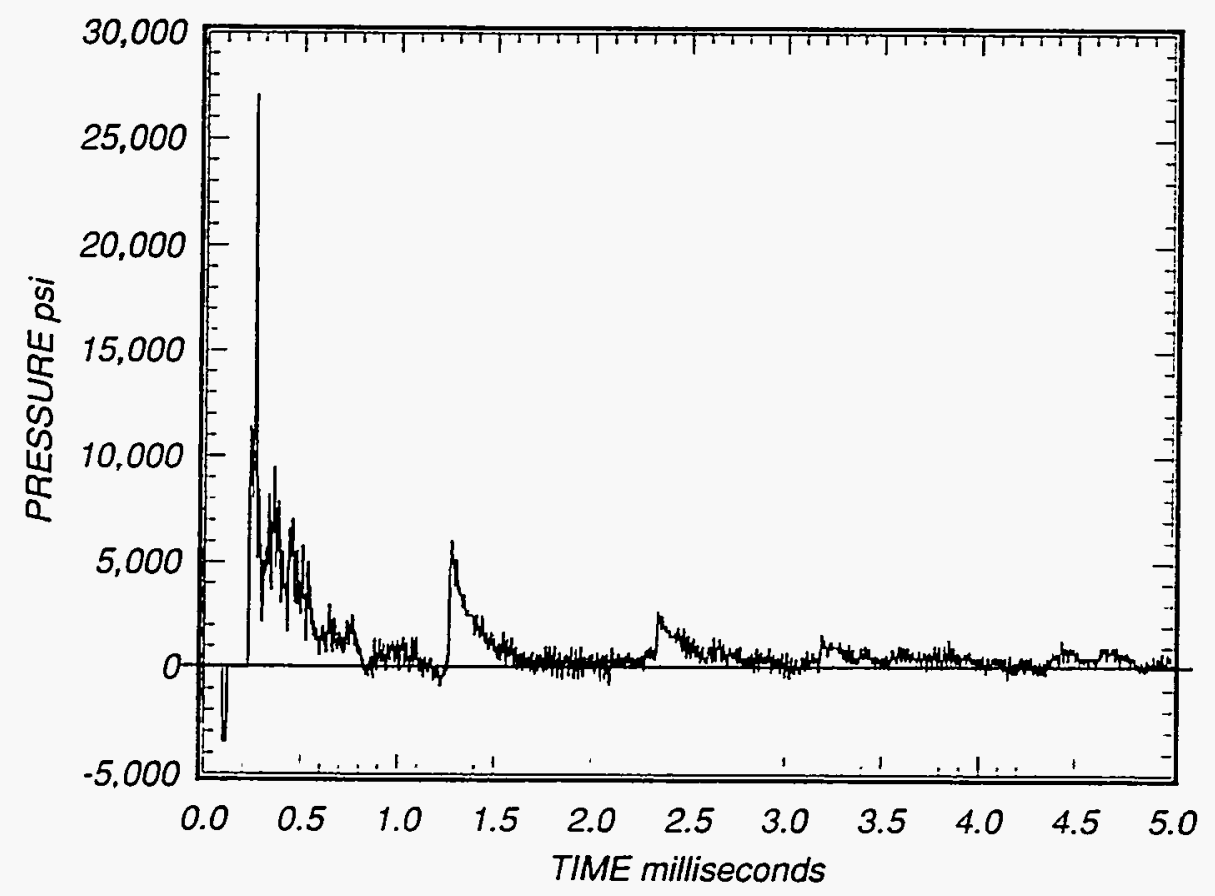

Figure 9: Pressure measured in Test H1562 gage 3.

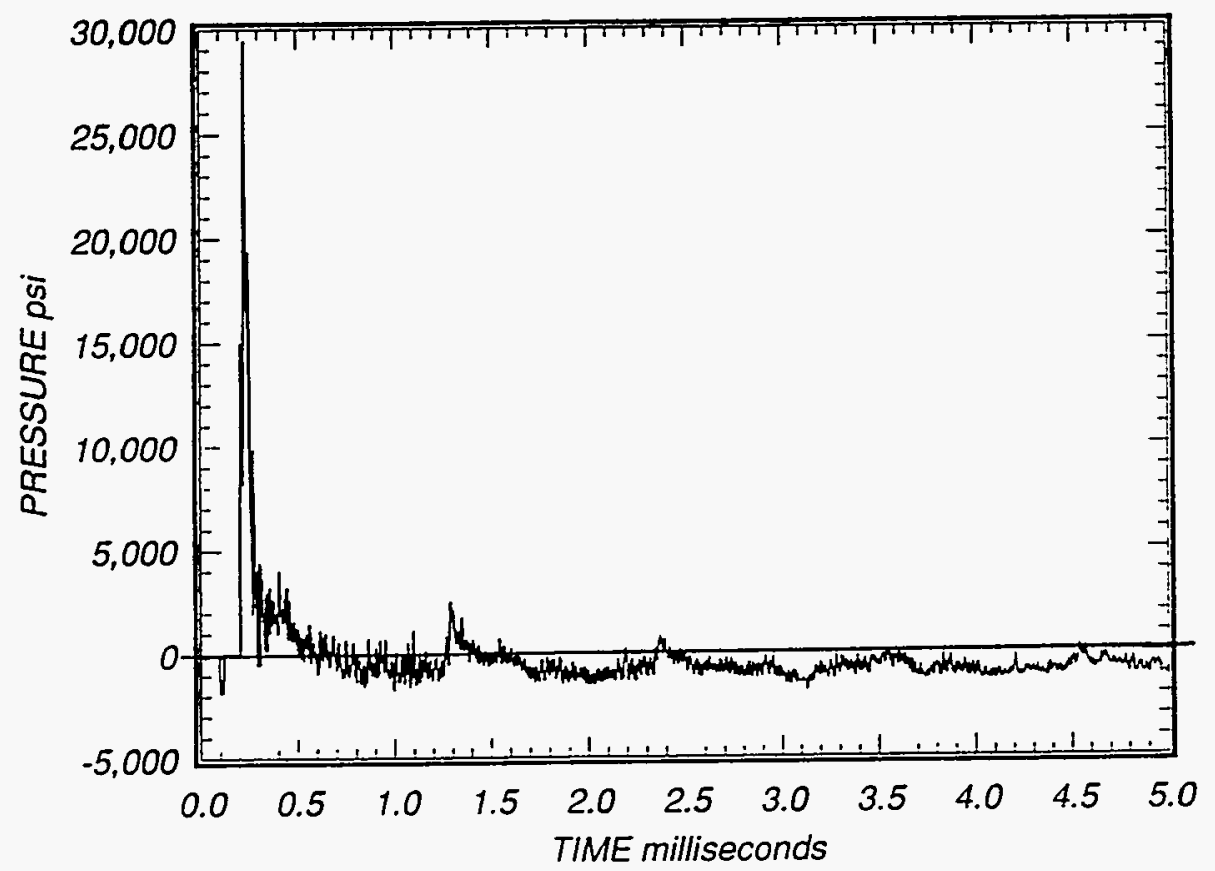

Figure 10: Pressure measured in Test H1573 gage 1. 


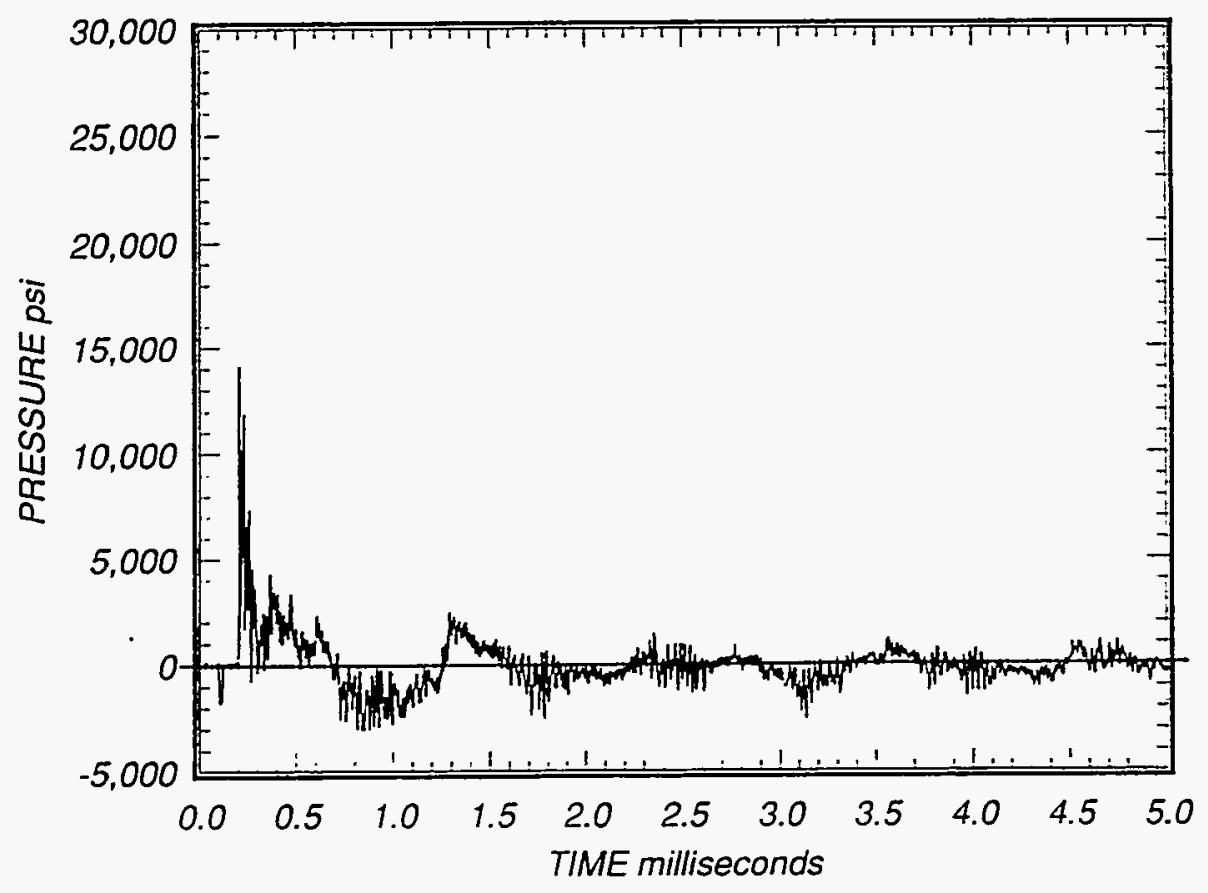

Figure 11: Pressure measured in Test H1573 gage 2.

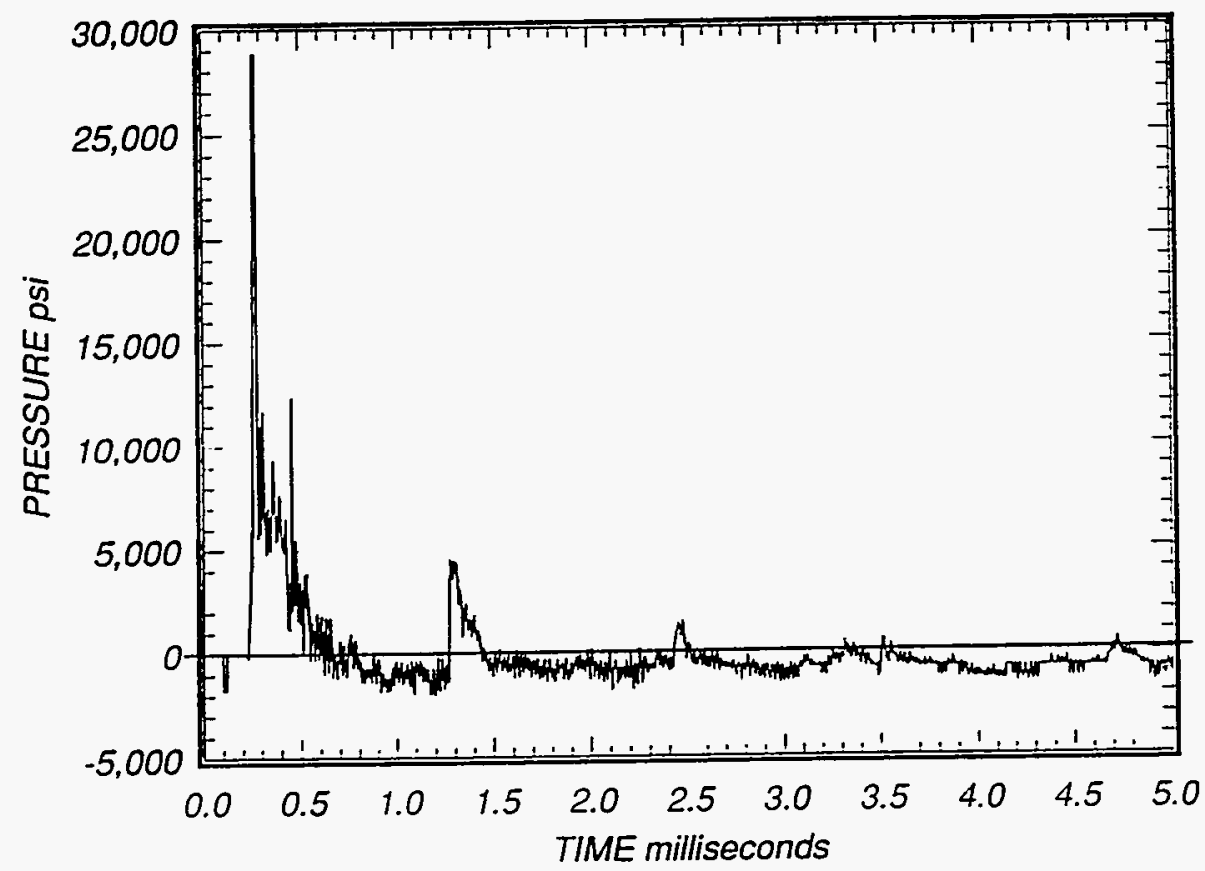

Figure 12: Pressure measured in Test $H 1573$ gage 3. 
Another question we wish to comment on are the initial compressive strains measured by some of the strain gages. The initial response of the vessel should be a large tensile peak corresponding to the first membrane expansion. On gages 5 and 6 shown in Figures 13 and 14, a short compressive strain appears before the first expansion peak. Since it does not appear on every gage, it is obviously a higher frequency mode. We believe it is excited by the nonuniformity of the pressure load. It appears to overcome and then reinforce the first membrane response, and is probably a large cause of the yielding at these gage locations.

We have been asked for specific recommendations for isolating the optical window from the structural response. A thicker gasket should certainly be used. Also, you should consider a design that alows a gap between the window and door as much as is possible given the constraint of maintaining a pressure seal. A suggested design is shown in Figure 15.

\subsection{Additional Work}

Also under Task 1, we are repeating the modal analysis done on a previous contract to better understand the vessel response. From each mode shape computed by NIKE3D we will be able to get the magnitude of the response at each gage location relative to the other modes. These can be compared to the modal decomposition done by Tom Beery of LANL to isolate the different modes contributing to the structural response. We expect to complete this work within the next two weeks. 


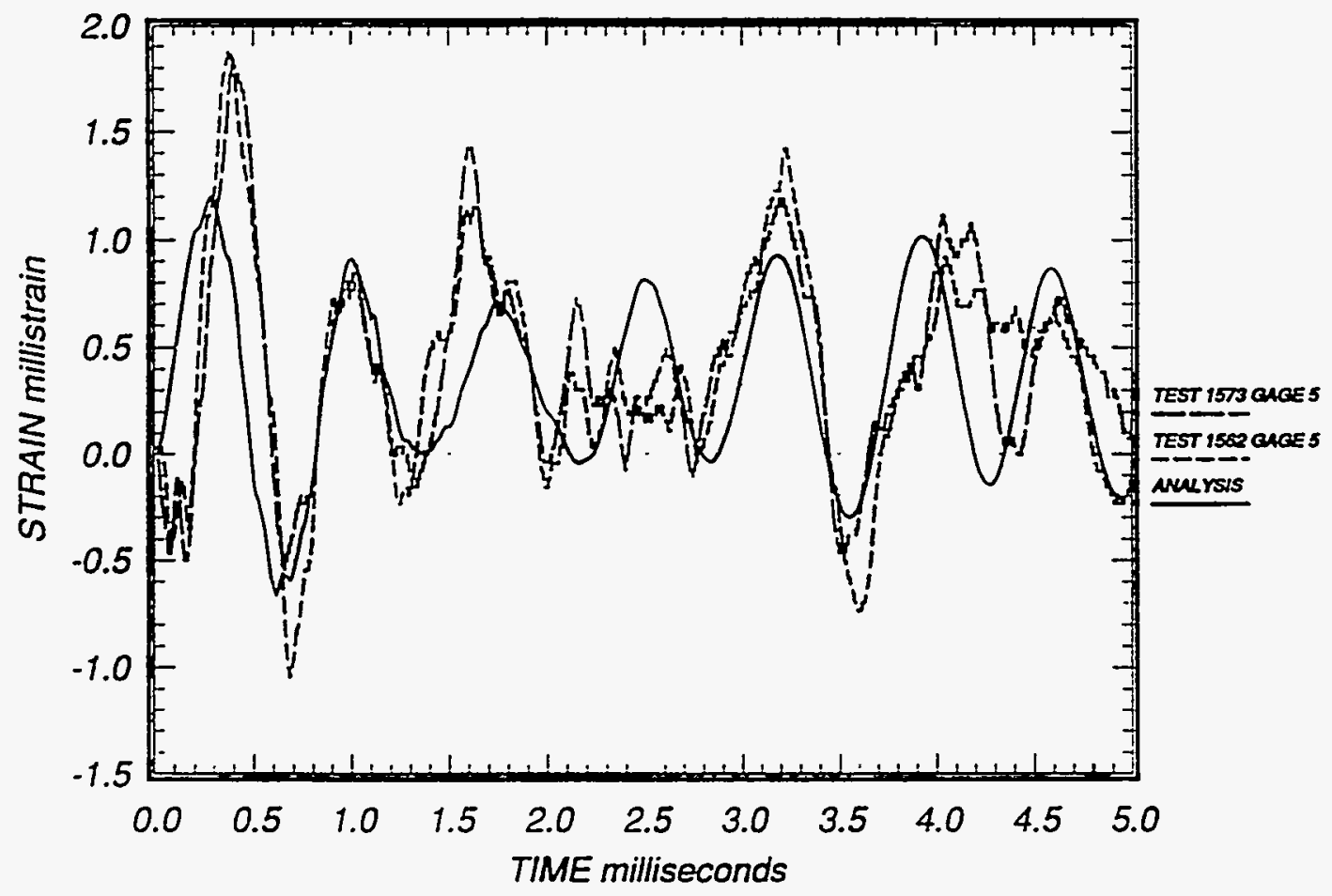

Figure 13: Predicted and measured strains for gage 5.

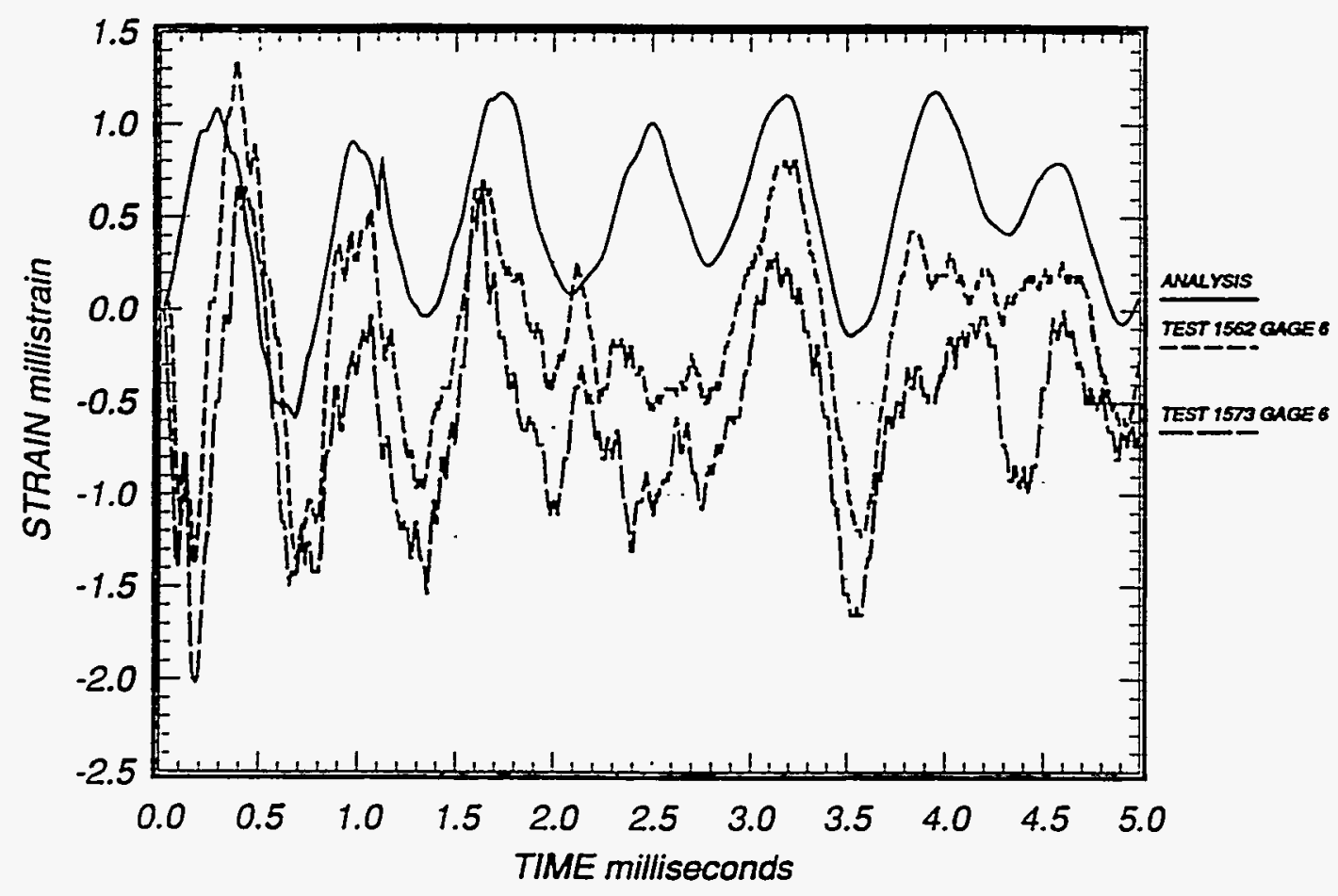

Figure 14: Predicted and measured strains for gage 6. 


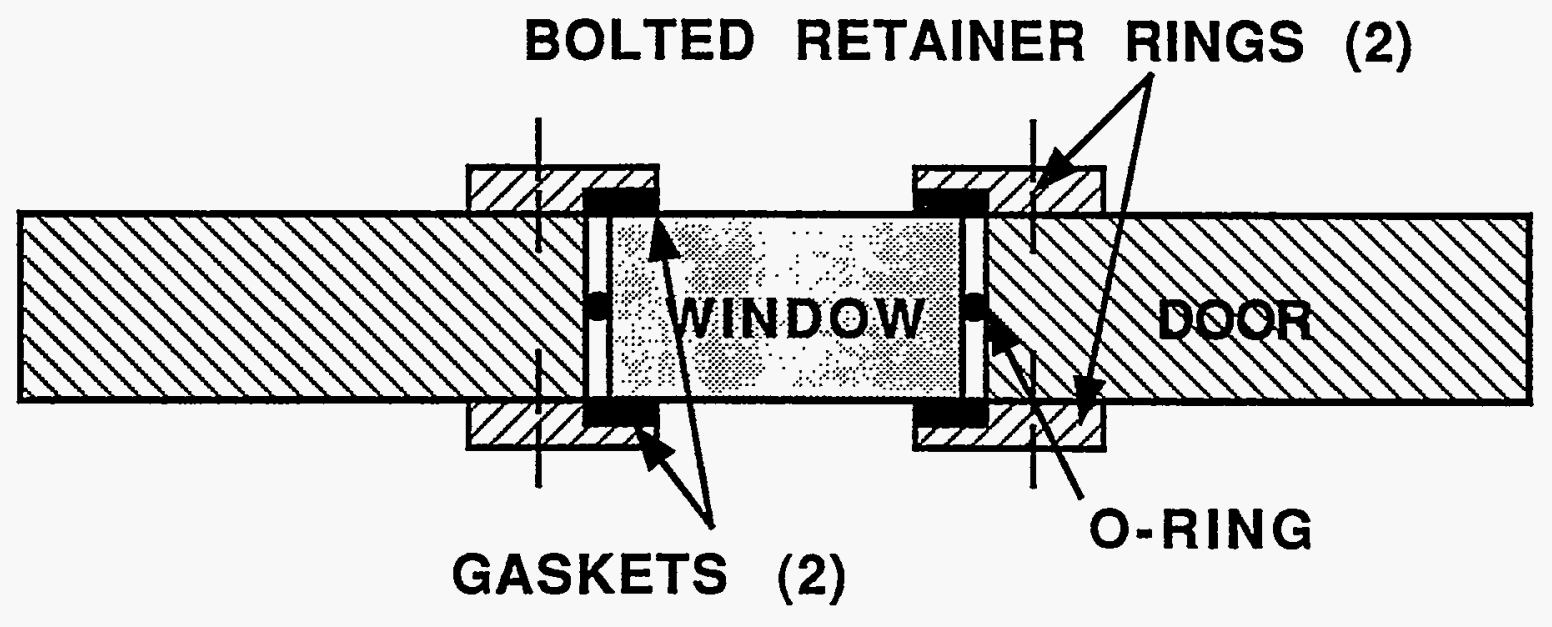

Figure 15: Suggested design for optical window mounting. 


\section{Task 3 - Finite Element Analysis of Confine- ment Vessel Doors}

One of the most important aspects of the confinement door analysis is the study of bolt prestress. The prestress of the bolts needs to be included in the door model in a realistic manner. We are investigating a method of including the prestress which will enable us to study the interaction of the door and bolts statically as well as dynamically. We will first model the closure as shown in Figure 16. The nozzle is modelled as solid; i.e., the portion of the bolt going into the nozzle is assumed to be rigidly attached to the nozzle material. The closure door is modelled with a bolt hole. The bolt head is modelled explicitly, but the shank of the bolt is represented by a spring having the stiffness of the bolt which is easily calculated. The length of the spring is initially set at some value less than the thickness of the door. The initial spring length depends on the amount of prestress we wish to represent. The node representing the bottom of the spring is given an enforced displacement to bring it down to the surface of the nozzle. The analysis code will calculate the resulting equilibrium position for the bolt and door. This analysis will be done as a static case in NIKE3D. By varying the initial length of the spring representing the bolt, we can study the effect of bolt prestress in a static sense. We believe that we can also input the results of the NIKE analysis as an initial condition in a DYNA3D analysis. This would allow a good representation of the prestress for subsequent dynamic analyses.

To test out the method, we developed the mesh shown in Figure 17. It represents a small portion of the closure of one of the side ports. Symmetry conditions are applied so that two bolts are represented, much like the two bolt circles present on the closure. We are in the process of performing the NIKE3D analysis of this model. We will report the results in the next progress report. 


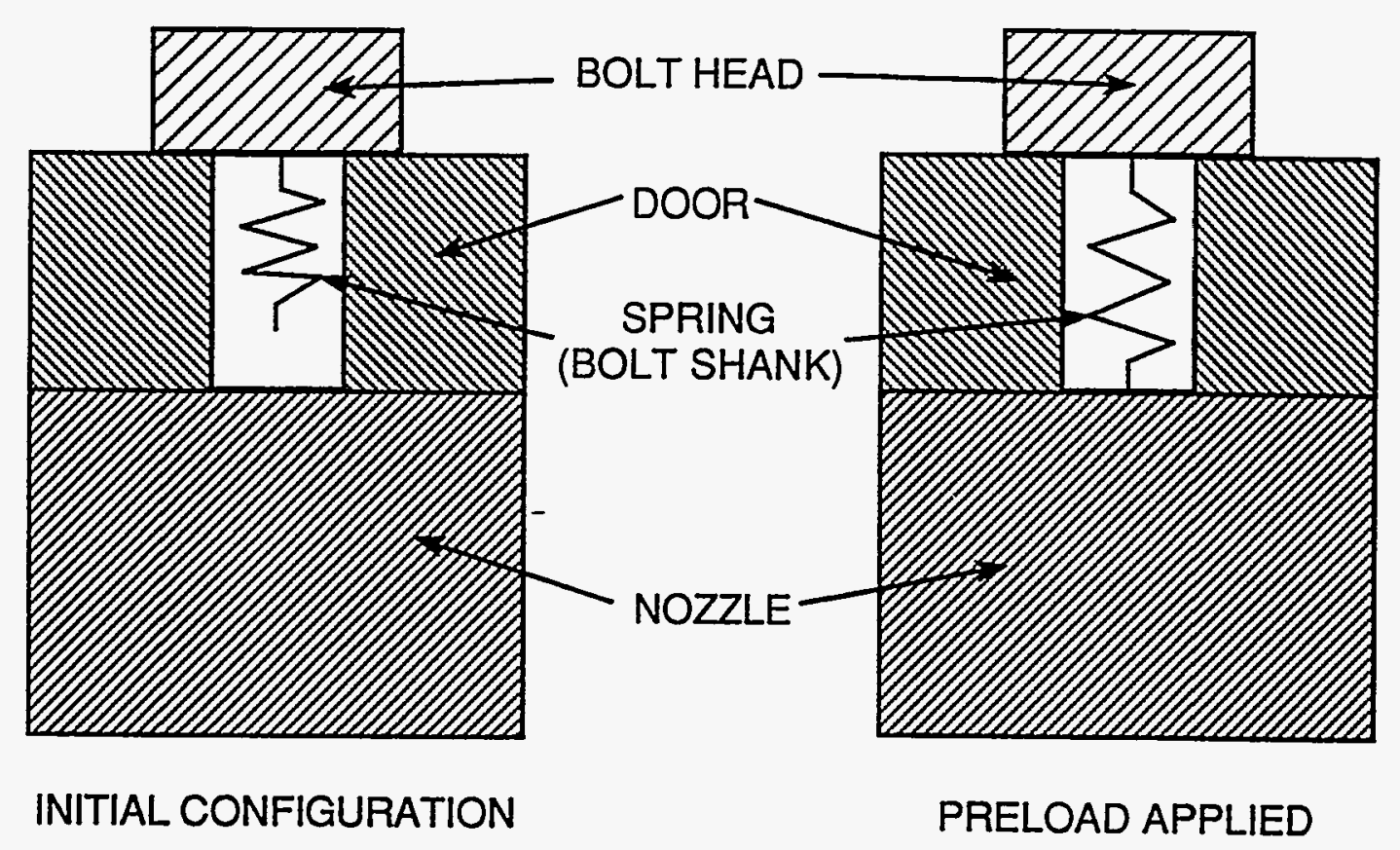

Figure 16: Schematic showing bolt preload modelling method.

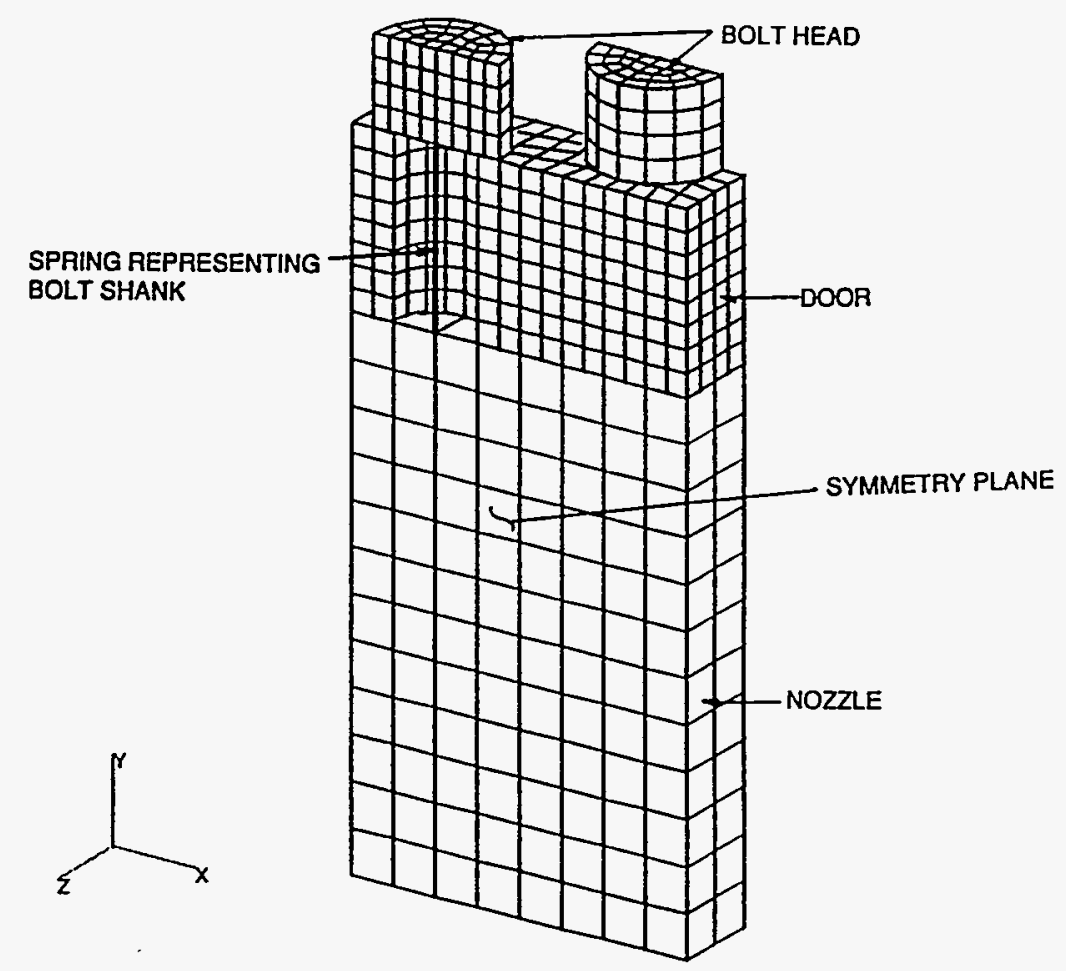

Figure 17: Finite element mesh for NIKE3D bolt preload analysis. 


\section{PROGRESS REPORT FOR CONFINEMENT VESSEL ANALYSIS Barbara B. Lewis APTEK, Inc June 17,1993}

We have completed Task I, correlation of new vessel data. This progress report gives our assessment of the most recent vessel tests and the correlation between the new tests and finite element analyses.

The tests were numbered $\mathrm{H}-1573$ and $\mathrm{H}-1562$ and were fired on November 9 and 10, 1992 , respectively. The first test, $\mathrm{H}-1573$ was a vessel response test which was intended to duplicate the vessel tests done in November of 1991. APTEK had correlated the earlier tests with fininte element analyses of the vessel, and some questions remained concerning high strains at the bottom of the vessel. Test $\mathrm{H}-1573$ was identical to the previous $40 \mathrm{lb}$ tests except that a Burke tube was used to support the explosive charge while the explosive was freely suspended in the earlier tests. The effect of the tube will be discussed later in this report. The second test, H-1562, was for development of the optical port. In addition to the Burke tube, this test also had additional components on the inside of the ports to protect the windows. Instrumentation for each test consisted of 3 pressure gages, 3 strain gage rosettes of 3 elements each, and 2 accelerometers. The locations of the gages are given in the memo by $\mathrm{W}$. E. Baker, Los Alamos memo number M-4:93-187. The test data was provided to us by Tom Beery of Los Alamos. We also used information from reports by W. E. Baker, Christopher Romero and Tom Duffey.

We examined the test data for overall quality, differences between the two tests, and differences between gages. We also correlated the test results with analysis using the finite element models that we had previously developed. These observations and comparisons are presented here according to the different types of data, followed by a discussion of the implications and conclusions that can be drawn from the tests.

\section{Observations and Correlation of Test Data}

\subsection{Pressure}

Figure 1 shows the three pressures measured for test $\mathrm{H}-1573$ for the first half millisecond of recording time. Gages 1 and 2, which are on the upper hemisphere of the vessel, show the pressure increasing at 0.20 milliconds while gage 3 , on the bottom hemisphere, shows no response until about 0.23 milliseconds. Note the timing signal 


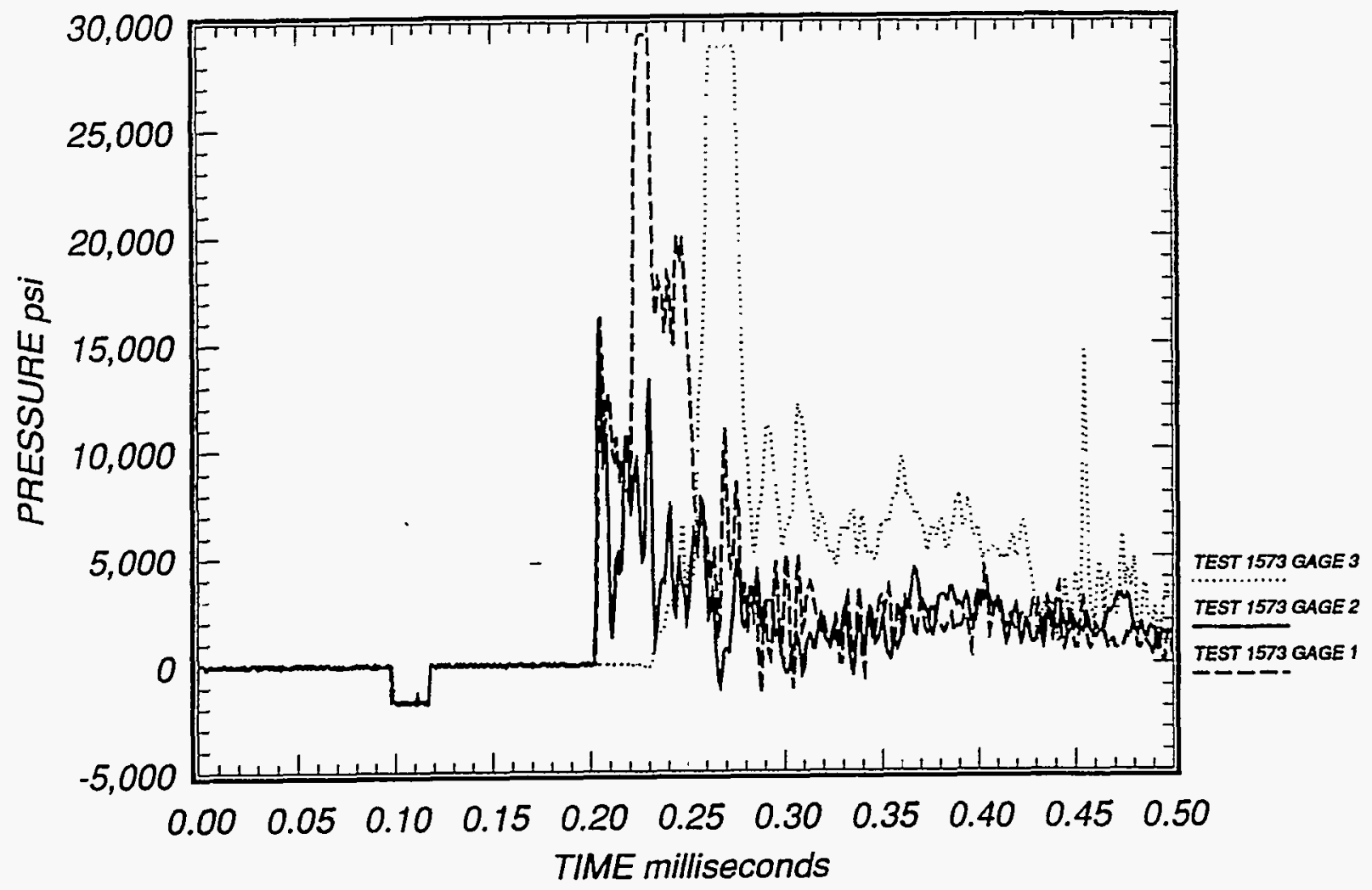

Figure 1: Pressures measured in Test H-1573.

dip at 0.10 milliseconds indicating that the delayed start in gage 3 is a true delay, and not a shift in the recording time. This indicates a non-uniformity of the loading, possibly due to shadowing of the bottom hemisphere by the Burke tube. The pressures recorded in test H-1562 show a similar delay for gage 3 . Also, the magnitudes of the three pressures are very different. The peak magnitude for gage 3 appears to have been clipped. That is, the recording band was not large enough to capture the peak. The pressures measured in test H-1562 show the same trends, Figure 2, but have lower magnitudes.

Al Bowman of Los Alamos predicted the pressure and APTEK used the predictions in the finite element analyses. Figure 3 shows a comparison of the analysis and gage 2 of Test H-1573. The shapes of the pressure curves match the predicted pressure fairly well. The test data has been shifted in time to match the initial rise time of the predicted pressure. The timing and magnitudes of the predicted pressure reflections match the test data well. The predicted pressure is generally higher than measured between the pulses. 


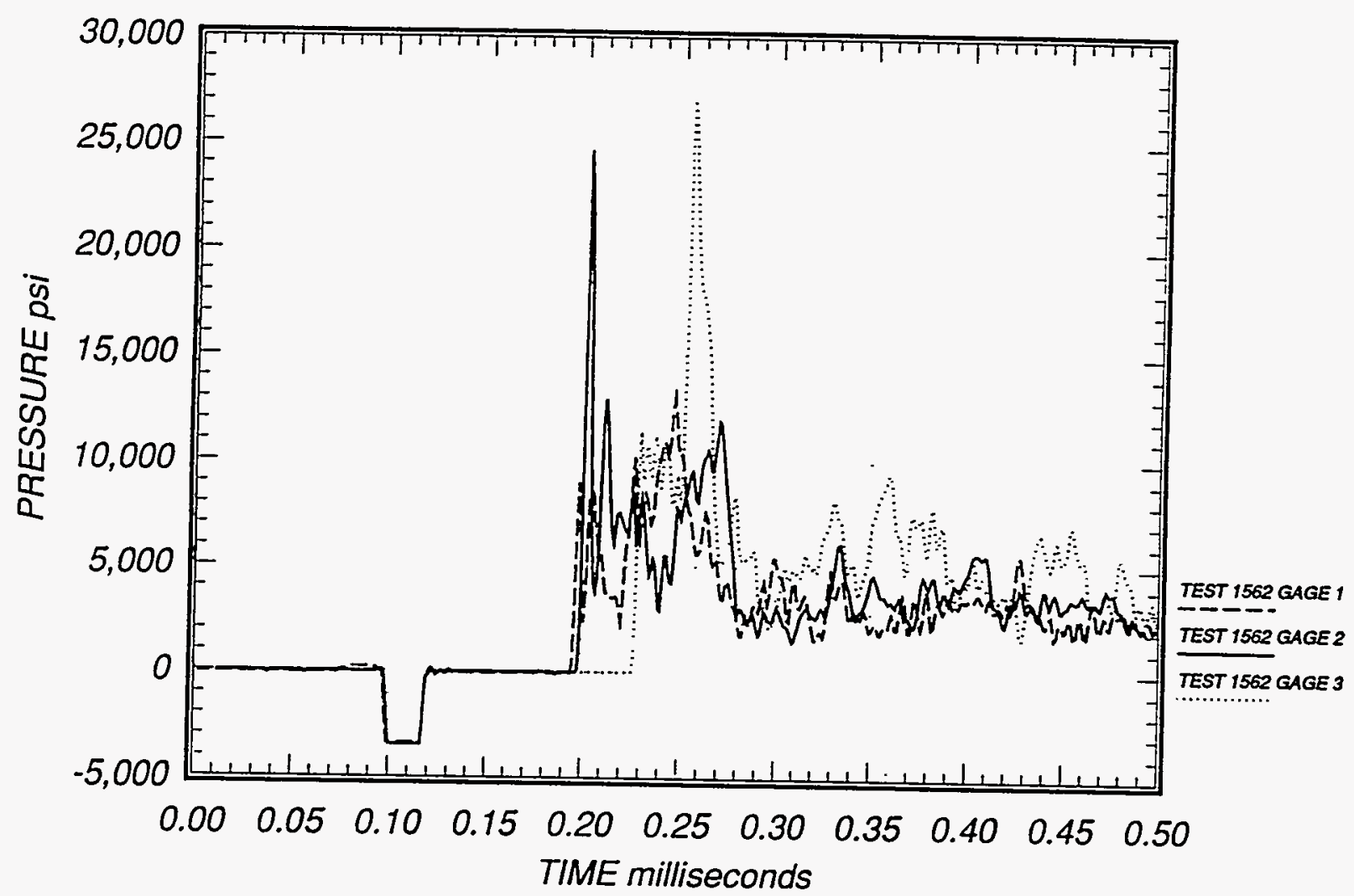

Figure 2: Pressures measured in Test H-1562.

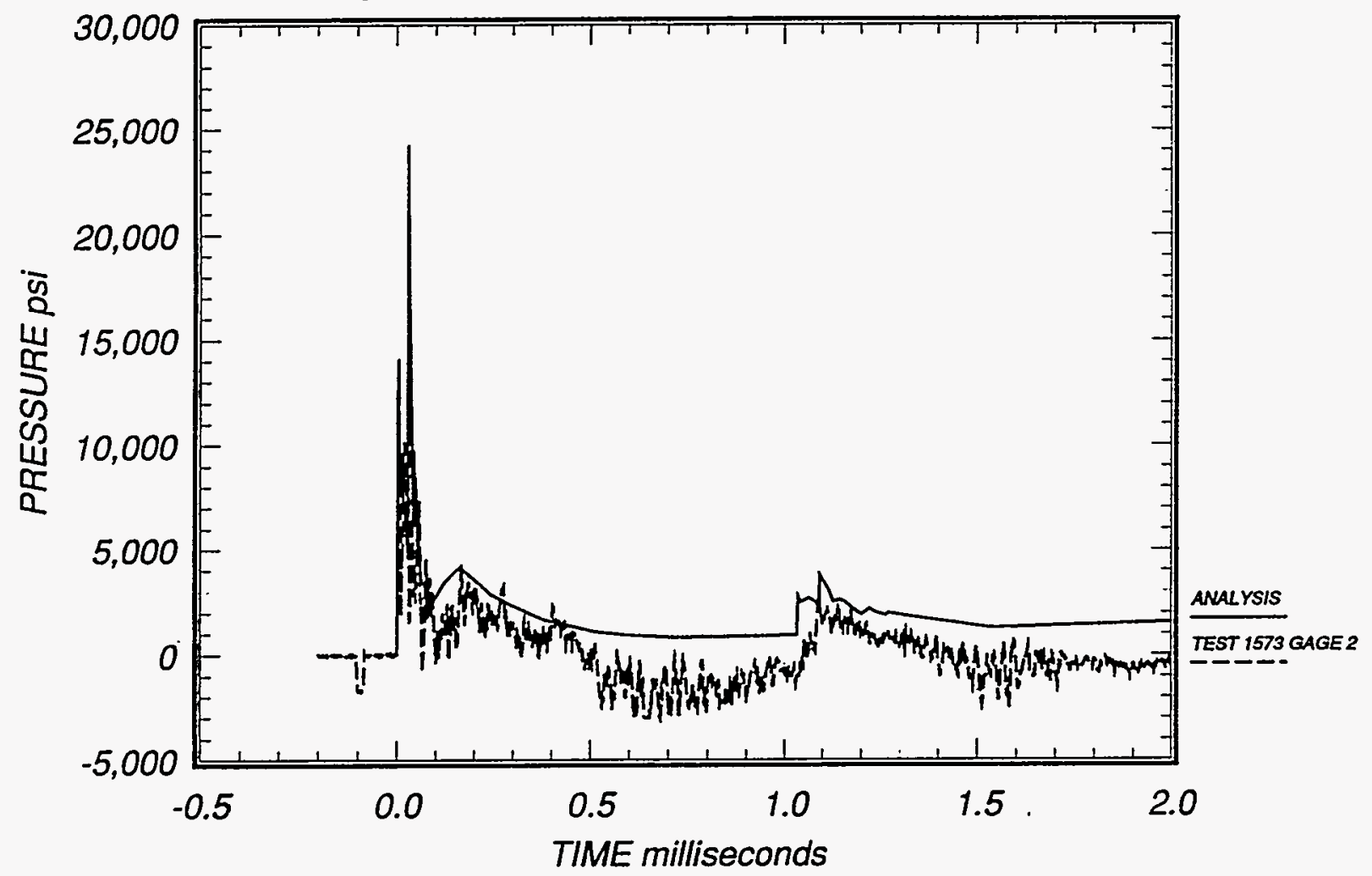

Figure 3: Comparison of predicted and measured pressures. 


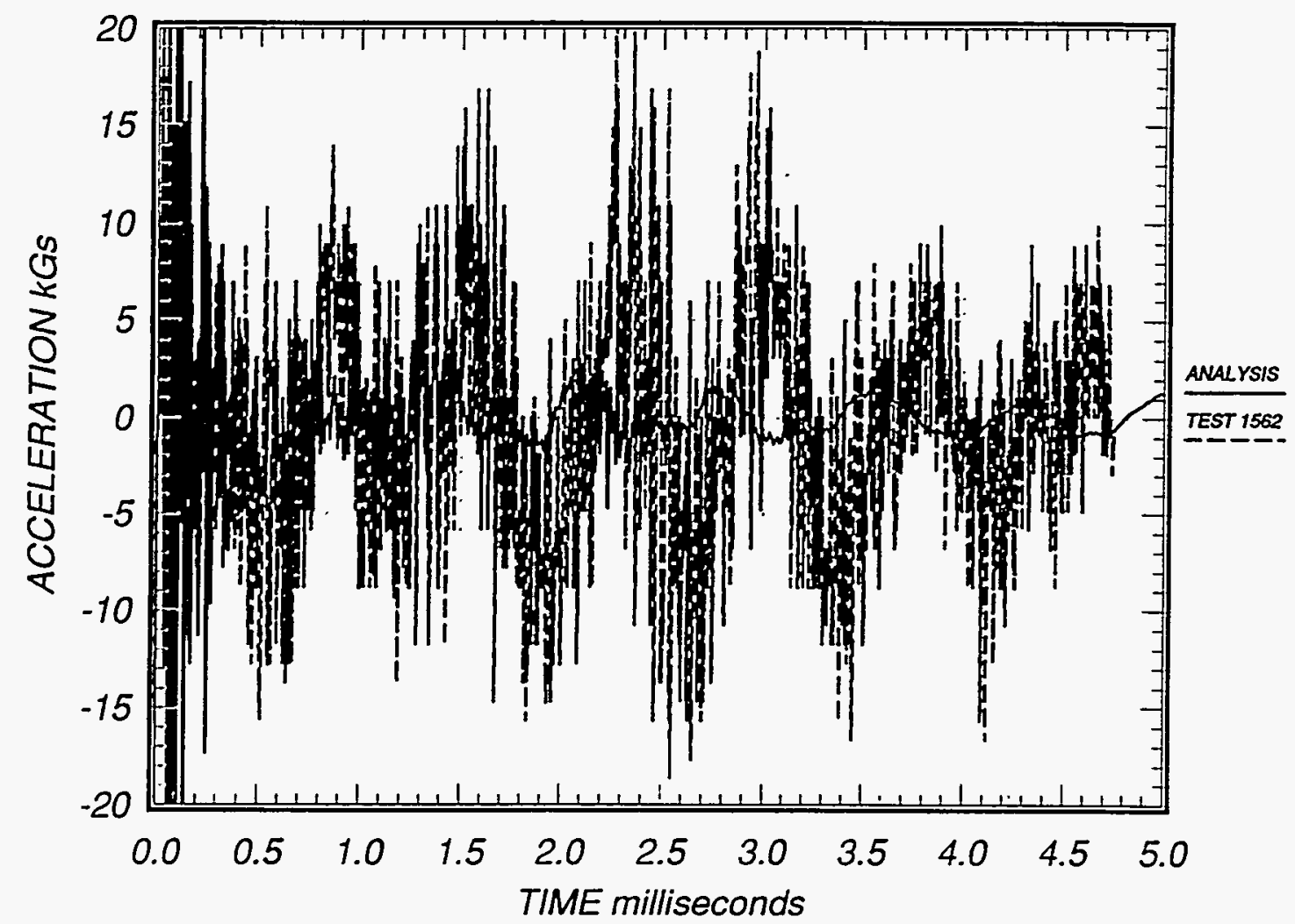

Figure 4: Comparison of predicted and measured accelerations.

\subsection{Accelerations}

Of the four accelerometer recordings, only one recording appears to be valid. Figure 4 shows the accelerometer data from gage 1 of test $\mathrm{H}-1562$ along with the accelerations predicted using the finite element model. This accelerometer was located on the port door just outside of a quartz window. The analytical curve is out of phase with the test, but the same fundamental frequency is apparent in both curves. The test results have a considerably higher magnitude, due largely to the presence of higher frequency response.

\subsection{Strains}

The strain gages were three rosettes of three gages each. Gages 1 through 3 were at the bottom pole of the vessel; gages 4 through 6 were at 45 degrees longitude and -72 degrees latitude; gages 7 through 9 were at 0 degrees longitude and -72 degrees latitude. Figure 5 shows the orientations of the gages.

Figures 6 through 11 show the comparison of predicted and measured strains for gages 4 through 9 . The two tests compare well with each other, and the analysis matches 


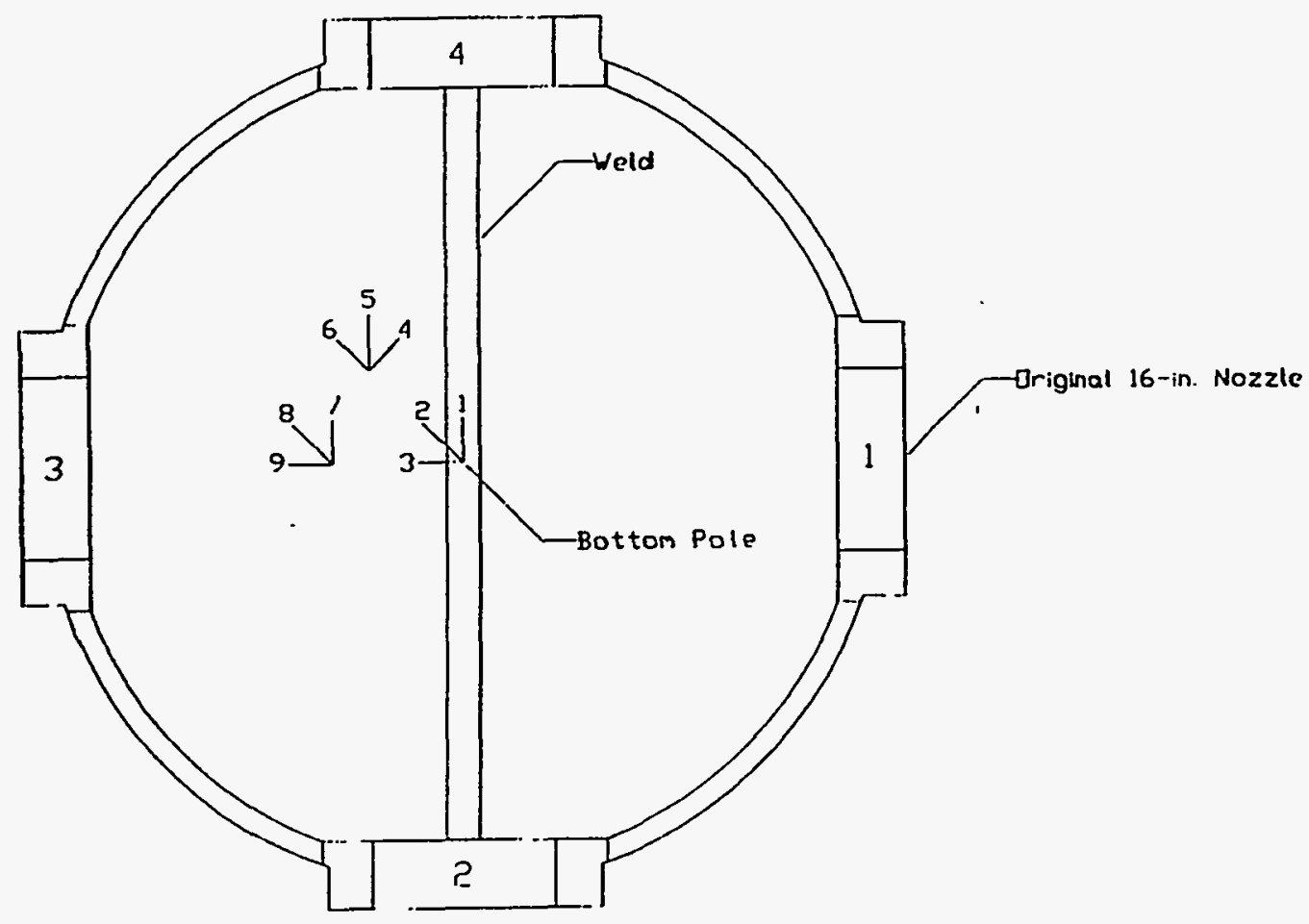

Figure 5: Orientation of strain gages.

the fundamental frequency reasonably well. The magnitudes of the measured strains are higher than the predicted peaks and the beating phenomenon observed in earlier tests is again apparent in these plots. Measurements of the strain gage circuits made after the tests indicated permanent strains at all gages. These were reported by Baker and are apparent in the data as an offset of the test curves from each other and from the analysis. This is especially apparent for gage 4 which had the largest permanent strains. Higher permanent strains were recorded for the first test than for the second, consistant with the work hardening property of steel. Since the onset of yielding is based on the total strain state at a given location and time, it is difficult to determine when yielding is indicated from this data. However, the first peak of each measured strain history is higher than the peak of the analysis which stayed elastic. Also, the offset between the curves is apparent almost from the beginning of the data. 


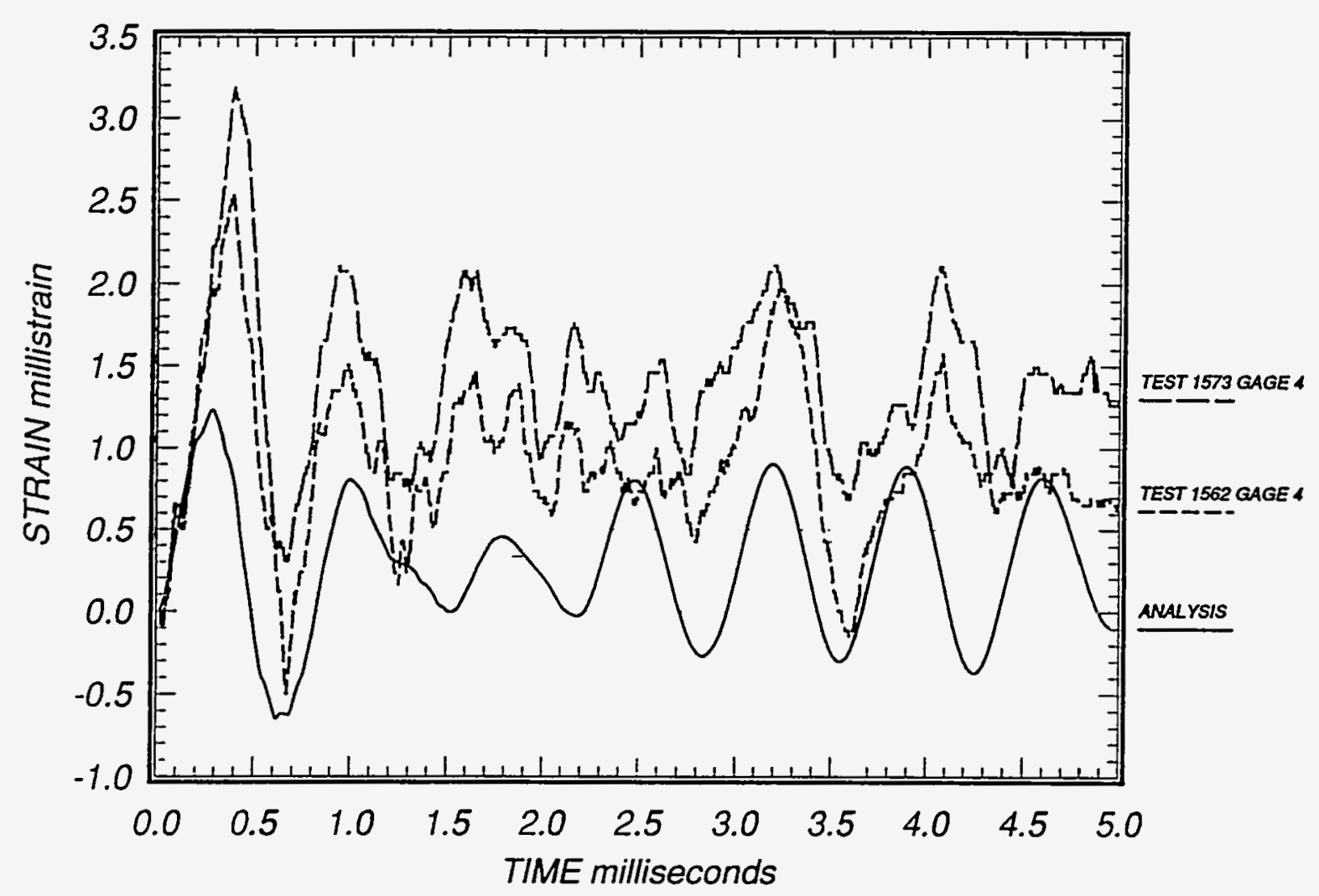

Figure 6: Comparison of predicted and measured strains for gage 4.

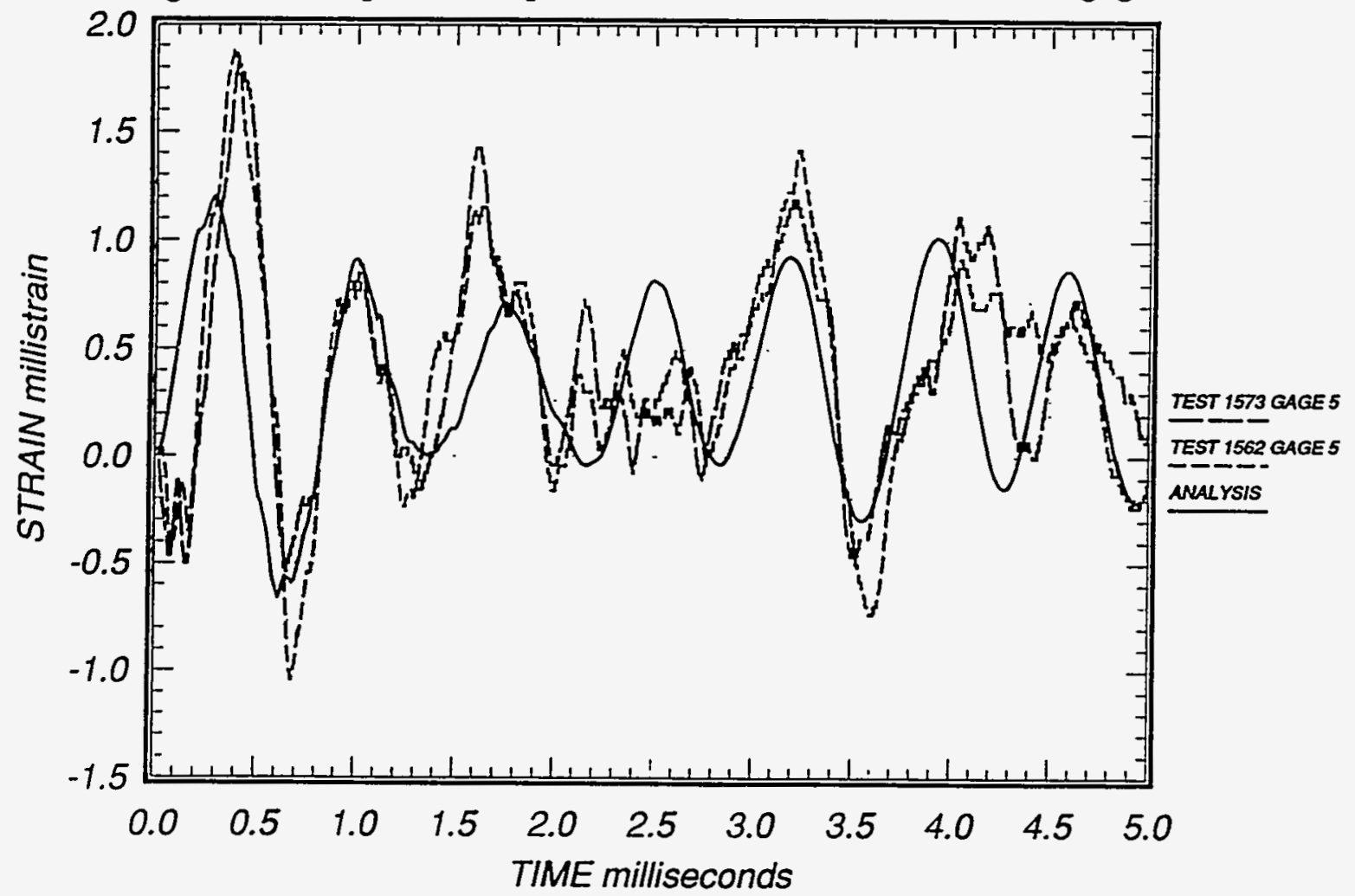

Figure 7: Comparison of predicted and measured strains for gage 5 . 


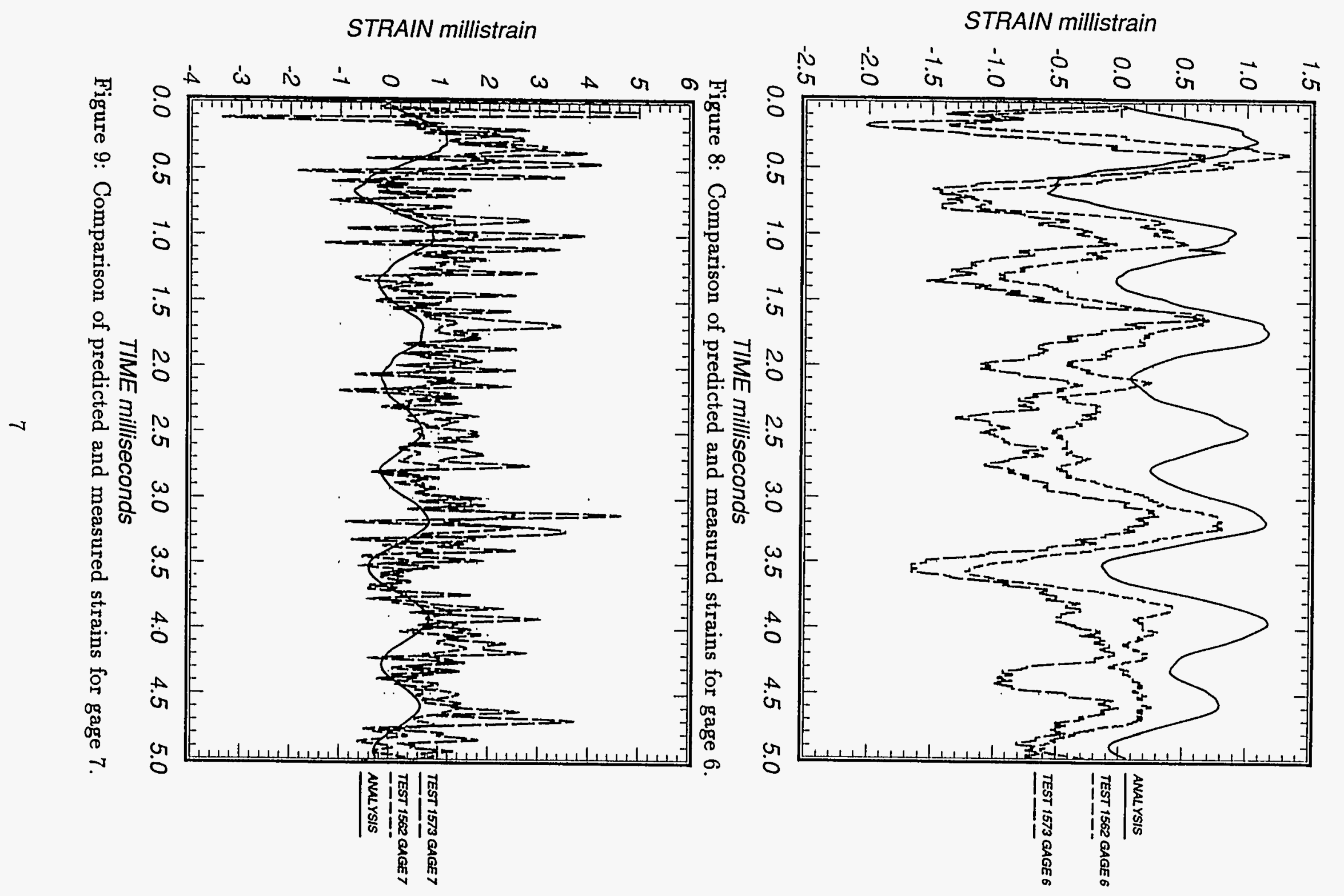




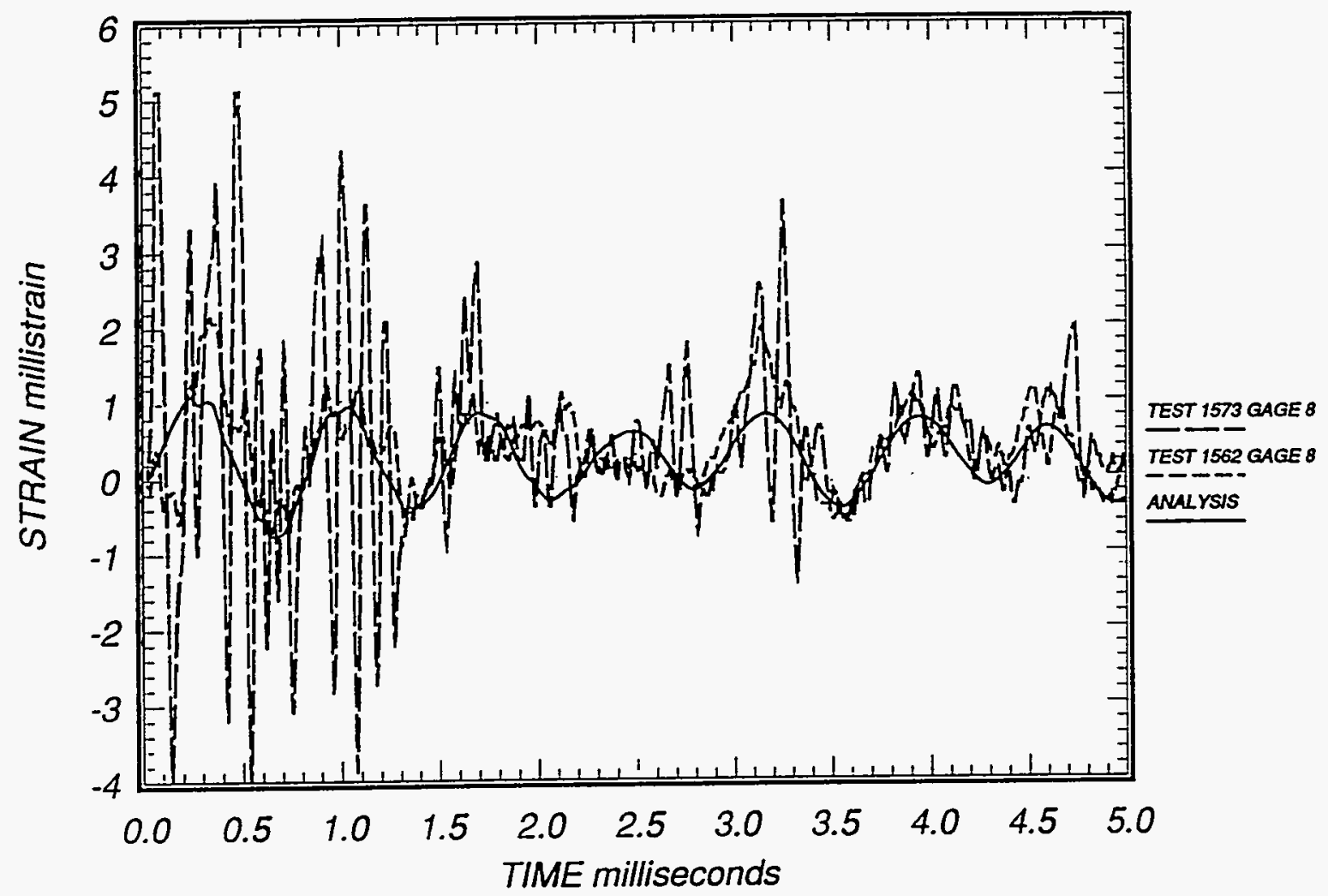

Fiøure 10: Comparison of predicted and measured strains for gage 8.

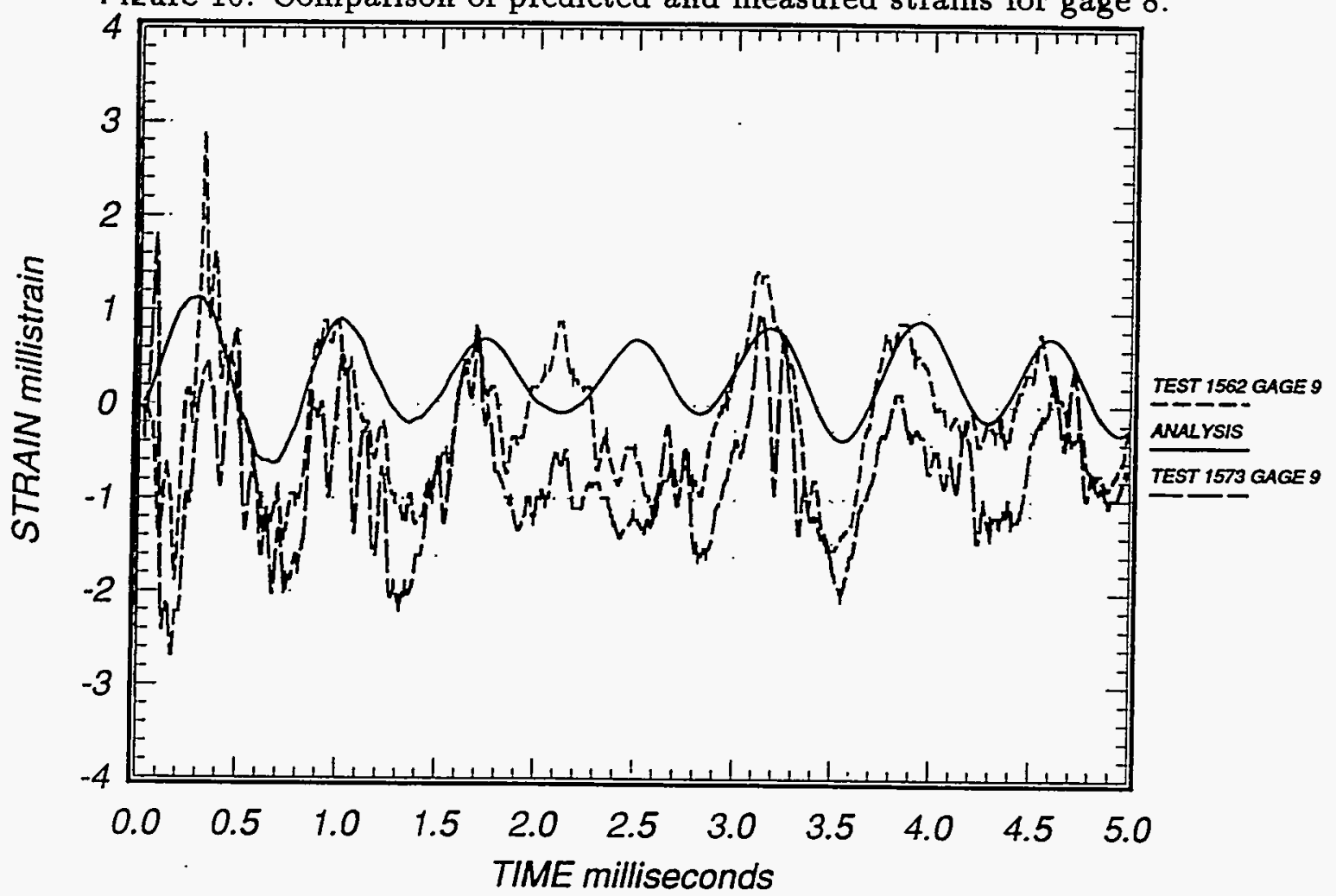

Figure 11: Comparison of predicted and measured strains for gage 9 . 


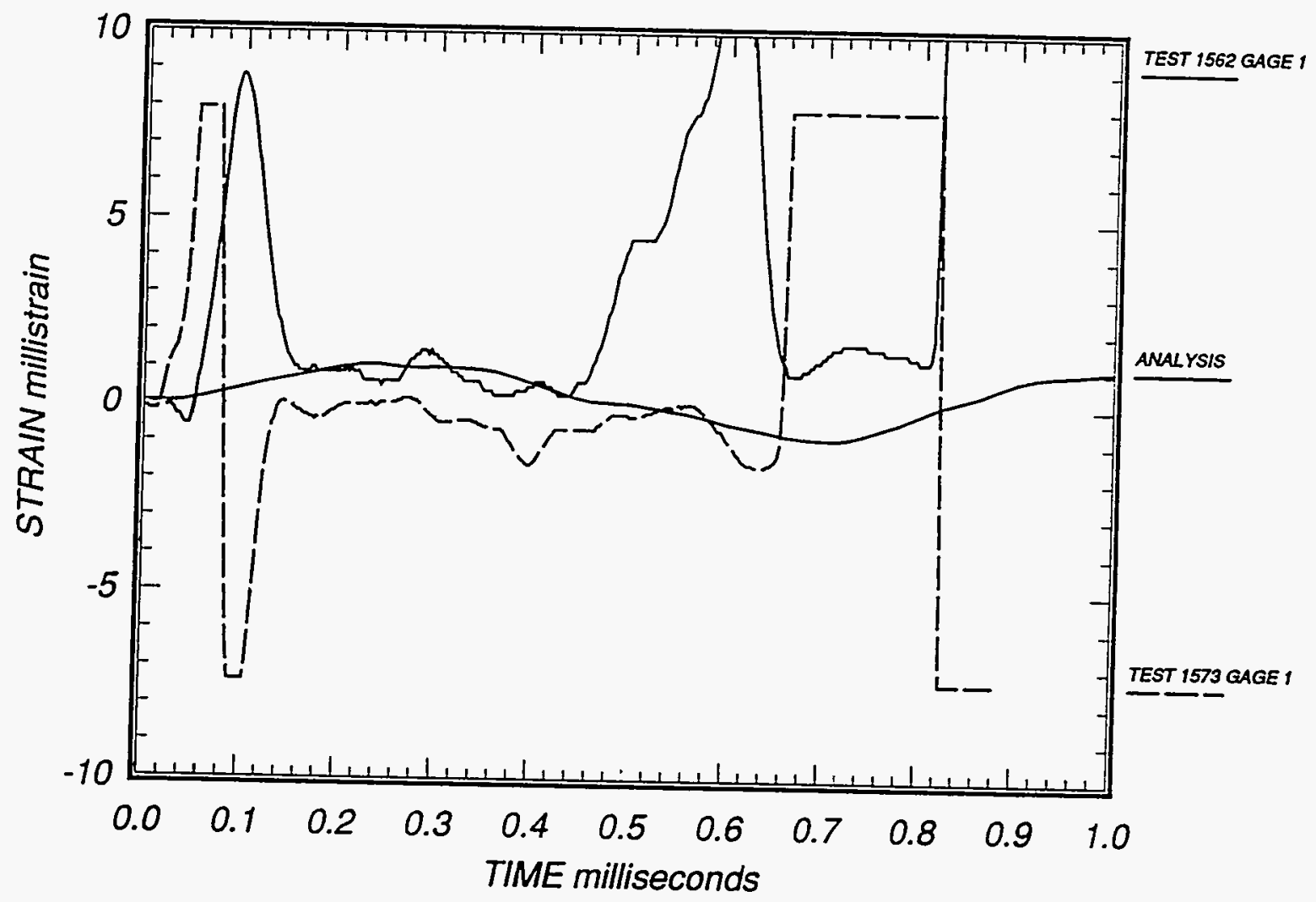

Figure 12: Comparison of predicted and measured strains for gage 1.

All six of these gages show high frequency content, especially gages 7 and 8 . The most obvious high frequency component is about $10 \mathrm{kHz}$. This response was not apparent in the previous tests, but since it is close to the upper frequency filter, it might have been filtered out in the 1991 tests.

Gages 1 through 3 at the bottom of the vessel were destroyed during both tests. The data was lost after about 0.25 milliseconds, but even the data recorded prior to that time is suspect. Figures 12 and 13 show the strains recorded by gages 1 and 3 for both tests and the corresponding analytical prediction. The initial peaks measured for the two tests are very different in character and are much higher in magnitude than the predicted strains. 


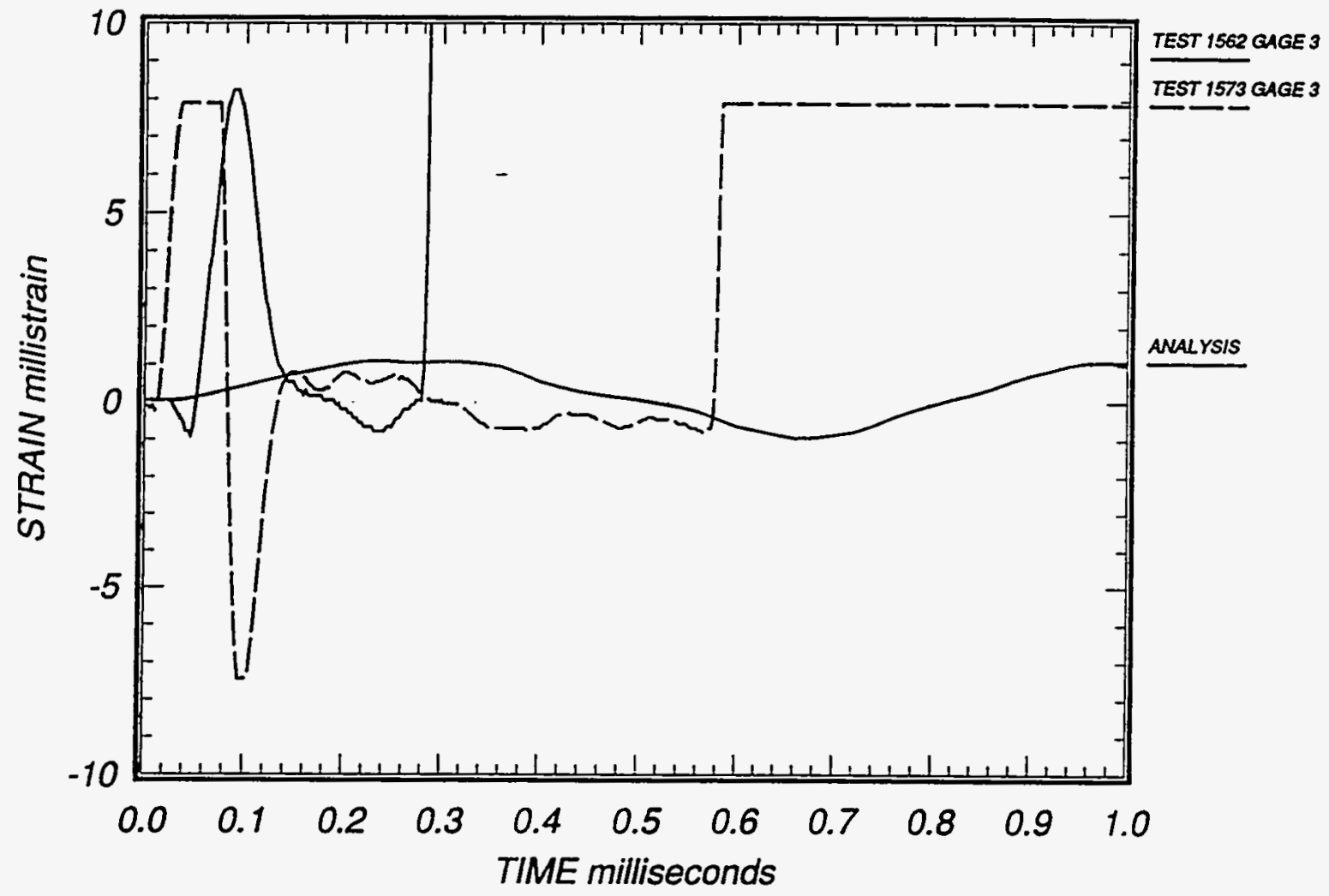

Figure 13: Comparison of predicted and measured strains for gage 3 . 


\section{Discussion of Results}

The overall purpose for performing test $\mathrm{H}-1573$ was to obtain data to determine if yielding is occurring at the bottom of the vessel and if so, why. For this test, the answer to the first part of the question is an unambiguous yes. The bottom of the vessel did yield due to the $40 \mathrm{lb}$ explosive charge. Unfortunately, the reason for the yielding is not clear. The results are clouded by the presence of material used to support the explosive in these tests but not in the earlier tests. The support was made of a Burke tube and some plywood. It is possible that the tube focused the pressure at the bottom of the vessel, causing larger strains than would otherwise have occurred. Shadowing of the lower portion of the vessel, giving nonuinform pressures, is evidenced by the differences in the pressure measurements. The gages were placed at locations according to suggestions made by APTEK personnel. Unfortunately, we did not include enough gages to obtain direct comparisons between the earlier tests and this latest series. The bottom strain gages were lost in both sets of tests, and the pressure measurements from the earlier tests are of poor quality. Without a direct comparison, it is difficult to assess how much the change in the test set up affected the results. We did note that the strains measured at -73 degrees latitude and 0 and 45 degrees longitude are in-phase with each other while the 0 and 45 degrees strains at -55 degrees latitude from the previous tests are out of phase. We do not know if that is a result of the mode shape being excited or a difference caused by the changed loading.

The correlation of strain measurements with analysis show good agreement for the frequencies, but the peak magnitudes are significantly underpredicted. This suggests that the mass and stiffness of the finite element model, which control the frequencies, are adequate representations of the real structure. The magnitudes of the response are controlled by the driving function, i.e. the pressure.

Test H-1562 was done to test two optical window designs. The tapered window was cracked during the test and the cylindrical window was blown out. Both windows had cones to protect them from the direct blast. If the cones worked as planned, the damage to the windows was caused by interaction with the structure. We were surprised to see that the strains were very similar between the two tests. We had theorized that the additional mass of the cones attached to the ports would have made a more significant difference in the test results. Differences were apparent in the magnitudes of the measured pressures, but the trends in the data were the same for both tests. That is, both tests showed a delay in the pressure at gage 3, both showed differences in peak magnitude between the three gages, and both showed the same pattern of reflected pressure. 


\section{Conclusions and Recommendations}

The following are conclusions and recommendations drawn from assessment and correlation of tests $\mathrm{H}-1573$ and $\mathrm{H}-1562$ :

- Yielding did occur at the bottom of the vessel for these tests. The yielding appeared to have occurred during the first membrane response.

- The presence of a support tube in the vessel may have caused focusing of the pressure at the bottom, obscurring the response mechanism thought to have caused yielding in earlier tests.

- The frequencies predicted using the finite element analysis correlated fairly well with the test results, but the analysis did not predict the yielding measured at the -73 degrees locations. This suggests that the mass and stiffness representation of the structure is adequate, but improvements should be made in the load definition.

- Excellent pressure measurements were obtained. They showed nonuniformities of the pressure in both time and magnitude.

- Better methods of obtaining acceleration data for the windows need to be developed. A pressure measurement alongside the window (within the protected area of the cone) would aid in determining the loads on the windows.

- We still believe that the greatest threat to the windows is the load caused by response of the vessel. We recommend that steps be taken to isolate the windows as much as possible from the vessel motion. 
Los Alamos National Laboratory

P. O. Box 1663, Mail Stop P942

Los Alamos, NM 87545

Attn: Christopher Romero

Subject: Progress Report for Confinement Vessel Analysis Subcontract.

Reference: Subcontract Number 9-XH3-0607K-1

Dear Christopher,

Attached are three copies of the Progress Report for the Confinement Vessel Analysis Contract for work from July 13 th to August 31st. If you have any questions, please call.

Sincerely,

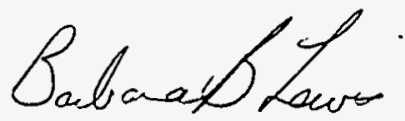

Barbara B. Lewis

(719)576-8100

cc: C. Vigil, LANL M/S P274 w/3 copies

E. Fitzgerald, APTEK

B. Lewis, APTEK

C. Niemet, APTEK 
PROGRESS REPORT FOR CONFINEMENT VESSEL ANALYSIS

Barbara B. Lewis

APTEK, Inc

July 13 to August 31,1993

During this time period, we have completed work on Task 1 and begun work on Tasks 2 and 3.

\section{Meeting at Los Alamos}

Barbara Lewis and Yvonne Murray of APTEK visited LANL on August 13th to view the confinement and safety vessels and to obtain information needed for the completion of the program.

\section{Task 1}

We have obtained more information from the modal analysis done on a previous contract. The NIKE3D finite element code was used to determine the first twenty modes of the confinement vessel and compute mode shapes for each mode. We used the shapes to determine the magnitudes of strains at each gage location with respect to the overall mode shape for each frequency. These were provided to Tom Beery of LANL for comparison with his modal decomposition results.

\section{Task 2 - Analysis of Safety Vessel}

During our visit to Los Alamos, we agreed on two scenarios for damage to the safety vessel. The first is impact from a fragment, specifically the door and nozzle of the 22 inch port. The other analysis will be of half of the confinement vessel impacting the seal of the safety vessel.

Modelling is underway for the first analysis. We have estimated a velocity for the fragment using the impulse-momentum relationship:

$$
A \int P d t=m v
$$




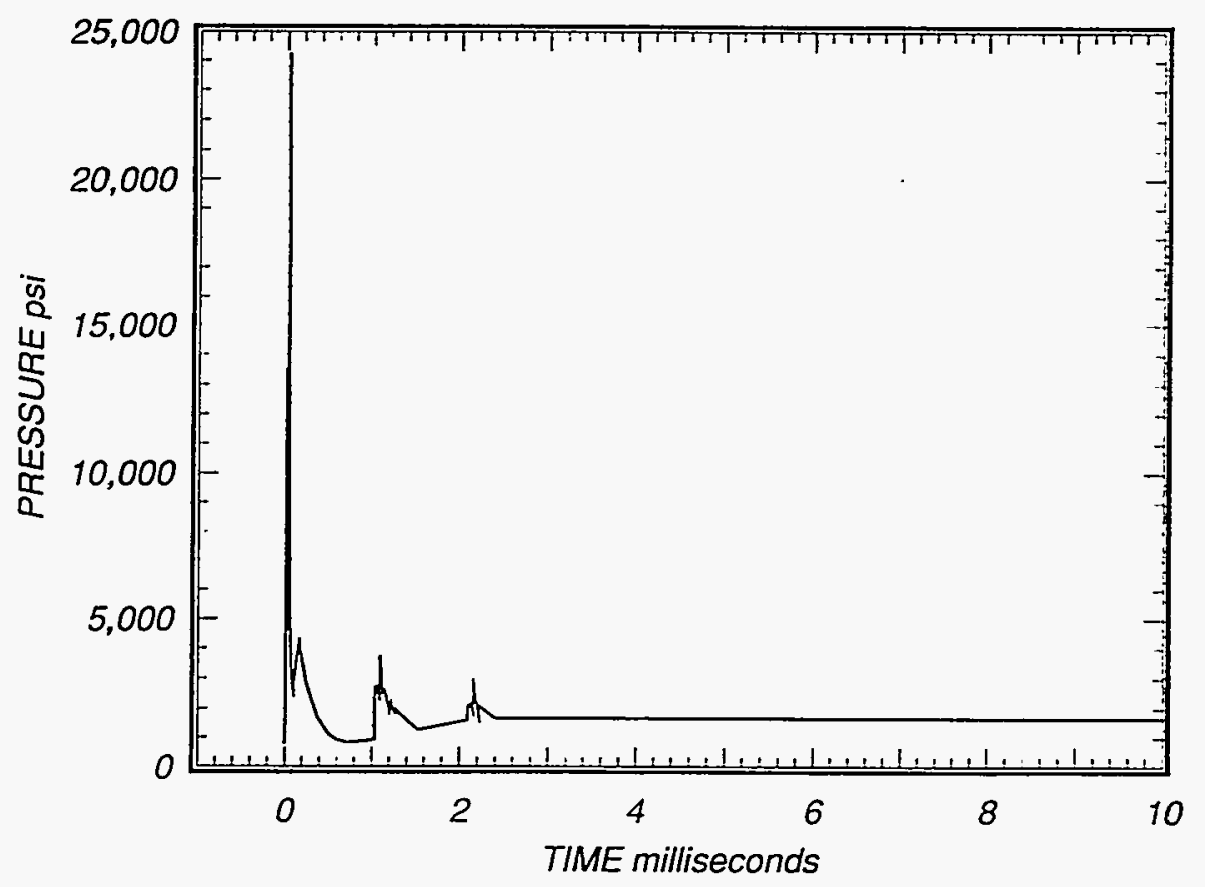

Figure 1: Predicted reflected pressure for $40 \mathrm{lb}$ charge.

where $A$ is the area of the fragment; $P$ is the pressure on the fragment as a function of time, $t ; m$ is the mass of the fragment; and $v$ is the velocity of the fragment. For lack of better definition, we used the predicted reflected pressure inside the vessel. By integrating that pressure, we obtain the specific impulse $\int P d t$ as a function of time. The pressure and specific impulse are shown in Figures 1 and 2, respectively. We assumed breakage around the nozzle weld which gave an area of 908 square inches and a mass of $3.96 \mathrm{lb}-\mathrm{s}^{2} /$ in. The calculated velocity as a function of time is shown in Figure 3. Integration of this curve gives the displacement, Figure 4. By knowing the distance the fragment must travel before impact, the time of impact and the velocity at impact can be determined. (If you at Los Alamos have a better definition of the pressure behind the fragment, we would welcome it.) 


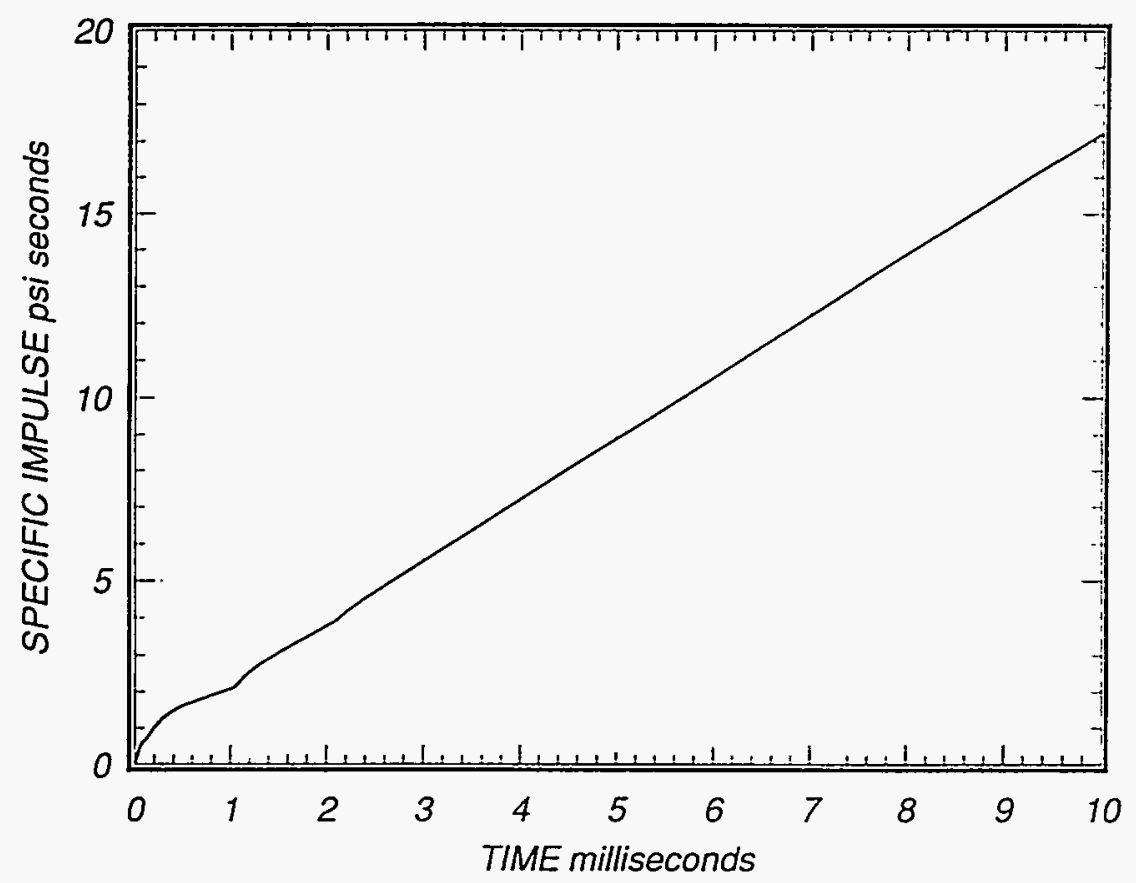

Figure 2: Specific impulse from reflected pressure.

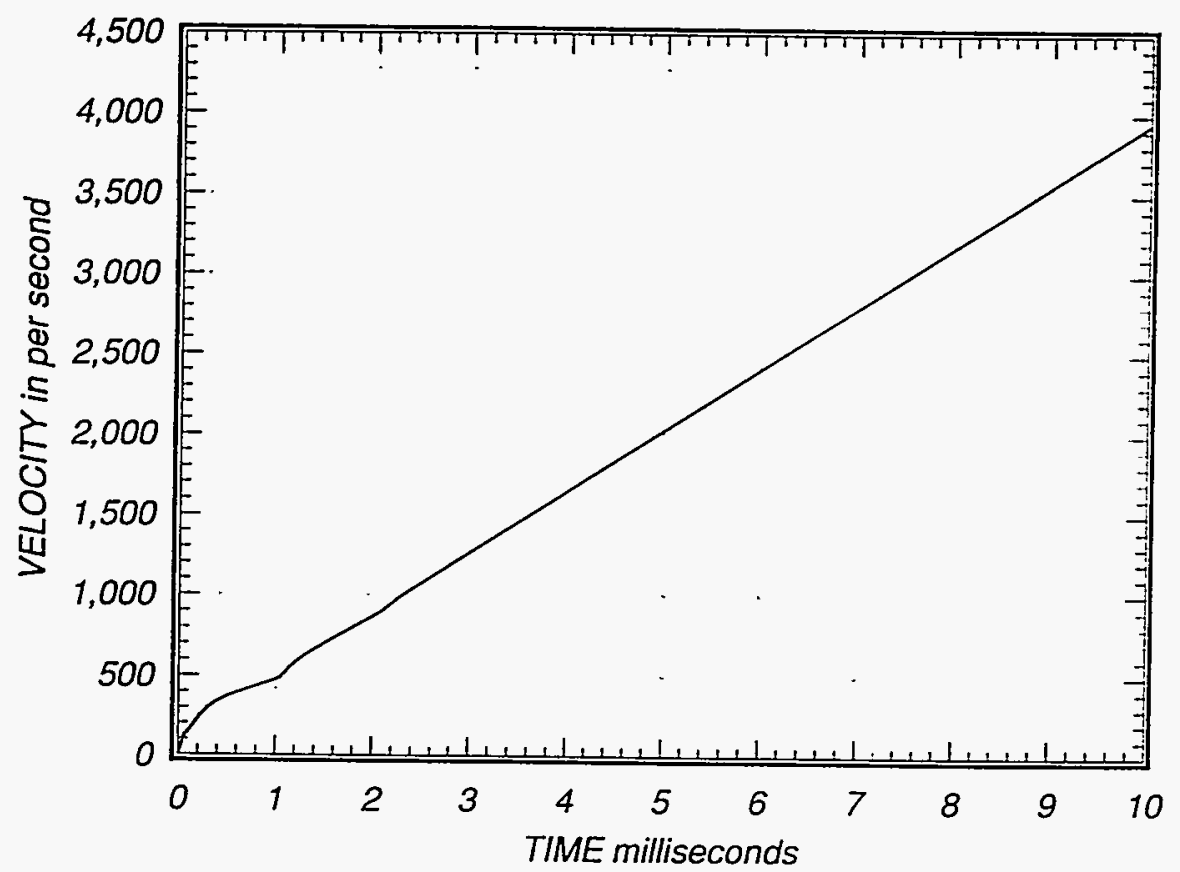

Figure 3: Velocity of top fragment. 


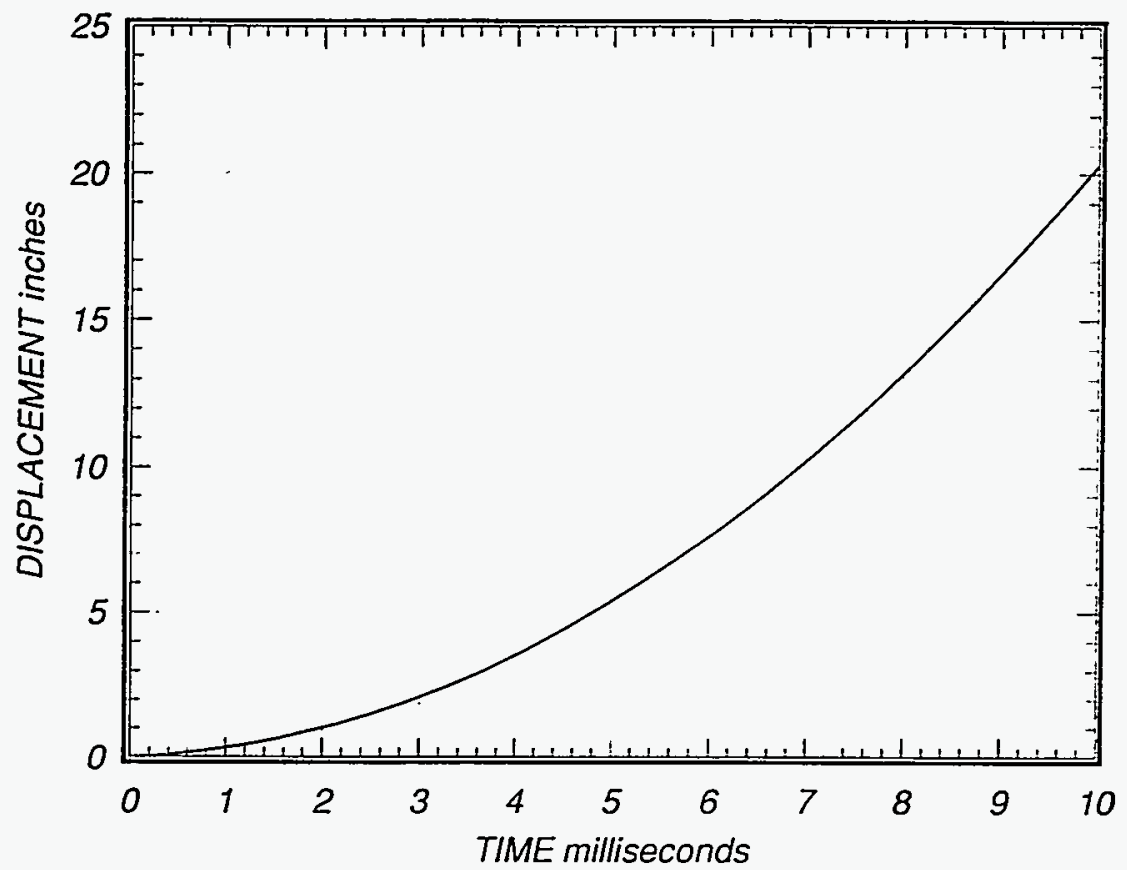

Figure 4: Displacement of top fragment. 


\section{Task 3 - Finite Element Analysis of Confine- ment Vessel Doors}

The major reason for performing analysis of the confinement vessel doors is to investigate the integrity of the seal. This encompasses the structural integrity of the door and nozzle as separate structural elements and the relative motion between the door and nozzle which could cause leakage of gases around the seals. The vessel must withstand an initial dynamic load and a quasi-static internal pressure. In addition, we would like to obtain a better understanding of the effect of the bolt preload, especially as it affects the dynamic response of the structure.

\subsection{Bolt Preload}

We have investigated several methods for including the bolt prestress in a finite element analysis. We originally tried to model the preload as described in the last progress report where the bolt shank was modelled using a discrete spring element. The results were not satisfactory, however, so we tried several other methods. The most successful method uses a temperature change to preload the bolts. We modelled the bolt shank with continuum elements as shown in Figure 5 . The bottom of the bolt shank is fixed to the top of the nozzle using a sliding interface without gaps. The use of a sliding interface without gaps as opposed to a tied interface allows the bolt to contract radially, as it would realistically do.

The material model used for the bolt shanks is a temperature dependent elasticplastic model. The initial preload is applied by decreasing the temperature of the bolt shanks while holding the temperature of the surrounding material constant. The bolts attempt to shorten due to cooling, causing compression of the door between the bolt head and the nozzle. By setting the Poisson's Ratio of the bolt shank material to zero, we obtain the proper one-dimensional axial stresses in the bolt shank. That is, the stress in a material due to temperature change is $\sigma=\frac{E \alpha T}{1-2 \mu}$ which is a bulk effect. By setting $\mu$ to zero, we obtain a better estimate of the axial stresses in the bolt due to tightening.

We could not get NIKE3D to run the analysis; this model has many slide surfaces which cause difficulties in the stiffness matrix used by an implicit code such as NIKE3D. We ran the analysis using DYNA3D with an initial temperature option. The material is initialized with the temperature differential specified and allowed to respond for a time sufficient to extend beyond the initial transients. The stresses that occur during this time can be much larger than the stresses due to the slowly applied preload, so we set the yield stress value for the bolt shanks to a very large number, 


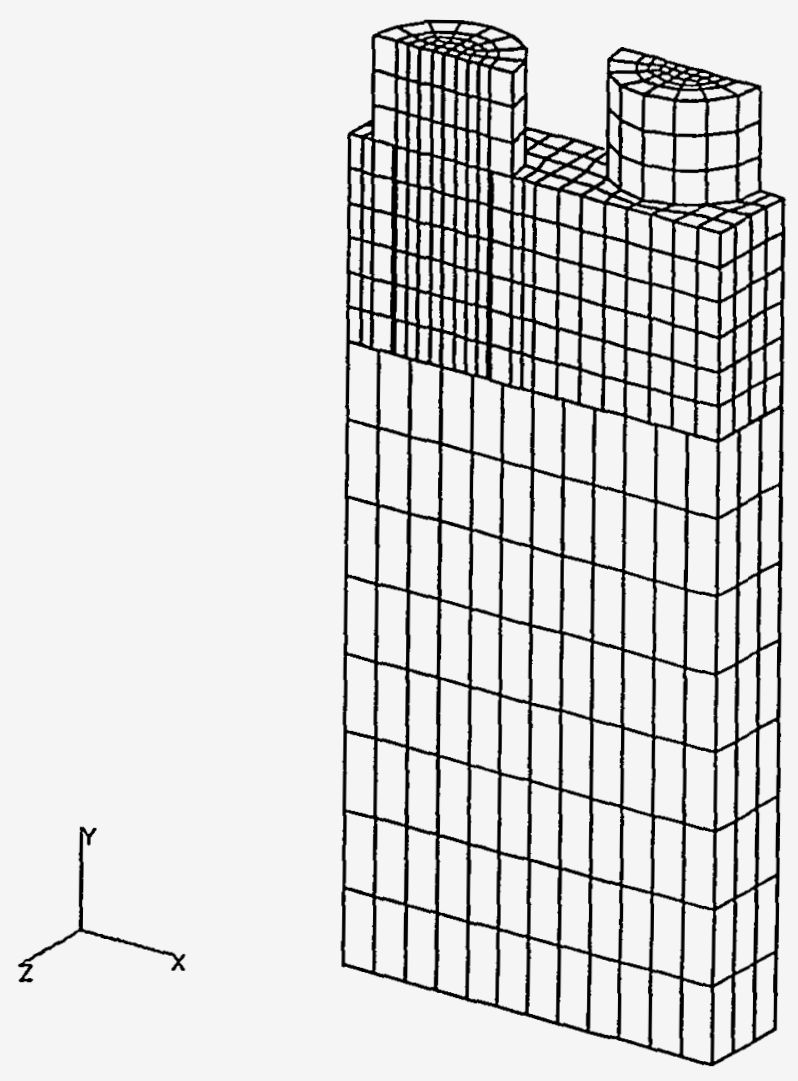

Figure 5: Bolt preload model.

insuring that the bolts do not yield during the rapid response. Figure 6 shows the axial stresses at the center of one of the bolt shanks as a function of time.

The first temperature input to the bolt shanks was -513 degrees which, in a completely unconstrained bolt, would give a thermal strain equivalent to that corresponding to a stress of 100,000 psi. Some results are shown in Figures 7 through 9 . The first figure is of the axial ( $y$-direction) bolt stresses. Note that the axial stress is fairly uniform in the bolt shank and is on the order of 40,000 psi. Figure 8 shows the $y$-stresses in the cover from the top and side. Figure 9 shows the y-stresses in the nozzle. The stresses are tensile in the area of bolt attachment and compressive where the cover contacts the nozzle, as expected. We can model any preload by varying the initial temperature. This is the method we will use to model the preload for future three-dimensional analyses. 

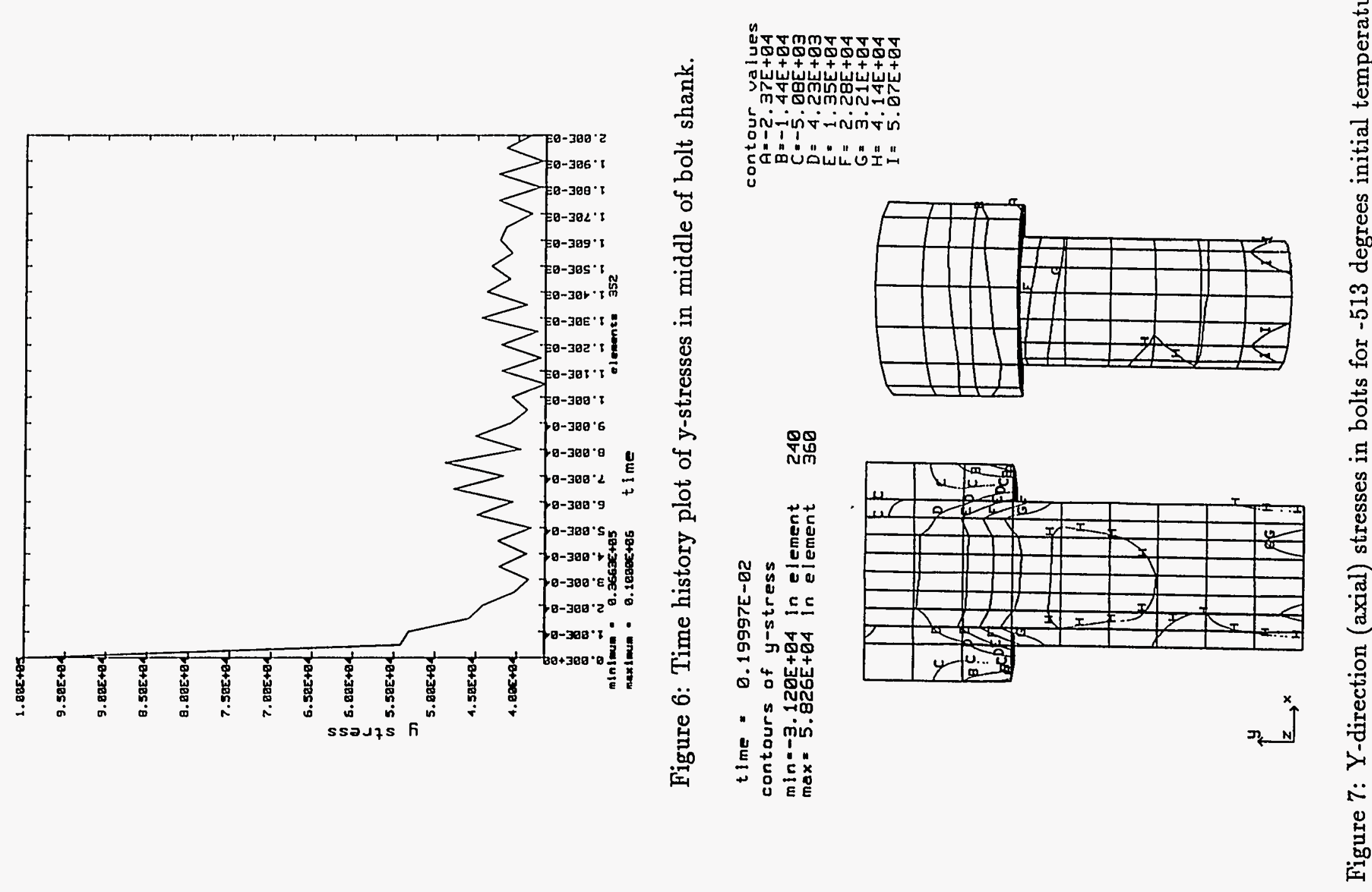

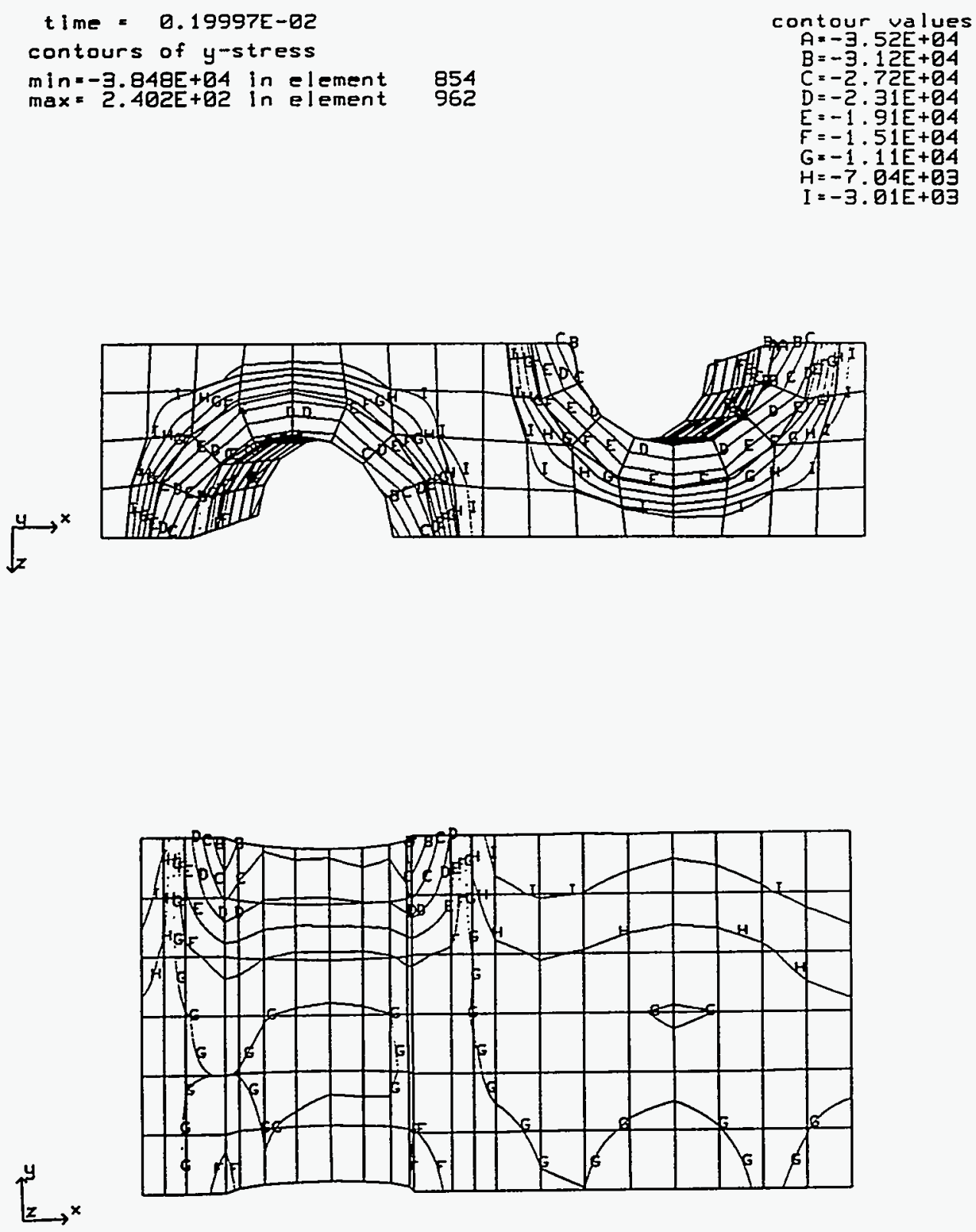

Figure 8: Y-direction stresses in cover for -513 degrees initial temperature. 

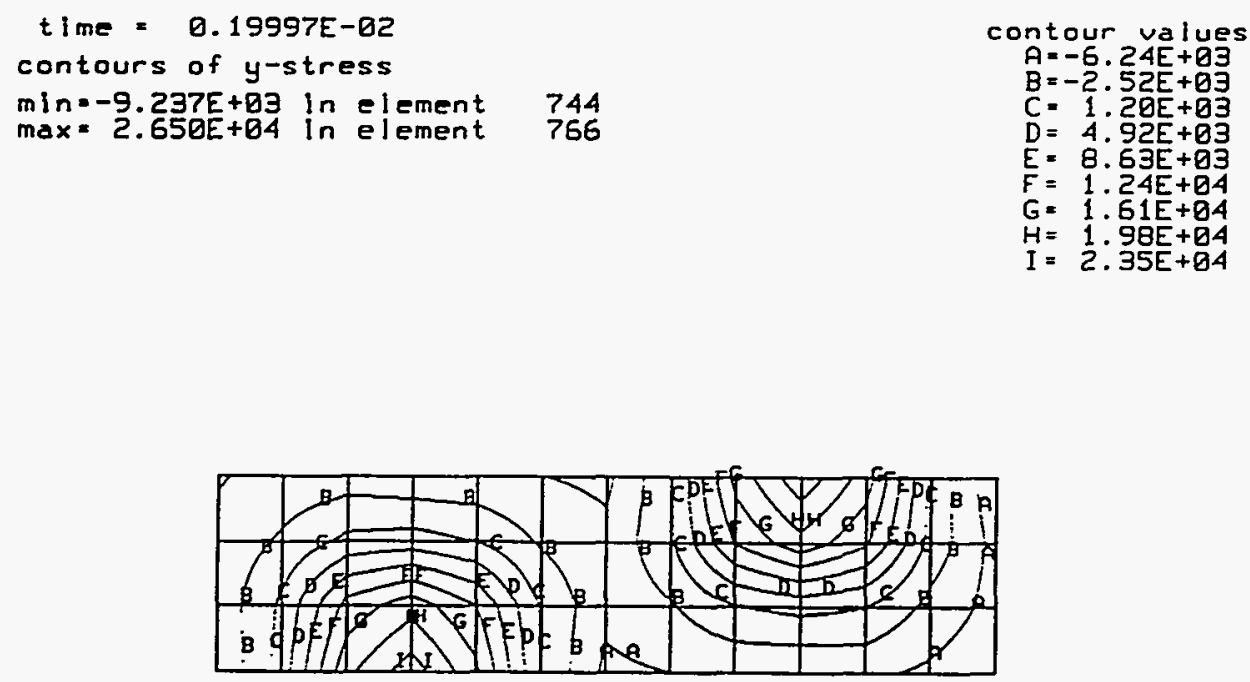

$$
\sum_{z}^{y}{ }^{x}
$$

Figure 9: Y-direction stresses in nozzle for -513 degrees initial temperature. 


\subsection{Port Closure Analysis}

Figure 10 shows a two-dimensional axisymmetric model made to analyze the 16 inch port closure. All o-ring grooves including the upper one (which is no longer part of the design) have been included. Symmetry conditions were placed on the bottom of the model to simulate the rest of the shell and a similar port on the opposite side of the shell. We have finished the static analysis of the structure for the quasi-static internal pressure of $1675 \mathrm{psi}$. This pressure was used in the original qualification analyses of the structure for conformance to the pressure vessel code. We are now running the model with the dynamic load.

The method used to model the bolt closure is a series of rigid constraints between the nodes on top of the nozzle and the nodes on the cover. Four nodes on the nozzle, two at each bolt circle, are attached by rigid constraints in the $\mathrm{x}$-direction to the four nearest nodes on the cover plate. These simulate the constraint of the bolts to not allow sliding between the cover and nozzle. In addition, the same four nodes on the nozzle are rigidly attached to four nodes on the top of the cover in the y-direction to simulate the attachment of the two pieces by the bolt. That is, the rigid constraint goes from the nozzle where the bolt would be attached to the top of the cover where the bolt head would bear against the cover. This method of modelling the bolts in two-dimensions does not allow us to include any preload, but the bolts are modelled as perfectly rigid. While we can not use the results of these analyses to predict cover lift-off and bolt stresses, we can get an idea of the stresses in the cover, especially any stress concentrations that may be present.

\section{$5 \quad$ Future Work}

In the coming month we plan to complete the analyses described for Tasks 2 and 3 . We will extend our Task 3 analyses to look at the larger port and the doors without the upper o-ring groove. We also plan to perform a three-dimensional analysis of one of the port closures to study the effect of bolt preload. 


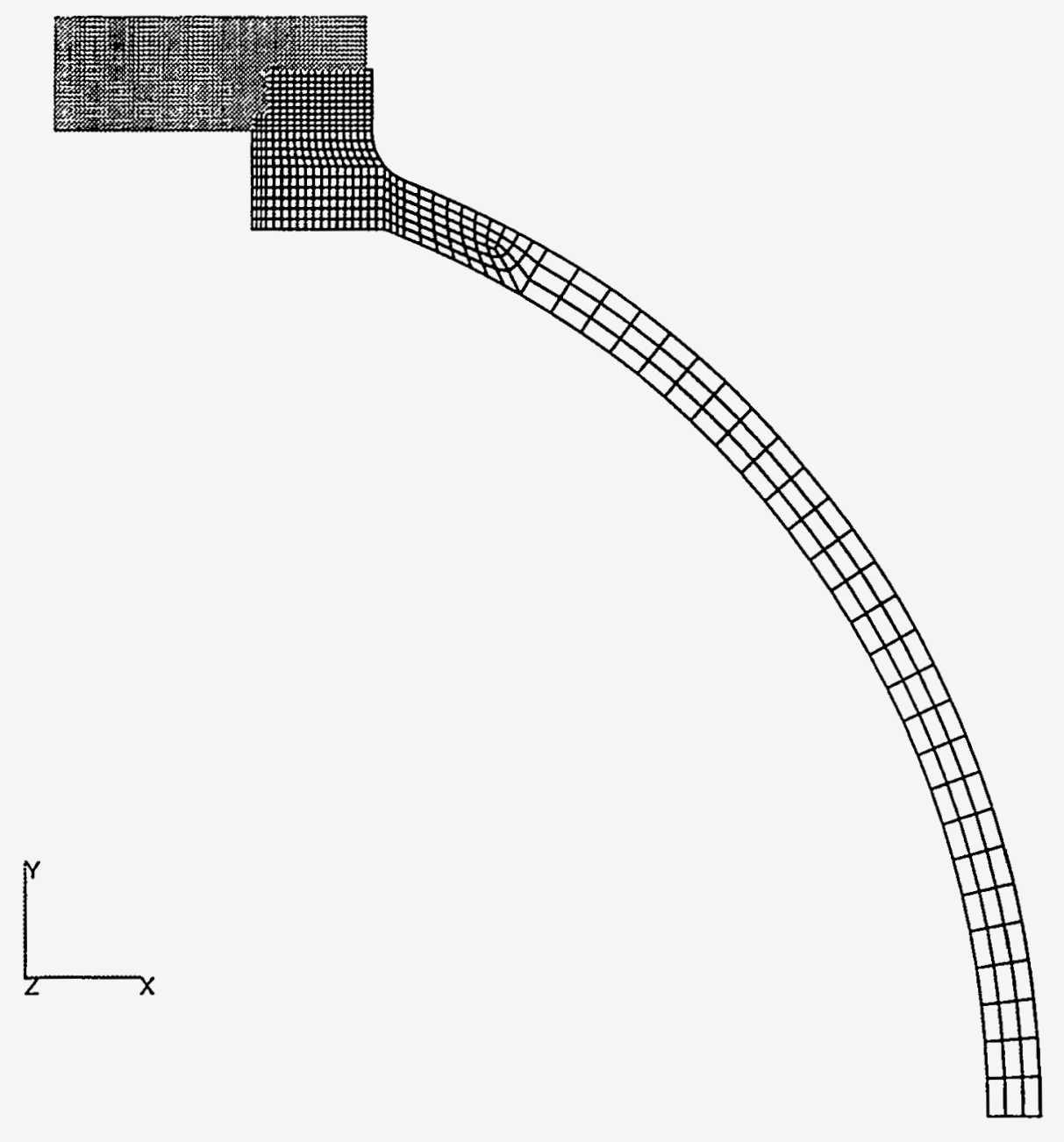

Figure 10: Axisymmetric model of 16 inch port closure. 


\section{PROGRESS REPORT FOR CONFINEMENT VESSEL ANALYSIS Barbara B. Lewis \\ Yvonne D. Murray \\ APTEK, Inc}

September 1 to September 30, 1993

We have continued work on Tasks 2 and 3 during September.

\section{Task 2 - Analysis of Safety Vessel}

One issue discussed at that Los Alamos meeting held on August 13 is possible penetration of the safety vessel if the nozzle of the confinement vessel were to fracture. High pressure gases from the internal detonation would accelerate the fractured nozzle into the safety vessel. Our concern is whether the high strength bolt heads attached to the nozzle would penetrate the lower strength safety vessel.

We are performing a finite element analysis of the bolt head and nozzle penetrating the safety vessel using the Arbitrary Lagrangian Eulerian (ALE) technique implemented in the DYNA2D code. Basically ALE is an automated technique for reducing mesh distortion. ALE is commonly used in penetration analyses to remap distortions of the penetrated medium, which in this case is the safety vessel. Severe mesh distortions compromise computational accuracy and increase the overall cost of an analysis through a reduction in the time step size. At a user specified time step frequency, the ALE technique determines is mesh distortions exceed predefined criteria. If so, the nodes are moved to improve mesh uniformity and the solution variables are remapped.

One slice through the axisymmetric finite element mesh is shown in Figure 1a and a close-up of the penetrator is shown in Figure 1b. Only one-half of the safety vessel is modeled because a plane of symmetry is assumed along the horizontal mid-plane through the vessel. The shape of the penetrator (nozzle with bolt head) has been idealized as an axisymmetric cone, with the 90 degree tip of the cone representing the bolt head. The mass of the cone is equal to the mass of the nozzle, thus determining the height of the nozzle. The nozzle is assumed to have fractured around the weld line.

To perform the penetration analysis, the penetrator will be given an initial velocity, and the calculation will be run until the velocity of the penetrator is reduced to zero. We are in the process of determining the velocity of the penetrator as it impacts the safety vessel, using the following two methods: 
- We are performing an inhouse literature search using the DIALOG database to assess possible fragment (penetrator) velocities and masses;

- We are running an inhouse gas dynamics code which analyzes the flow of gas from one chamber (the confinement vessel) to a second chamber (the safety vessel) through an orifice of specified area. We are enhancing the code to allow for an increase in the orifice area with time. This modification would model the increase in flow area as the nozzle separates from the containment vessel, thus allowing the gases to flow into the containment vessel and the pressure to equalize. The acceleration history of the nozzle will be calculated from the difference in pressure in each chamber. 


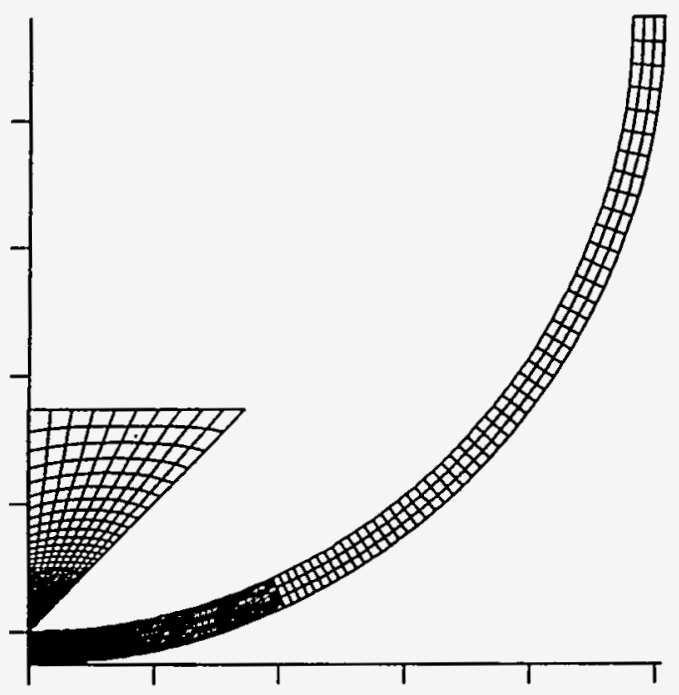

(a) Full view.

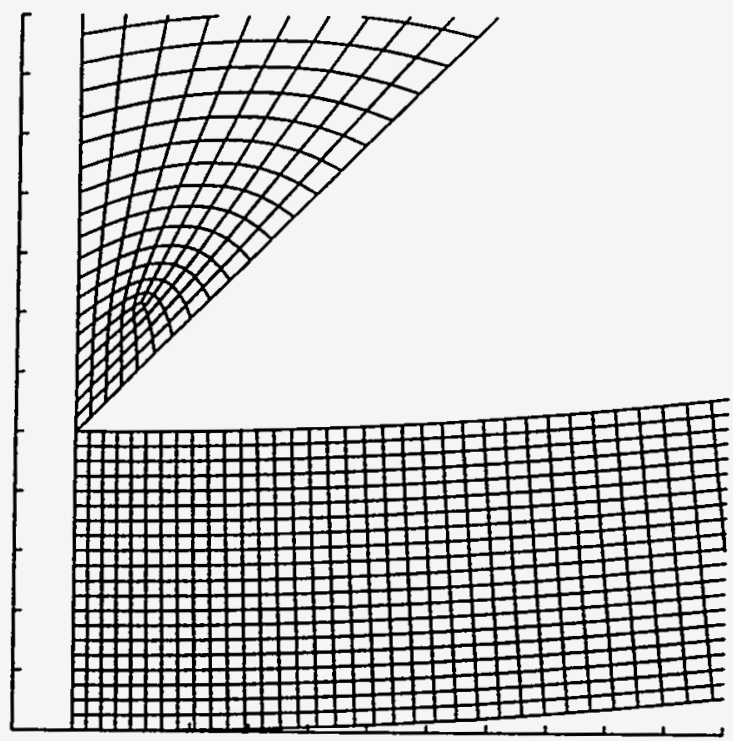

(b) Close up of safety vessel and penetrator tip.

Figure 1: Idealized undeformed mesh of nozzle (penetrator) and safety vessel. 


\section{Task 3 - Finite Element Analysis of Confine- ment Vessel Doors}

Figure 2 shows a close-up view of the two-dimensional axisymmetric model in the area of the closure. The elements are colored according to material number to show the o-rings. The static analysis, using an internal pressure of $1675 \mathrm{psi}$, gave the stresses shown in Figure 3. While there is some stress concentration around the uppermost o-ring groove, the results show that the highest stresses are in the area of the bolt attachments. Therefore, modelling of the bolts is very important. Also, this analysis predicts a gap of about 0.001 to 0.005 inches between the cover and nozzle in the area containing the two neoprene o-rings and 0.007 to 0.012 inches gap on the surface containing the inconel ring. Keep in mind that this is without any kind of preload on the bolts. All of these results point to the necessity of modelling the bolts. Therefore, we have spent most of this reporting period developing a three-dimensional model of the 16 inch port.

Figure 4 shows a three-dimensional model of the 16 inch port door. The model consists of over 28,000 elements representing half of the door, 32 bolts, and half of the nozzle. Symmetry boundary conditions simulate the other half of the closure. We plan to use save segments in DYNA3D to include the effect of the rest of the structure. We used these successfully in the past to analyze the port window. To utilize the save segment capability, two analyses are done. The first is of a model which will give a good representation of the whole structure, but not necessarily a good representation of the the details of the area of interest. An interface is defined interior to this model at the boundary of the portion of interest and displacements calculated at this interface are saved during the analysis. In our case, the first model was the original quarter-symmetric model of the confinement vessel. The ports were modelled adequately enough to contribute to the overall response, but not in enough detail to study the ports themselves. The interface was defined around the nozzle where it joins the main shell of the vessel and the displacements of the shell-nozzle interface were saved as a function of time as the analysis progressed. The second analysis is of a more detailed model of the portion of interest with the location of the previously saved interface as its outer boundary. Our second model is the port model shown in Figure 4. The displacements saved from the first analysis are applied as external loads on the second model which simulates the remainder of the structure. We are currently running this analysis using the dynamic pressure load due to a 40 lb charge. 


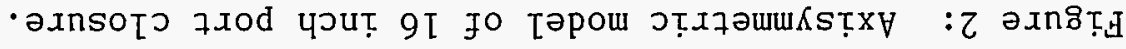

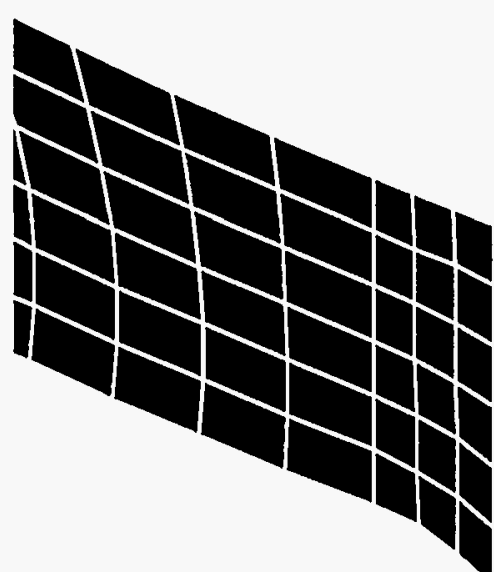

$$
x
$$
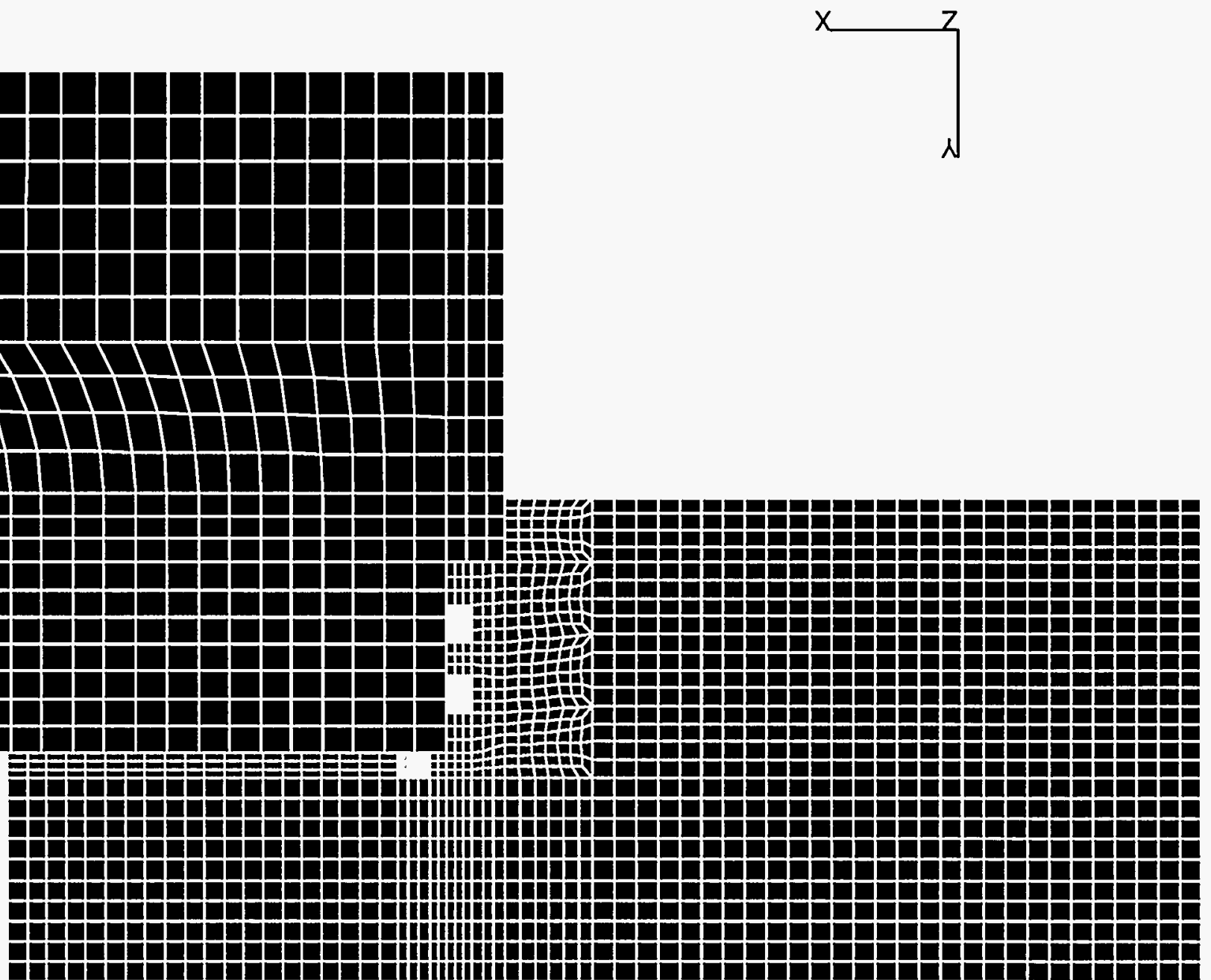


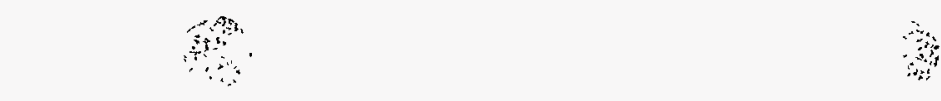

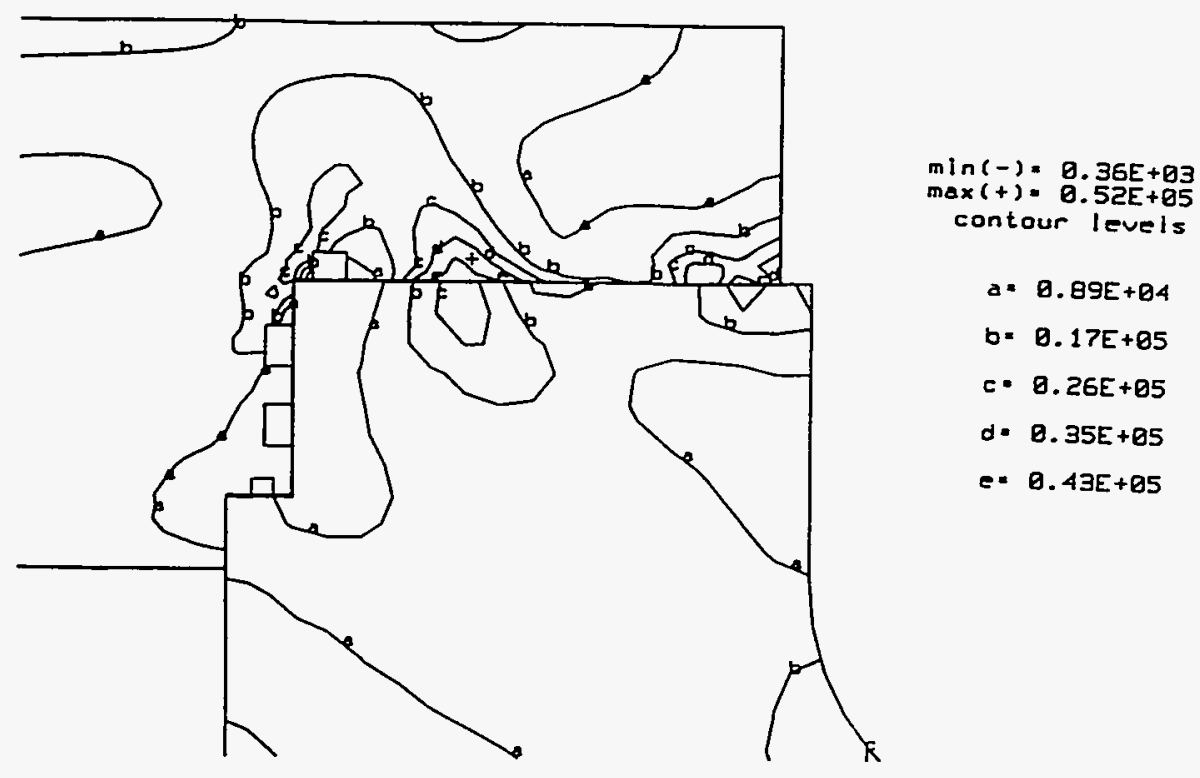

Figure 3: Stresses predicted in 16 inch port closure for 1675 psi internal static pressure.

\section{Future Work}

We will continue with the analyses described for Tasks 2 and 3 . We will also begin analyses of the 22 inch port and an impact of the safety vessel seal, as agreed. 


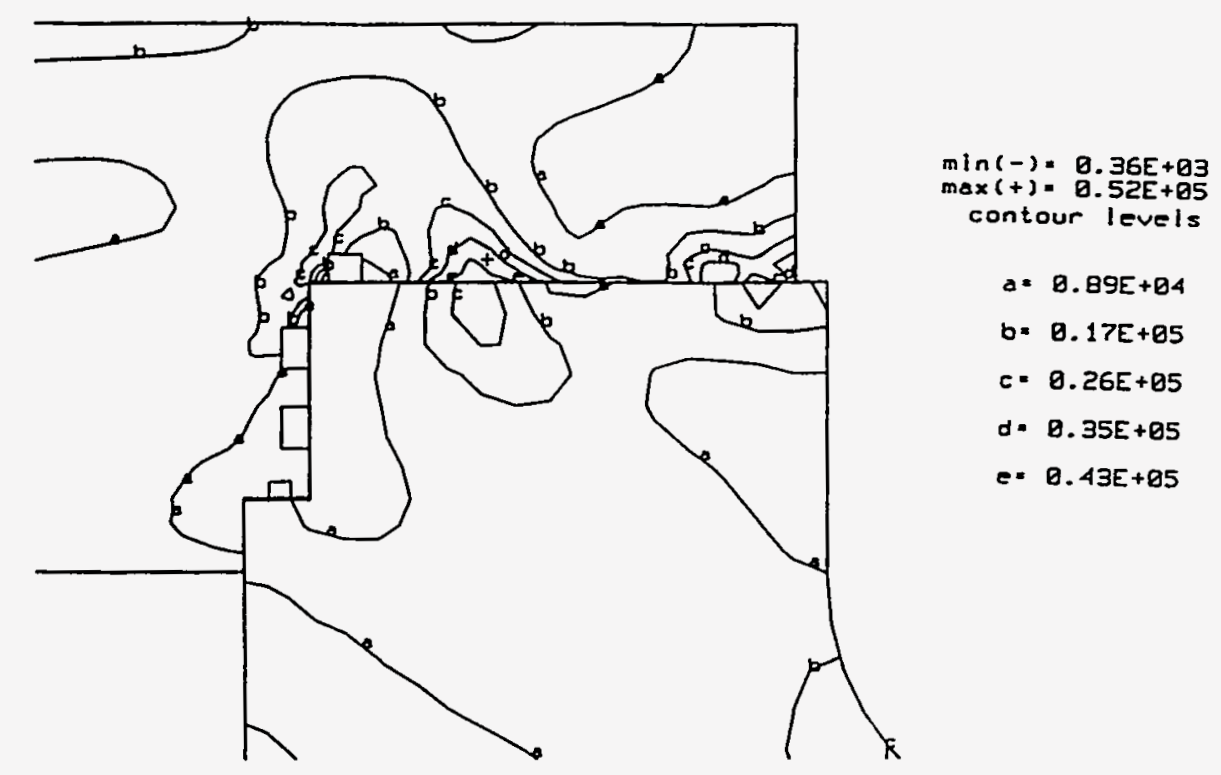

Figure 3: Stresses predicted in 16 inch port closure for 1675 psi internal static pressure.

\section{Future Work}

We will continue with the analyses described for Tasks 2 and 3 . We will also begin analyses of the 22 inch port and an impact of the safety vessel seal, as agreed. 


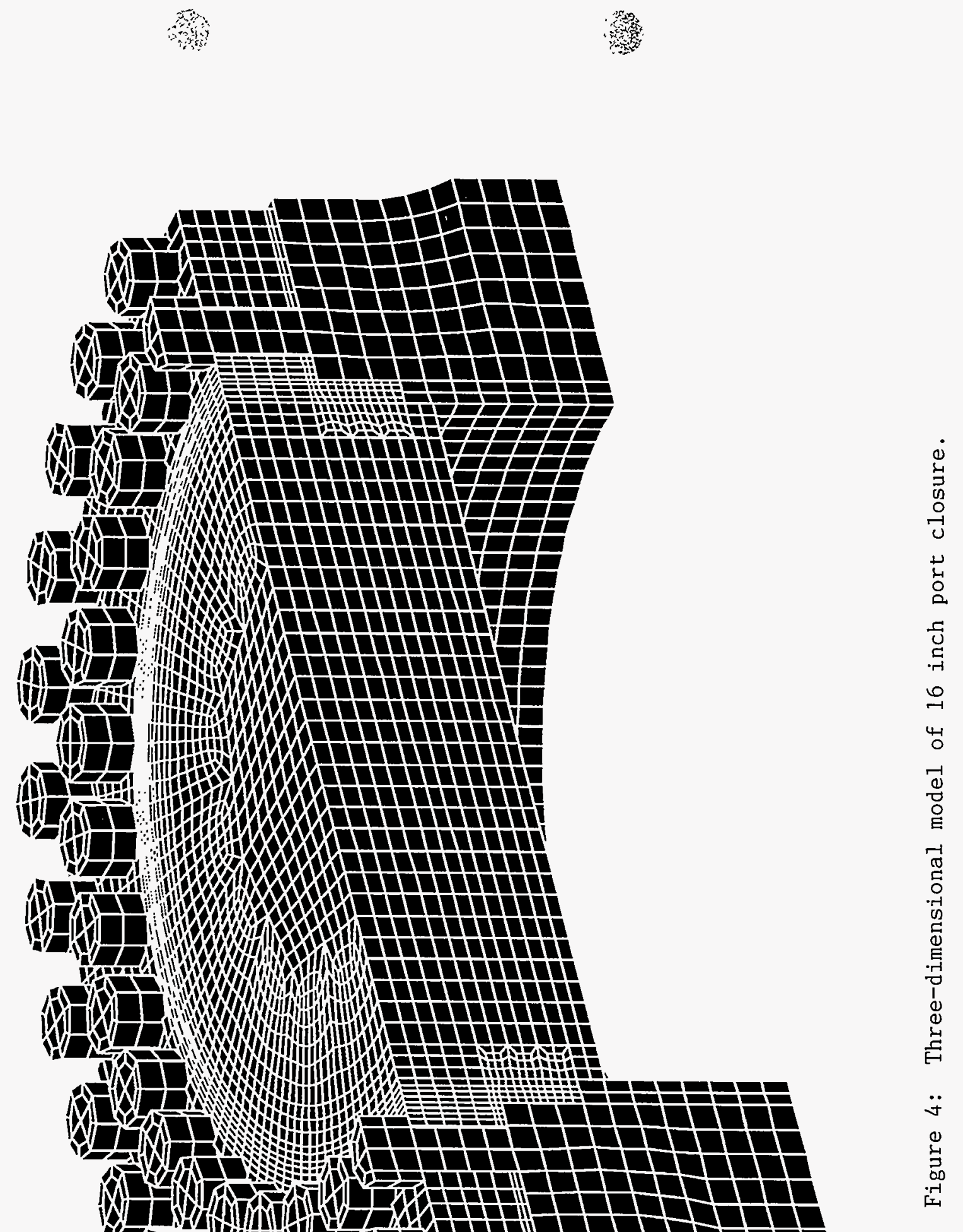

